\author{
$B / B L I O T E C A$ \\ Facuildade de Ciências Farmacenticas

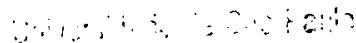 \\ UNIVERSIDADE DE SÃO PAULO \\ FCF / FEA / FSP \\ Programa de Pós-Graduação Interunidades \\ em Nutrição Humana Aplicada - PRONUT
}

\title{
DIETA HABITUAL DE ADOLESCENTES DE UMA ESCOLA ESTADUAL DO MUNICÍPIO DE SÃO PAULO
}

Graziela Mantoanelli

Dissertação para obtenção do grau de Mestre

Orientadora:

Prof ${ }^{a}$ Assoc. Sonia Tucunduva Philippi 


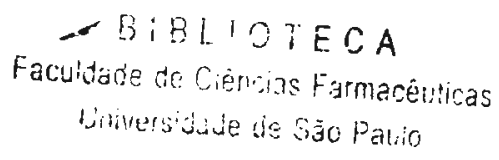

UNIVERSIDADE DE SÃO PAULO

FCF / FEA / FSP

Programa de Pós-Graduação Interunidades em Nutrição Humana Aplicada - PRONUT

\section{DIETA HABITUAL DE ADOLESCENTES DE UMA ESCOLA ESTADUAL DO MUNICÍPIO DE SÃO PAULO}

(versão revisada)

Graziela Mantoanelli

Dissertação para obtenção do grau de Mestre

Orientadora:

Prof $^{\mathrm{a}}$ Assoc. Sonia Tucunduva Philippi 


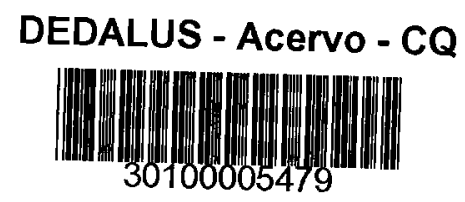

Autorizo, exclusivamente para fins acadêmicos e científicos, a reprodução total ou parcial desta dissertação, por processos fotocopiadores.

Assinatura:

Data: / 2003

Mantoanelli, Graziela

Dieta habitual de adolescentes de uma Escola Estadual do Município de São Paulo. São Paulo / Graziela Mantoanelli - São Paulo, 2003.

Dissertação (mestrado) - Faculdades de Ciências Farmacêuticas da USP. Faculdade de Economia, Administração e Contabilidade da USP. Faculdade de Saúde Pública da USP. Programa de Pós-Graduação Interunidades em Nutrição Humana Aplicada.

1. adolescentes 2 . consumo alimentar de adolescentes 3 . hábito alimentar de adolescentes 4.dieta habitual. 


\title{
DIETA HABITUAL DE ADOLESCENTES DE UMA ESCOLA ESTADUAL DO MUNICÍPIO DE SÃO PAULO
}

\author{
Comissão Julgadora \\ Dissertação para obtenção do grau de Mestre \\ Prof $f^{a}$ Assoc. Sonia Tucunduva Philippi \\ Orientador/ Presidente
}

$1^{\circ}$ Examinador

$2^{\circ}$ Examinador

São Paulo, de de 2003 
Aos meu pais: Benedita Ap Mantoanelli, Euclides Mario Mantoanelli Ao meu marido Bruno D'Angelo pela força pela confiança pelo amor 
Os obstáculos que a vida nos impõe só são transpostos com o auxilio da família e dos amigos, mais que isso, com o carinho e a disposição dispensadás por aqueles que nos amam. Agradeço a todos por me auxiliarem a finalizar mais uma etapa de minha vida, em especial

À minha orientadora Prof ${ }^{\mathrm{a}}$ Assoc. Sonia Tucunduva Philippi, mais que uma orientadora, uma amiga, uma mãe, espero nunca te decepcionar.

À Prof ${ }^{a}$ Dr $^{\mathrm{a}}$. Betzabeth Slater Villar, pela amizade, prontidão, auxilio nos momentos desesperadores.

Ao Prof. Dr ${ }^{a}$ Maria do Rosário Dias de Oliveira Latorre por me ensinar a ir além.

As minhas companheiras de quase todos os dias Marcia Nacif, Raquel Parra pelo ouvido amigo nas horas de desabafo.

À Luciana Benevides, minha mais nova amiga, que sempre esteve disponível para me ajudar não importando o que fosse.

Aos meus amigos Shane Amaya e John Bargiel por um auxilio e pelo carinho depositado em um dos momentos mais atribulados de minha vida

Ao amor da minha vida, Bruno D'Angelo, que sempre me ajudou a juntar os pedaços e a seguir em frente......sem você eu não conseguiria colocar um ponto final nesta etapa da minha vida. 


\section{SUMÁRIO}

Página

\section{INTRODUÇÃO}

Métodos para avaliar o consumo alimentar ................................ 01

$O$ adolescente e suas necessidades...............................................

Consumo alimentat na adolescência ........................................... 12

\section{OBJETIVOS}

Objetivo geral

Objetivos especificos

\section{CASUÍSTICA E MÉTODOS}

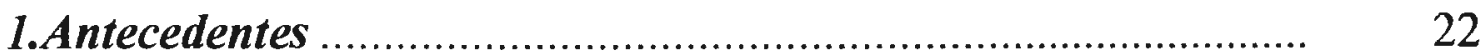

2.Delineamento do estudo ...........................................................

3.População de estudo............................................................. 22

4. Coleta de dados ................................................................ 22

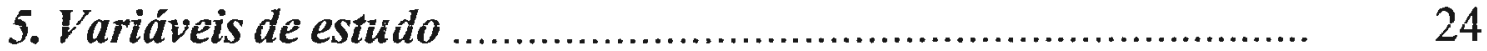

6.Análise dos dados.................................................................

6.1 Análise das médias dos nutrientes........................................... 25

6.2 Análise do consumo dos grupos de alimentos........................ 26

6.3Análise das freqüências das refeições........................................ 27

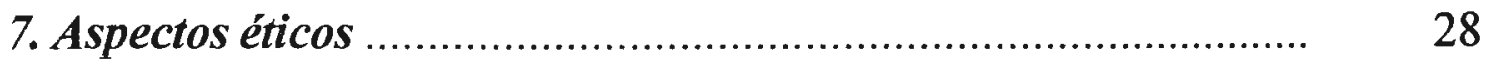

\section{RESULTADOS}

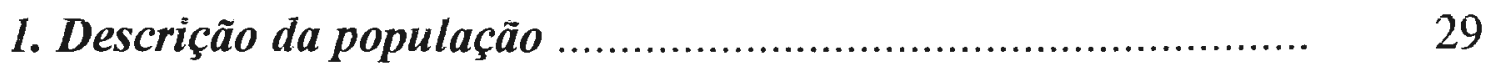

1.1 Distribuiçäo por gènero ................................................................... 29

1.2 Distribuição etária ....................................................................... $\quad 30$ 
Página

2.2 Consumo alimentar ............................................................

2.1. Consumo de nutrientes................................................... 31

2.2.Consumo dos grupos de alimentos..............................................

2.2.1 Média em gramas ........................................................... 43

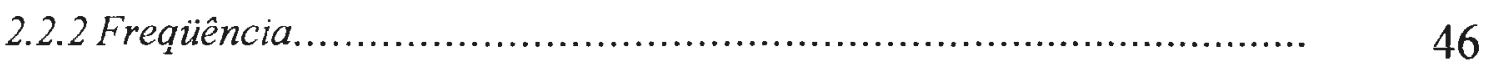

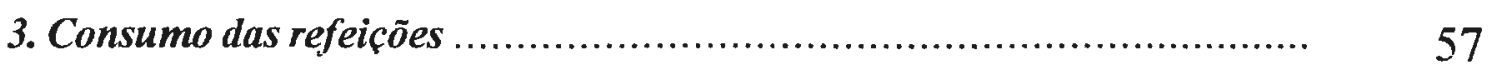

\section{DISCUSSÃO}

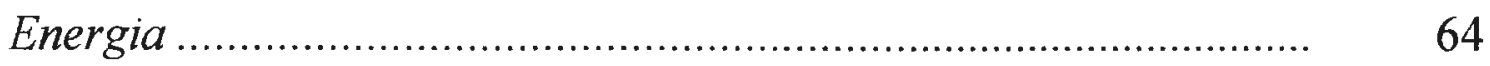

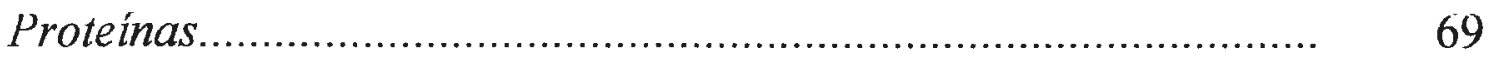

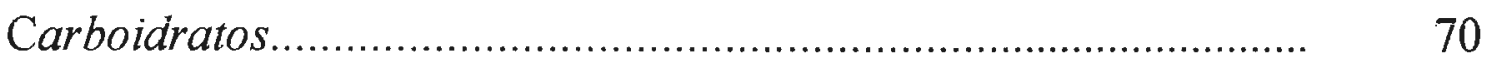

Gordura total e insaturada ................................................... $\quad 72$

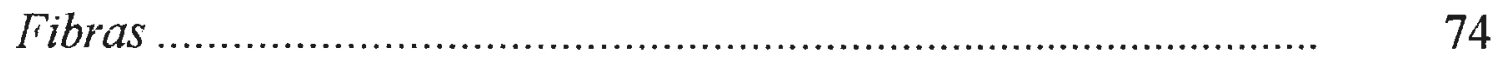

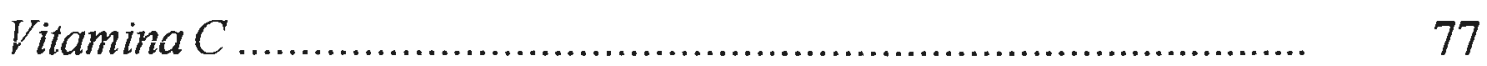

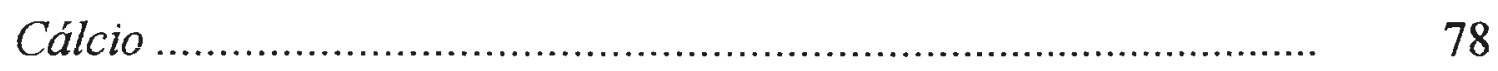

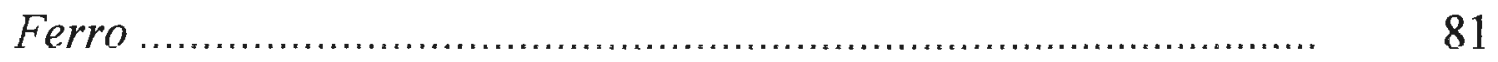

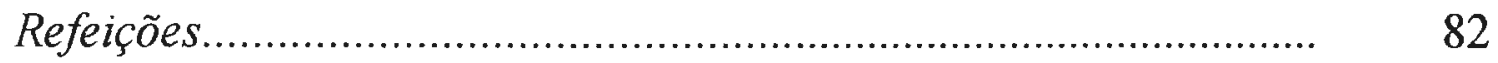

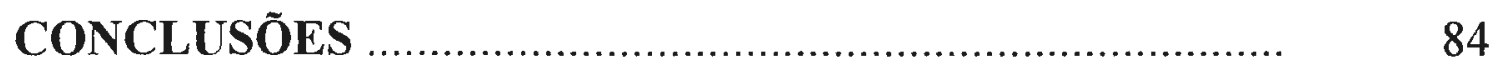

REFERÊNCIAS BIBLIOGRÁFICAS ….......................... 85 
RESUMO 
Mantoanelli, G. Dieta habitual de adolescentes de uma Escola Estadual do Município de São Paulo. São Paulo 2003. [Dissertação de mestrado Programa de Pós-Graduação Interunidades em Nutrição Humana Aplicada - FCF/FEA/FSP- USP]

Introdução: O padrão alimentar, com alto teor de gordura, colesterol, açúcar refinado e o baixo teor de ácido graxos poliinsaturados e fibras presente na dieta dos adolescentes, é considerado o principal responsável pelo aumento da morbidade e mortalidade em adultos, pois resulta em aumento da prevalência de obesidade e conseqüentemente de doenças crônicas não transmissíveis. Objetivo: Avaliar a dieta habitual qualitativa e quantitativamente de adolescentes de ambos os sexos de uma Escola Estadual do Município de São Paulo - SP. Casuística e Métodos: Foram avaliados adolescentes de ambos os gêneros entre 14 e 18 anos e 11 meses de idade, em quatro momentos diferentes durante seis meses. Utilizou-se o Recordatório 24 horas para avaliar o consumo alimentar e os dados foram processados pelo software Virtual Nutri. As análises estatísticas (Kolmogorov-Smirnov, teste $\mathrm{T}$ Student bicaudal para amostras repetidas, Wilcoxon Signed Rank Test e McNemar) foram realizadas pelo SPSS 11.0. Resultados: O consumo de gordura total foi superior a $30 \%$ em todos os dias de análise; o consumo de fibras obteve uma tendência de melhora nos dias úteis, assim como a gordura insaturada; o alimento com consumo mais freqüente foi o arroz e o consumo dos salgados (pão de queijo, coxinha, esfiha, etc.) aumentou durante os dias da semana. O café da manhã teve um declínio de consumo durante o feriado. Conclusões: $O$ conhecimento do da dieta habitual dos 
adolescentes possibilita o planejamento de políticas públicas de saúde voltadas à nutrição, orientações dietéticas específicas ao grupo e possíveis intervenções.

Descritores: adolescentes, consumo alimentar de adolescentes, hábito alimentar de adolescentes, dieta habitual. 
ABSTRACT 
Mantoanelli, G. Dieta habitual de adolescentes de uma Escola Estadual do Município de São Paulo. [The Eating Habits of Adolescents in a State School in São Paulo] São Paulo (BR); 2003 [Dissertação de mestrado Programa de Pós-Graduação Interunidades em Nutrição Humana Aplicada - FCF/FEA/FSP- USP]

Introduction: High amounts of fat, cholesterol, refined sugar, and low amounts of fat acid and fibers present in the diets of adolescents is results in high rates of obesity, chronic non-communicable diseases, and death in adults. Objective: Evaluate qualitatively and quantitatively the daily eating habits of adolescent males and females from a São Paulo city state school. Methods: Students between the ages of 14 years and 18 years 11 months old in four different times in a six month period were evaluated. The students logged their food i._ake over a 24 hour period and the data was processed by the Virtual Nutri software. The statistical analysis (Kolmogorov-Smirnow, T Student test for two repeated samples, Wilcoxon Signed Tank Test, and McNemar) was made by SPSS 11.0. Results: For every day of the test, fat accounted for more than $30 \%$ of the caloric intake. The fiber intake showed a tendency to improve on week days when compared with week ends, as did the intake of unsaturated fats. The food most frequently consumed was rice. Snacks were consumed mostly on the holiday, and during holidays the students frequently skipped breakfast. Conclusions: This study of the eating habits of adolescents can help shape the public policies of health, nutrition, and diet for specific groups and interventions. 
Keywords: Adolescents, eating habits, eating habits of adolescents, food intake of adolescents 


\section{LISTA DE TABELAS}

Página

Tabela 1: Distribuição percentual e numérica dos adolescentes segundo estágio 30 de vida $c$ gêncro de uma Escola Estadual de scgundo grau do municipio de São Paulo, 1999.

Tabela 2: Contribuição de energia proveniente de Proteína (g), Carboidratos (g) c Gordura total (g), consumidos pclos adolescentes no feriado, segunda, quarta $e$ quinta-feira, de uma Escola Estadual de segundo grau do município de São Paulo, 1999.

Tabela 3: Médias de Energia e dos nutrientes consumidos pelos adolescentes no fcriado, scgunda, quarta c quinta-fcira, dc uma Escola Estadual dc scgundo grau do município de São Paulo, 1999.

Tabela 4: Médias em gramas de grupos alimentares consumidos pelos adolcsccntcs no fcriado, scgunda, quarta c quinta-feira, de uma Escola Estadual de segundo grau do município de São Paulo, 1999.

Tabela 5: Médias em gramas de grupos alimentares consumidos pelos adolcscentcs no fcriado, scgunda, quarta c quinta-fcira, de uma Escola Estadual de segundo grau do município de São Paulo, 1999.

Tabela 6: Distribuição das mudanças entre os adolescentes que deixaram ou passaram a consumir os grupos alimentares no fcriado, scgunda, quarta c quintafeira, de uma Escola Estadual de segundo grau do município de São Paulo, 1999.

Tabela 7: Distribuição das mudanças entre os adolescentes que deixaram ou passaram a consumir os grupos alimentares no feriado, segunda, quarta e quintafeira, de uma Escola Estadual de segundo grau do município de São Paulo,1999. 


\section{Página}

Tabela 8: Distribuição das mudanças entre os adolescentes que deixaram ou passaram a consumir os grupos alimentares no feriado, segunda, quarta e quintafeira, de uma Escola Estadual de segundo grau do município de São Paulo, 1999.

Tabela 9: Distribuição das mudanças entre os adolescentes que deixaram ou passaram a consumir os grupos alimentares no feriado, segunda, quarta $\in$ quintafeira, de uma Escola Estadual de segundo grau do município de São Paulo, 1999.

Tabela 10: Distribuição das mudanças entre os adolescentes que deixaram ou passaram a consumir os grupos alimentares no feriado, segunda, quarta $€$ quintafeira, de uma Escola Estadual de segundo grau do município de São Paulo, 1999

Tabela 11: Distribuição das mudanças entre os adolescentes que deixaram ou 56 passaram a consumir os grupos alimentares no feriado, segunda, quarta e quintafeira, de uma Escola Estadual de segundo grau do município de São Paulo, 1999

Tabela 12: Distribuição de mudanças dos adolescentes que deixaram ou passaram a consumir as refeições no feriado, segunda, quarta $€$ quinta-feira, de uma Escola Estadual de segundo grau do município de São Paulo, 1999.

Tabela 13: Média, desvios padrão, kolmogorov-smirnov e nível de significância dos valores consumidos de energia $\&$ nutrientes em logaritmo na base 10 , dos adolescentes no feriado, segunda, quarta e quintas-feiras, de uma escola estadual do Município de são Paulo, 1999. 


\section{LISTA DE FIGURAS}

Página

Figura 1: Distribuição percentual dos adolescentes segundo gênero de uma 29

Escola Estadual de segundo grau do município de São Paulo, 1999.

Figura 2: Consumo de energia dos adolescentes no feriado, segunda, quarta

e quinta-feira, de uma Escola Estadual de segundo grau do município de São Paulo, 1999.

Figura 3: Consumo de proteína dos adolescentes no feriado, segunda, quarta e quinta-feira, de uma Escola Estadual de segundo grau do município de São Paulo, 1999.

Figura 4: Consumo de gordura total dos adolescentes no feriado, segunda, quarta e quinta-feira, de uma Escola Estadual de segundo grau do município de São Paulo, 1999.

Figura 5: Consumo de ferro dos adolescentes no feriado, segunda, quarta e quinta-feira, de uma Escola Estadual de segundo grau do município de São Paulo, 1999.

Figura 6: Consumo de carboidrato dos adolescentes no feriado, segunda, quarta e quinta-feira, de uma Escola Estadual de segundo grau do município de São Paulo, 1999.

Figura 7: Consumo de gordura insaturada dos adolescentes no feriado, segunda, quarta e quinta-feira, de uma Escola Estadual de segundo grau do município de São Paulo, 1999.

Figura 8: Consumo de fibra dos adolescentes no feriado, segunda, quarta e quinta-feira, de uma Escola Estadual de segundo grau do município de São Paulo, 1999. 
Figura 9: Consumo de vitamina $C$ dos adolescentes no feriado, segunda, quarta e quinta-feira, de uma Escola Estadual de segundo grau do município de São Paulo, 1999.

Figura 10: Consumo de cálcio dos adolescentes no feriado, segunda, quarta e quinta-feira, de uma Escola Estadual de segundo grau do município de São Paulo, 1999.

Figura 11: Distribuição da freqüência do consumo de achocolatado em pó, 46 açúcar, leite e café, dos adolescentes no feriado, segunda, quarta e quintafeira, de uma Escola Estadual de segundo grau do município de São Paulo, 1999.

Figura 12: Distribuição da freqüência do consumo arroz, batata, feijão, came bovina e de frango dos adolescentes no feriado, segunda, quarta e quinta-feira, de uma Escola Estadual de segundo grau do município de São Paulo, 1999.

Figura 13: Distribuição da freqüência do consumo biscoitos, pães, bolo e macarrão dos adoleseentes no feriado, segunda, quarta e quinta-feira, de uma Escola Estadual de segundo grau do município de São Paulo, 1999.

Figura 14: Distribuição da freqüência do consumo alface, verduras e frutas dos adolescentes no feriado, segunda, quarta e quinta-feira, de uma Escola Estadual de segundo grau do município de São Paulo, 1999.

Figura 15: Distribuição da freqüência do consumo óleos e queijos dos adolescentes no feriado, segunda, quarta e quinta-feira, de uma Escola Estadual de segundo grau do município de São Paulo, 1999. 


\section{Página}

Figura 16: Distributição da fĩeqüêneia do consumo refrigerante, salgado, 51 salgadinho, sanduiches e doces dos adolescentes no feriado, segunda, quarta e quinta-feira, de uma Escola Estadual de segundo grau do município de São Paulo, 1999.

Figura 17: Distribuição da freqüência de consumo do café da manhã no feriado, segunda, quarta e quinta-feira, de uma Escola Estadual de segundo grau do município de São Paulo, 1999.

Figura 18: Distribuição da frequiência de consumo do lanche da manhã no feriado, segunda, quarta e quinta-feira, de uma Escola Estadual de segundo grau do munieípio de São Paulo, 1999.

Figura 19: Distribuição da freqüência de consumo do almoço no feriado, segunda, quarta e quinta-feira, de unza Escola Estadual de segundo grau do município de São Paulo, 1999.

Figura 20: Distribuição da freqüência de consumo do lanche da tarde no feriado, segunda, quarta e quinta-feira, de uma Escola Estadual de segundo grau do município de São Paulo, 1999.

Figura 21: Distribuição da freqüência de consumo do jantar no feriado, segunda, quarta e quinta-feira, de uma Escola Estadual de segundo grau do município de São Paulo, 1999.

Figura 22: Distribuição da freqüência de consumo do lanche da noite no feriado, segumda, quarta e quinta-feira, de uma Eseola Estadual de segundo grau do município de São Paulo, 1999. 
Figura 23: Distribuição de freqüência do consumo do lanche da noite no feriado, segunda, quarta e quinta-feira, de uma Escola Estadual de segundo grau do município de São Paulo, 1999.

Figura 24: Distribuição da curva normal para as médias de energia consumidas no feriado, segunda-feira, quarta-feira e quinta-feira, de uma Escola Estadual do Município de São Paulo em 1999.

Figura 25: Distribuição da curva normal para as médias de proteína II consumidas no feriado, segunda-feira, quarta-feira e quinta-feira, de uma Escola Estadual do Município de São Paulo em 1999.

Figura 26: Distribuição da curva normal para as médias de carboidrato consumidas no feriado, segunda-feira, quarta-feira e quinta-feira, de uma Escola Estadual do Município de São Paulo em 1999.

Figura 27: Distribuição da curva normal para as médias de gordura total consumida no feriado, segunda-feira, quarta-feira e quinta-feira, de uma Escola Estadual do Município de São Paulo em 1999.

Figura 28: Distribuição da curva normal para as médias de gordura insaturada consurnidas no feriado, segunda-feira, quarta-feira e quinta-feira, de uma Escola Estadual do Município de São Paulo em 1999.

Figura 29: Distribuição da curva normal para as médias de fibra consumidas VI no feriado, segunda-feira, quarta-feira e quinta-feira, de uma Escola Estadual do Município de São Paulo em 1999.

Figura 30: Distribuição da curva normal para as médias de vitamina $C$ VII consumidas no feriado, segunda-feira, quarta-feira e quinta-feira, de uma Escola Estadual do Município de São Paulo em 1999. 


\section{Página}

Figura 31: Distribuição da curva normal para as médias de cálcio VIII consumidas no feriado, segunda-feira, quarta-feira e quinta-feira, de uma Escola Estadual do Município de São Paulo em 1999.

Figura 32: Distribuição da curva normal para as médias de ferro consumidas IX no feriado, segunda-feira, quarta-feira e quinta-feira, de uma Escola Estadual do Município de São Paulo em 1999.

\section{LISTA DE QUADROS}

Página

Quadro 1: Agrupamento inicial dos alimentos consumidos pelos XI adolescentes no feriado, segunda-feira, quarta-feira e quinta-feira, em uma Escola Estadual do Município de São Paulo em 1999.

Quadro 2: Grupos alimentares consumidos mais freqüentemente pelos XIII adolescentes no feriado, segunda-feira, quarta-feira e quinta-feira, en una Escola Estadual do Município de São Paulo em 1999. 
ABREVIATURAS E SIGLAS

\section{SIGLA DESCRIÇÃO}

$\begin{array}{cl}\text { Rec 24h } & \text { Questionário recordatório de 24 horas } \\ \text { OMS } & \text { Organização Mundial da Saúde } \\ \text { DRIs } & \text { Dietary References Intakes } \\ \text { EUA } & \text { Estados Unidos da América } \\ \text { LOG10 } & \text { Logaritmo da base 10 } \\ \text { IC } & \text { Intervalo de confiança } \\ \text { CNS } & \text { Conselho nacional do ministério da saúde } \\ \text { RDAs } & \text { Recommended Dietary Allowances } \\ \text { PAA } & \text { Pirâmide alimentar adaptada } \\ \text { AHF } & \text { American Health Foundation } \\ \text { NHANES } & \text { National America Surveys }\end{array}$




\section{LISTA DE ANEXOS}

ANEXO I Gráficos do teste Komogorov-Smirnov para aderência à curva I normal para energia e nutriente

ANEXO II Tabelas do teste Komogorov-Smirnov - aderência à curva normal para LOG10 da energia e nutriente

ANEXO III Quadro do agrupamento inicial dos alimentos consumidos XI pelos adolescentes

ANEXO IV Quadro dos 23 grupos de alimentos

ANEXO V Parecer do Comitê de Ética da Faculdade de Saúde Pública da XIV Universidade de São Paulo 
INTRODUCÃO 


\section{Métodos para Avaliar o Consumo Alimentar}

A epidemiologia se define pelo estudo das determinantes de doenças e suas distribuições em populações. Com estudos epidemiológicos pode-se estimar fatores, que aplicados à Saúde Pública, auxiliam no planejamento de programas e na melhoria da qualidade de assistência á população (Majem \& Bartrina 1995).

A epidemiologia nutricional baseia-se em dados de consumo alimentar, na descrição do estado nutricional da população, na distribuição de doenças relacionadas e na avaliação da efetividade de programas de intervenção nutricional (Majem \& Bartrina 1995, Verdú \& Gonzalez 1995). Ela também se destaca no de desenvolvimento de instrumentos de medição do consumo alimentar individual e populacional, assim como na sua avaliação (Villar 2001).

A avaliação do consumo alimentar consiste na determinação das quantidades ingeridas dos nutrientes durante um período de tempo, para assim, obter informações sobre a dieta habitual do indivíduo. Isso permite a comparação com as recomendações nutricionais e verificar as possíveis relações de déficit ou de excesso alimentar (Verdú \& Gonzalez 1995). Portanto, o conhecimento do padrão alimentar, dos hábitos de consumo e das quantidades de alimentos ingeridas por indivíduos ou por grupos populacionais, é importante para o planejamento de políticas públicas (Majem 1995).

A informação dietética pode ser obtida em vários níveis: nacional, mediante uso de metodologias que se baseiam na disponibilidade de alimentos do país, o familiar na distribuição interna do orçamento familiar destinado à aquisição de 
alimentos e o individual, no consumo de alimentos que serão transformados em energia e nutrientes por meio de tabelas de composição de alimentos (Majem 1995).

Para medir o consumo individual podem ser utilizados diversos métodos que diferem, pela forma como se obtém a informação e pelo momento ou período de tempo a ser medido. Pode-se avaliar o consumo atual, o passado imediato ou ainda um período passado específico (Majem 1995, Dwyer 1994, Thompson \& Byers 1994, Dwyer 2003).

Os métodos são divididos em dois grandes grupos, os prospectivos e os retrospectivos (Dwyer 1994, Dwyer 2003). Os prospectivos são os métodos que avaliam o indivíduo no instante em que o alimento é consumido. Incluem o diário alimentar, a pesagem de alimentos e análise em duplicata, medindo o consumo atual do indivíduo (Dwyer 1994, McPherson et al. 2000, Dwyer 2003).

Os métodos retrospectivos incluem o Recordatório de 24 horas - Rec 24h, que mede o consumo atual, o questionário de frequência alimentar e a história alimentar, que medem o consumo habitual do indivíduo (Dwyer 1994, McPherson et al. 2000, Dwyer 2003).

Há grandes controvérsias sobre qual é o método mais adequado e fidedigno para medir o consumo real dos alimentos. Não existe um método a ser considerado padrão ouro, pois cada um possui vantagens ou desvantagens e a sua utilidade dependerá dos objetivos e das variáveis apresentadas nos estudos (Majem 1995, NAS/NRC 1992, Thompson \& Byres 1994). 
Os fatores que influenciam a escolha de um método de avaliação do consumo são: a população a ser estudada, os recursos disponíveis (financeiros, humanos e materiais), os nutrientes a serem analisados e o desenho metodológico (Majem 1995, Thompson \& Byres 1994). Deve-se considerar ainda o nível de detalhamento e de precisão na determinação das quantidades consumidas (NAS/NRC 1992). Todas essas variáveis podem tornar o processo da medida de consumo impreciso, especialmente com técnicas de medidas que são metodologicamente limitadas (McPherson et al. 2000).

O instrumento ideal é aquele de fácil utilização, baixo custo e principalmente, com a capacidade de medir o consumo com suficiente precisão (Willett 1994). O Rec 24h é um dos métodos mais utilizados para a avaliação do consumo alimentar descrevendo a ingestão média de grupos populacionais (Majem \& Barba 1995). Ele consiste em quantificar todos os alimentos consumidos e bebidas ingeridas pelo indivíduo nas 24 horas precedentes à entrevista, ou seja, no dia anterior (Thompson \& Byres 1994, Gibson 1990).

Quando há interesse em quantificar a ingestão média de energia e nutrientes de grupos populacionais que possuem culturas diferentes, o Rec 24 h, mostra-se útil, pois permite a descrição de um número amplo de alimentos e de hábitos alimentares, além de ter aplicação rápida e conseqüentemente pode-se ter maior adesão por parte dos entrevistados (Majem \& Barba 1995, Villar 2001).

O sucesso do Rec 24 h depende da memória, da cooperação e da capacidade de comunicação e expressão do entrevistado, assim como da habilidade do pesquisador em estabelecer um bom canal de comunicação com a pessoa entrevistada 
(Thompson \& Byres 1994, Majem \& Barba 1995). A obtenção de respostas precisas, não tendenciosas, exige muita destreza, sendo necessário um treinamento adequado dos entrevistadores. Estes deverão possuir amplo conhecimento dos hábitos e costumes da comunidade, dos alimentos consumidos por ela e do seu modo de preparo (Thompson \& Byres 1994).

Devido ao fato deste método estar diretamente vinculado com a habilidade individual de recordar o seu consumo alimentar, há fatores que podem influenciar os entrevistados como: idade, sexo, nível de escolaridade, entre outros (Majem \& Barba 1995).

A idade influência as repostas principalmente em faixas etárias extrema, crianças e idosos, necessitando que as pessoas responsáveis relatem tais informações (Villar 2001). Treiber et al.(1990), Domel et al. (1994), Frank (1994) relatam que adolescentes a partir de 12 e 13 anos de idade possuem habilidade suficiente para responder o Rec 24 h com precisão sem auxilio de adultos.

O detalhamento sobre o tamanho e volume das porções consumidas é fundamental, para isto, o entrevistador poderá utilizar álbuns de fotografias, medidas geométricas ou medidas caseiras para seu auxilio. No Brasil, onde as diferenças culturais são grandes entre individuos que habitam a mesma cidade ou região, se faz necessário perguntar a forma de preparo dos alimentos, pois duas preparações diferentes, com ingredientes distintos, podem receber a mesma nomenclatura (Villar 2001).

A maior limitação do Rec $24 \mathrm{~h}$ é que uma medida provavelmente não represente a ingestão habitual do indivíduo, devido à elevada variabilidade 
intrapessoal/ interpessoal (Majem \& Barba 1995, Villar 2001). Dessa forma a credibilidade do método dependerá do número de indivíduos avaliados e da variabilidade interpessoal. Contudo, quando é repetida mais de duas vezes, a confiabilidade do $\operatorname{Rec} 24 \mathrm{~h}$ dependerá da variabilidade intrapessoal, que por sua vez depende da população e dos nutrientes estudados (Villar 2001).

O principal aspecto a ser considerado quando se trabalha com consumo alimentar de indivíduos ou populações é a variabilidade da dieta (Willett 1998). Mesmo que haja um padrão estável de consumo, não existem elementos de consistência, considerando-se dessa forma, o consumo diário de alimentos um evento aleatório (Villar 2001).

Inúmeros fatores contribuem para a variação diária do consumo alimentar de uma forma sistemática, como por exemplo, o dia da semana ou a estação do ano. Ao se considerar esses fatores haverá uma diminuição nas fontes de erros das medidas de consumo (Willett 1998, Liu 1994).

A magnitude das influências na variação do consumo alimentar está relacionada com fatores socioeconômicos, culturais e ambientais. Por exemplo, o sistema de transporte e preservação de alimentos, países onde esse sistema não é desenvolvido as estações do ano possuem um efeito importante no consumo alimentar, já naqueles desenvolvidos, esse efeito é muito pequeno. Outro aspecto a ser considerado, é a concentração de nutrientes em certos tipos de alimentos, especialmente os micronutrientes, pois leva a uma alta ou baixa ingestão conforme a escolha alimentar do dia (Willett 1998). Para que esses tipos de variações estejam 
englobados na avaliação do consumo alimentar deve-se considerar as médias de várias medidas alimentares, ou seja, a média de vários dias (Willett 1998). 


\section{$O$ adolescente e suas necessidades}

A adolescência é considerada uma fase de transição gradual da infância para a idade adulta, representado um dos períodos mais importantes do ciclo de vida do ser humano. É o momento em que o crescimento e o desenvolvimento do indivíduo se completam, culminando com plena capacidade de reprodução (Colli 1999a , Colli $\left.1999^{\mathrm{b}}\right)$

Essa fase, conhecida como puberdade, engloba uma série de modificações biológicas, entre elas: o estirão de crescimento (aceleração e desaceleração do crescimento do esqueleto e órgãos); o desenvolvimento das gônadas (órgãos de reprodução e caracteres secundários); mudanças de composição corporal (distribuição de gordura) e crescimento do esqueleto e da musculatura (Clavien et al. 1996, Cavadini et al. 1999).

Além das mudanças morfológicas, ocorrem as psicológicas e as comportamentais (Albano \& Souza 2001). O adolescente está desenvolvendo e definindo sua identidade, sua auto-imagem, seu estilo de vida de forma a se ajustar a uma vida social, familiar e escolar, para se tornar um adulto (Philippi 1992, ParryJones 1994, Schmidt 1994, Campos 1995, Gambardella 1995).

Esse ajuste é caracterizado por comportamentos de contestação da autoridade e quebra de padrões. O adolescente é vulnerável, volúvel, seguidor de líderes, grupos e moda, possuindo preocupações ligadas ao corpo e à aparência (Philippi 1992, Parry-Jones 1994, Schmidt 1994, Campos 1995, Gambardella 1995). 
Para se delimitar o periodo da adolescência pode-se utilizar diferentes critérios como: idade cronológica, desenvolvimento físico e características psicológico-sociais. A idade é o critério mais utilizado devido sua facilidade e baixo custo de execução (Bianculli 1995, Colli 1999ª).

Segundo a Organização Mundial da Saúde (OMS), são adolescentes aqueles entre 10 e 19 anos de idade, sendo que no Brasil, o censo de 2000 constatou que mais de 35 milhões de pessoas encontravam-se nesse estágio de vida (OMS 1995, IBGE 2002).

A adolescência pode ser dividida em duas fases: primeira entre 10 e 14 anos, com o início das mudanças puberais, e a segunda entre 15 e 19, onde há o término do crescimento e desenvolvimento morfológicos (OMS 1995). Apesar dessas delimitações cronológicas, o final da adolescência não é determinado precisamente, pois para o indivíduo tornar-se adulto, deve ter uma consolidação da identidade, independência da família, autodeterminação, além do amadurecimento da sexualidade. $O$ termo juventude é utilizado como um prolongamento da adolescência, possuindo uma etapa pós puberal e compreendendo a faixa etária dos 15 aos 24 anos (Albano \& Souza 2001).

Durante a adolescência o indivíduo ganha cerca de 20 a $25 \%$ de sua altura e $50 \%$ do seu peso definitivos, sendo, portanto, um período de intenso anabolismo, no qual a nutrição é peça fundamental para que o adolescente atinja seu potencial máximo de crescimento e desenvolvimento (Saito 1999, Giovannini et al. 2000).

As necessidades nutricionais relacionam-se com as mudanças na composição corporal do adolescente. Estão ligadas à idade fisiológica e cronológica, às etapas de 
maturação sexual e a velocidade de crescimento dos indivíduos (Eisenstein 1995). É durante esse período que a variabilidade individual e populacional se faz presente, pois indivíduos normais, com a mesma idade e sexo, podem se encontrar em fases de desenvolvimento diferentes (Colli 1999 ${ }^{\mathrm{b}}$ ).

As necessidades nutricionais para o adolescente não estão determinadas de maneira precisa, devendo-se, portanto, considerar diversos fatores para seu crescimento e desenvolvimento saudável (Olmedilla \& Granado 2000, Sperar 2002).

A quantidade de consumo de energia deve acompanhar as variações de crescimento do indivíduo, portanto o pico máximo de ingestão calórica deve coincidir com o pico máximo da velocidade de crescimento (Saito 1999). Segundo Giovannini et al. (2000) a quantidade energética recomendada a um adolescente, além de considerar o momento de desenvolvimento puberal, deve levar em conta também o aumento na quantidade de massa magra (quantidade de massa muscular), pois há diferença no metabolismo da massa gorda (quantidade de gordura corporal) e da massa magra, sendo o da segunda muito mais intenso.

A proteína durante essa fase de desenvolvimento é utilizada não só para o processo de manutenção corpórea, como também para o crescimento de novos tecidos, devendo-se considerar a idade fisiológica ao invés da cronológica para a determinação de suas necessidades (Giovannini et al. 2000). Sabe-se que o metabolismo de proteínas é super sensível a restrições calóricas, portanto, a ingestão inadequada de energia pode acarretar em prejuízo na síntese de tecidos e conseqüentemente no crescimento e desenvolvimento dos indivíduos em pleno estirão da adolescência (Eisenstein 1995). 
Como a qualidade de distribuição das gorduras saturadas e insaturadas e dos carboidratos simples e complexos está associados às doenças crônicas não transmissíveis em outros estágios de vida, às necessidades para esses nutrientes devem considerar os aspectos preventivos nessa faixa etária (Giovanini et al. 2000).

Os micronutrientes são essenciais para o crescimento e desenvolvimento, para a manutenção do sistema imunológico e de outros fatores metabólicos e funç̧ões fisiológicas dos adolescentes (Olmedilla \& Granado 2000).

Com relação aos minerais, durante o estirão da adolescência há um aumento da necessidade de todos eles, mas em especial o cálcio, ferro e zinco (Eisenstein 1995). Esses nutrientes são os principais envolvidos no crescimento e na maturação sexual do adolescente e sabe-se que suas retenções corpóreas são aumentadas durante essa fase (Olmedilla \& Granado 2000, Spear 2002). Isso ocorre porque, durante a puberdade, aproximadamente $45 \%$ do esqueleto adulto é formado, há um aumento de $25 \%$ de células vermelhas e a síntese protéica está em sua atividade máxima (Olmedilla \& Granado 2000).

Os dados sobre as necessidades de vitaminas para os adolescentes são limitados, principalmente nos países da América Latina, onde os estudos são realizados com amostras não significativas da população. Porém pode-se afirmar que as necessidades nutricionais de vitaminas aumentam de forma proporcional a velocidade de crescimento e desenvolvimento puberais (Eisenstein 1995).

Sabe-se que com o incremento no consumo de energia, devido ao aumento da demanda, é necessária uma maior quantidade de tiamina, riboflavina e niacina, pois estão envolvidas no metabolismo dos carboidratos, assim como as vitaminas B12 e 
B6 com a síntese protéica. Aumentam também as necessidades de vitamina $\mathrm{D}, \mathrm{A}, \mathrm{C}$, e E a primeira devido ao crescimento do esqueleto $\_$as outras ao crescimento celular (Spear 2002).

Em relação ao que se é recomendado para os adolescentes atualmente pode-se utilizar as Dietary Reference Intakes (DRIs), que são valores referenciais para o consumo de nutrientes para populações saudáveis. As DRIs por razões práticas foram categorizadas cronologicamente ao invés da maturação sexual (Spear 2002).

A dificuldade em se estimar as recomendações para adolescentes estão ligadas ’̀̀ grande variação nas taxa de crescimento, atividade física, taxa de metabolismo e estados fisiológicos. Portanto, quando se trata de grupos populacionais as DRIs são utilizadas para analisar a adequação da dieta e predição de risco, mas para indivíduos devem ser utilizadas com cautela, sendo o ideal aliar a informações clínicas, bioquímicas e antropométricas (Spear 2002). 


\section{Consumo alimentar na adolescência}

A transição nutricional se refere às mudanças seculares no padrão alimentar e conseqüentemente nos nutricionais. Essas alterações resultam modificações na estrutura da dieta dos indivíduos e se correlacionam com as mudanças econômicas, sociais e demográficas (Popkin et al 1993).

As mudanças referentes ao padrão alimentar estão associadas a uma dieta com alto teor de gordura, colesterol, açúcar refinado e baixo teor de ácidos graxos poliinsaturados e fibras, acompanhadas de uma vida sedentária (Popkin 1993). Países industrializados tendem a esse padrão, sendo denominada "dieta ocidental" (Monteiro 1995).

Nos Estados Unidos da América (EUA), a tendência de padrão alimentar entre adolescentes é manter-se dentro da "dieta ocidental", pois o consumo excessivo de gordura total, gordura saturada e de sódio, o baixo consumo fibras na dieta do americano são fatores comumente encontrados. Ao longo de sete anos, (1989-96) houve um aumento significativo de $4 \%$ no consumo de gordura e de $15 \%$ de carboidrato por dia (Cavadini et al. 2000 ${ }^{\mathrm{a}}$ ). Somando-se a essas informações, estimase que adolescentes entre 12 e 15 anos necessitariam aumentar de 25 a $50 \%$ o seu consumo de fibras, e aqueles entre 16-19 anos no mínimo dobrar o consumo para atingir o recomendado para essa faixa etária (recomendado - idade do indivíduo $+5 \mathrm{~g}$ de fibras por dia) (Nicklas et al. 2000, Lytle 2002). 
Esse padrão presente nas dietas dos adolescentes é considerado o principal responsável pelo aumento da morbidade e mortalidade em adultos, pois resulta em um aumento da prevalência de obesidade e conseqüentemente de doenças crônicas não transmissíveis como: doenças cardiovasculares, hipertensão, alguns tipos de cânceres e diabetes tipo II (Clavien et al. 1996, Rolland-Cachera et al. 2000, Lytle 2002).

Em países subdesenvolvidos, a rápida transição nutricional cria uma situação em que a desnutrição e a obesidades co-existem. No Brasil essa situação já está instalada, pois a desnutrição ainda é relevante, especialmente em crianças de baixa renda e a obesidade vêm crescendo em adultos, também de baixa renda (Popkin et al. 1993, Monteiro et al 1995).

A obesidade entre adolescentes teve um aumento rápido entre os americanos nas últimas décadas (Lytle 2002). Os dados da NHANES II de 1976 a 1980 mostraram que os $5 \%$ dos adolescentes possuíam sobrepeso e $15 \%$ estavam em risco de sobrepeso. Na NHANES III de 1988 a 1994, 11\% dos adolescentes possuíam sobrepeso e $22 \%$ em risco. Aproximadamente $95 \%$ dos adolescentes americanos diagnosticados com diabetes tipo II possuíam um índice de massa corpórea acima do percentil 85 para idade e gênero, ou seja, com risco de sobrepeso (Lytle 2002).

Os dados sobre obesidade em adolescentes no Brasil são escassos, mas sabese que entre 1980 e 1994 houve aumento acentuado em sua prevalência (Monteiro 1998). Estudo realizado no município de São Paulo por Albano \& Souza (2001) mostrou que cerca de $32,6 \%$ dos adolescentes estudados do gênero masculino e $26,5 \%$ do gênero feminino estavam em risco ou com sobrepeso. 
O ganho de peso é resultado de um balanço positivo de energia, ou seja, se consome mais do que gasta (Lytle 2002), portanto, com o aumento da obesidade na adolescência, esperava-se um aumento no consumo de alimentos. Rolland-Cachera et al. (2000) em uma análise de diferentes estudos realizados entre 1930 a 1978 na Inglaterra, Estados Unidos e Austrália mostraram que houve uma redução progressiva no consumo da energia em crianças e adolescentes entre 1 e 18 anos de idade. Cavadini et al. $\left(2000^{\mathrm{a}}\right)$, também verificaram um decréscimo no consumo de energia em um período de 30 anos, entre adolescentes de 11 e 18 anos.

Essa alteração no consumo de energia pode ser justificada por dois fatores, um comportamental, que é a diminuição da atividade fisica desses adolescentes e outra metodológica, onde houve subestimação do consumo alimentar no momento da entrevista (Cavadini et âl. 2000ª , Rolland-Cachera et al. 2000).

Ao contrário desses estudos, entre NHANES II e NHANES III, houve um aumento no consumo médio de energia, de 100 para $300 \mathrm{kcal}$ por adolescente diariamente, mas também notou-se um decréscimo significante no gasto de energia entre crianças que atingiam a adolescência, especialmente para o sexo feminino (Lytle 2002).

Os fatores de prevenção da obesidade e co-morbidades devem ser aplicados em todas as etapas de desenvolvimento humano, pela garantia de uma nutrição adequada durante a idade adulta (OPAS \& OMS 1995, Uauy 1999). Apenas com a melhoria da alimentação nos EUA, o custo de tratamentos para doenças cardíacas, câncer e diabetes tipo II seriam reduzidos em 71 bilhões de dólares por ano (Lytle 2002). 
Como a adolescência é o período de maiores mudanças de atitudes, estilo de vida e de aquisição de independência, ocorrem importantes alterações nos hábitos alimentares, principalmente porque o indivíduo sofre influências do meio em que vive, uma vez que as atitudes e os hábitos se desenvolvem por meio das interações sociais (Clavien et al. 1996, Feunekes 1998, Cavadini et al. 1999)).

As influências nos hábito alimentares podem ser diretas, indiretas, conscientes ou inconscientes. A princípio, a dieta dos adolescentes está sob a influência de sua relação intrapessoal, ou seja, suas atitudes, crenças, conhecimentos, gostos, preferências alimentares, além de conveniência, custo e tempo disponível (Feunekes 1998, Story et al. 2002).

A relação interpessoal também é um fator a ser considerado, pois o ambiente social que inclui família, amigos e colegas, interfere muito nas escolhas alimentares (Story et al. 2002). Apesar dessas influências no padrão alimentar serem consideradas de grande importância, estudo realizado por Feunekes et al. (1998) mostrou que elas estão mais associadas aos "snacks" (alimentos ingeridos fora das três refeições principais - café da manhã, almoço e jantar - com baixa qualidade nutricional) ou às comidas consideradas "junk" (alimentos com alto teor de gordura saturada, açúcar, colesterol e/ou sal) (Gama 1999). Os autores ainda consideraram que os hábitos alimentares se correlacionam com o núcleo familiar ao invés dos amigos, pois verificou-se que as refeições e os lanches foram realizados principalmente com a família (Feunekes et al. 1998).

A falta de consistência sobre a influência dos amigos sobre as escolhas alimentares pode ser dada por diversas razões: os adolescentes procuram sua 
individualidade, sua autonomia, sua independência e, portanto, não querem admitir que suas atitudes são influenciadas (Story et al. 2002).

Assim como os adultos, os adolescentes podem não estar cientes das influências sociais em seus padrões alimentares, e os amigos e colegas estão relacionados mais indiretamente do que diretamente com as escolhas alimentares (Story et al. 2002).

O ambiente físico também é importante nesse sentido, pois está relacionado com o acesso e disponibilidade de alimentos. Locais que mais afetam as escolhas dos adolescentes são: escola, "fast-food", restaurantes, shoppings, etc. Ainda que sejam indiretas, não pode-se deixar de citar as influências da mídia, propagandas, normas culturais e sociais, produção de alimentos e distribuição (Story et al. 2002).

Todos os aspectos citados levam o adolescente a um padrão alimentar de: suprimir refeições, comer "snacks", realizar refeições fora de casa e o consumo rápido dos alimentos (Dwyer 1994, Dwyer 2003).

O café da manhã é a refeição menos realizada pelos adolescentes e com menor contribuição energética (Cavadini 1999, Slater 2001). Cerca de 15\% dos adolescentes dos países localizados no sudeste da Europa (Portugal, Espanha, Itália e Grécia) não tomam o café da manhã. Apesar de $85 \%$ desses individuos tomarem o café, essa refeição possui pouca contribuição energética e é inadequada do ponto de vista nutricional (Cruz 2000). Nos EUA, essa prática também é comum entre os adolescentes, mas o número daqueles que não fazem a refeição pode chegar a mais de $30 \%$ (Cruz 2000, Spear 2002). 
Nos países nórdicos (Dinamarca, Noruega, Islândia, Finlândia e Suécia) o café da manhã também foi a refeição menos freqüente entre adolescentes de 13 a 18 anos. O mesmo ocorreu na Suécia especialmente nas adolescentes que possuem o hábito de fumar (Samuelson 2000).

Rolland-Chacherra et al (2000) verificaram que cerca de $20 \%$ dos adolescentes admitem o fato de não tomarem o café da manhã, mas o baixo consumo energético desta refeição é compensado durante o resto do dia, principalmente com o consumo de "snacks".

Estudo realizado com jovens adultos (19 a 29 anos de idade) nos EUA, mostrou que entre $1977-78$ e $1994-96$ houve um aumento de $7 \%$ no consumo de "snacks" (Zizza et al. 2001). Na França cerca de 60\% dos adolescentes entre 16-17 anos de idade consomem "snacks" e $45 \%$ entre $11-13$ anos de idade (Choquet \& Ledoux 1994). Nos países Nórdicos houve um aumento de consumo desse tipo de alimento na faixa etária de 13 a 18 anos de idade e os itens mais consumidos foram refrigerante, bolos, sorvetes, batata "chips" (Samuelson 2000).

Zizza et al. (2001) ao compararem grupos de indivíduos que comiam "snacks" e os que não comiam, o primeiro obteve um consumo de carboidrato, gordura total e gorduras saturadas significativamente maior do que o segundo, mostrando que o consumo deste tipo de alimento contribui para o padrão alimentar descrito pela "dieta ocidental".

Zizza et al. (2001) correlacionam o incremento no consumo de energia e a densidade energética provenientes dos "snacks" ao aumento da obesidade nos EUA. 
O consumo de alimentos fora de casa também mostra-se uma variável importante, pois a refeição no domicílio possui uma qualidade nutritiva melhor do que aquelas consumidas em outros locais (Rolland-Cachera et al. 2000). Entre 197796, nos EUA, a energia proveniente do consumo de alimentos em domicílio, para adolescentes de 12 a 18 anos, diminuiu e conseqüentemente a proporção vinda de restaurantes e "fast-food" aumentou (Nielson et al. 2002). Estudo realizado com 379 adolescentes entre 11 e 12 anos, mostrou que 30\% do total energético provinha de alimentos consumidos fora de casa (Adamson et al. 1996).

Não se deve descartar influências como: treinamento esportivo, hábito de fumar e regimes alimentares, pois podem modificar as escolhas alimentares dos adolescentes (Dwyer 1994, Baker et al 2000, Dwyer 2003).

O treinamento esportivo, pode ser considerado um fator de proteção à qualidade alimentar de adolescentes e a sua falta está associada ao sobrepeso (Cavadini et al $2000^{\mathrm{b}}$, Spear 2002). Confirmando essas informações, Cavadini et al $2000^{\mathrm{b}}$, verificaram em adolescentes suíços, que aqueles que eram atletas possuíam hábitos alimentares mais saudáveis do que os não-atletas.

O hábito de fumar um é fator preocupante, pois normalmente é iniciado na adolescência e está associado ao aumento de consumo de álcool e a um baixo consumo de nutrientes essenciais (Rolland-Cacherra et al. 2000). Ele está associado há um menor consumo de proteína, carboidratos, fibras alimentares, tiamina, vitamina $\mathrm{C}$, cálcio e ferro e grande parte das meninas que fumam possuem sobrepeso (Rolland-Cacherra et al 2000, Barker et al 2000). 
Estudo realizado na Suécia, por Samuelson (2000) mostrou que o café da manhã é influenciado pelo hábito de fumar. Cerca de 35\% dos adolescentes do gênero masculino fumantes não tomavam café da manhã em relação a $17 \%$ dos não fumantes; ao se tratar do gênero feminino os números praticamente dobram $72 \%$ da fumantes não tomavam café contra $27 \%$ das não fumantes.

A preocupação com o peso corpóreo, resultando em regimes alimentares restritivos é comum entre adolescentes do gênero feminino (Barker 2000). Cerca de $17 \%$ dos adolescentes do gênero feminino entre 14-17 anos de idade fazem freqüentemente regime alimentar e com isso, há um consumo insuficiente de vários micronutrientes incluindo cálcio, vitamina C (Choquet \& Ledoux 1994, RollandCacherra et al. 2000).

Um consumo adequado de cálcio é essencial para o crescimento ósseo e se faz necessário para o adolescente atingir seu pico de formação óssea (Harel et al 1998). Diversos estudo afirmam que o consumo de cálcio entre adolescentes, de ambos os sexos, não atingem o recomendado para a idade (Harel et al 1998, Munõz et al 1997, Rolland- Cacherra 2000, Cruz 2000). Cavadini et al. (1999) verificaram por meio de questionário de freqüência alimentar que menos de $50 \%$ dos adolescentes que participaram da pesquisa consumiam leite e derivados, ou seja, mais da metade pode estar em risco de um baixo consumo de cálcio.

Os hábitos alimentares adotados durante a adolescência tendem a permanecer na idade adulta (Barker et al. 2000). Assim, a necessidade de se conhecer esses hábitos e o consumo alimentar é de suma importância, pois a intervenção nutricional tanto no nível individual como populacional possibilita uma melhoria no consumo 
alimentar desses indivíduos e também no controle de doenças crônicas não transmissíveis (FAO 1992, Cavadini et al. 2000a).

O presente estudo visa verificar as variações existentes nas dietas dos adolescentes e assim conhecer os fatores que influenciam o padrão alimentar dos mesmos. Esse é um início de um longo trabalho de conhecimento dos nossos adolescentes para que futuramente possam ser criados programas de saúde para influenciar positivamente as escolhas alimentares e conseqüentemente melhoria da saúde da população. 


\section{OBJETIVOS}




\section{Objetivo Geral}

Avaliar a dieta habitual qualitativa e quantitativamente de adolescentes de ambos os gêneros de uma Escola Estadual do município de São Paulo SP.

\section{Objetivos especifficos}

- Verificar a influência da variável dia da semana sobre a ingestão de energia, proteína, carboidrato, gordura total e insaturada, fibras, vitamina $\mathrm{C}$, cálcio e ferro;

- Avaliar a quantidade média e a freqüência dos alimentos mais referidos e compará-las nos 4 momentos de medição (feriado, segunda, quarta e quintafeira);

- Avaliar a frequuência das refeições e compará-las nos 4 momentos de medição (feriado, segunda, quarta e quinta-feira). 


\section{CASUÍSTICA E MÉTODOS}




\section{Antecedentes}

O presente estudo utilizou os dados coletados e processados por Slater (2001) no estudo "Desenvolvimento e validação de um questionário semi-quantitativo de freqüência alimentar para adolescentes", que teve por objetivo validar um questionário semi-quantitativo de freqüência alimentar. Neste estudo foram coletados dados de consumo alimentar de adolescentes que freqüentavam uma Escola Estadual de segundo grau localizada na região oeste da cidade de São Paulo.

\section{Delineamento do Estudo}

Estudo de coorte observacional prospectivo

\section{População de Estudo}

A população de estudo foi alunos, adolescentes do primeiro colegial entre 14 a 18 anos e 11 meses de idade de ambos os gêneros.

\section{Coleta de dados}

A coleta de dados de consumo alimentar foi realizada em 1999 por meio de Questionário Recordatório 24 horas $(\operatorname{Rec} 24$ h). Esse método foi eleito devido a sua rapidez, simplicidade, por interferir menos nos hábitos alimentares dos indivíduos e 
quando medido repetidas vezes pode estimar a ingestão habitual do indivíduo (Slater 2001).

Para uma maior adesão utilizou o Rec24 h proposto por Dunker (2003), o qual é aplicado em grupo e preenchido pelo próprio indivíduo, sendo este validado por Slater (2001) (Dunker 1999, Slater 2001, Dunker 2003).

O Rec24 h foi aplicado com o pesquisador no local de estudo, para as devidas orientações de preenchimento. Ainda foi utilizado um "kit" de utensílios e medidas caseiras, para uma melhor estimativa das quantidades, sendo utilizado antes do início do preenchimento e durante quando solicitado pelo adolescente (Slater 2001).

Os indivíduos foram avaliados em quatro momentos distintos, com um intervalo de 45 dias, durante 6 meses. Os meses avaliados foram: junho, agosto, outubro e novembro de 1999. As medidas foram realizadas em diferentes dias da semana sendo eles: segunda, quarta, quinta-feira e um feriado, tendo amostras respectivamente de $106,85,80$ e 80 indivíduos (Slater 2001).

Segundo Slater (2001) (...) "os alunos registraram o seu consumo dos alimentos separadamente, seguindo a ordem das refeições principais, incluindo a primeira refeição pela manhã, até a última, antes de dormir. Registraram-se não somente o tipo de alimento e a quantidade, mas também a forma de preparação do alimento e a hora de consumo, já que muitas vezes os alimentos consumidos durante o almoço se repetiam no jantar, em forma de outra preparação. Também foram registrados todos os alimentos consumidos na escola, assinalando-se, sempre que possível, as marcas comerciais dos alimentos industrializados". 
Após o levantamento dos dados, estes foram processados pelo software Virtual Nutri (Philippi et al. 1996), obtendo as informações de energia e de nutrientes consumidos pelos adolescentes estudados. A escolha deste software ocorreu devido sua utilização em diversos estudos, inclusive comparando-o a outros softwares, mostrando ele ser o ideal para o estudo (Slater 2001).

\section{Variáveis de estudo}

\section{Demográficas}

- Sexo;

- Idade (anos).

\section{Dietéticas}

- Energia

- Macronutrientes (Carboidrato, Proteína, Gordura Total e Insaturada);

- Fibra total;

- Micronutrientes (Vitamina C, Cálcio e Ferro);

- Grupo de alimentos;

- Alimentos.

\section{Dia alimentar}

- Dia da semana (feriado, segunda, quarta e quinta-feira). 


\section{Análise dos dados}

Após a digitação dos dados no software SPSS 11.0a, optou-se por trabalhar com os adolescentes que possuíam as 4 medidas, obtidas no feriado, segunda, quarta e quinta-feira, perfazendo um total de 64 indivíduos.

Os valores de perda variaram conforme o dia de análise, na segunda-feira a perda foi de 42 indivíduos, na quarta-feira e no feriado 16 e na quinta-feira 21 adolescentes.

As análises comparativas foram realizadas em relação ao feriado.

\subsection{Análise das médias dos nutrientes}

Aplicou-se o teste de Kolmogorov-Smirnov para verificar se eram normais as distribuições dos nutrientes; Energia em quilocaloria (kcal), Proteína em gramas (g), Carboidratos (g), Gordura total (g), Gordura insaturada (g), Fibras (g), Vitamina C micrograma (mg), Cálcio (mg) e Ferro (mg).

Constatou-se que a vitamina $C$, na segunda e na quinta-feira, o cálcio na quarta-feira e a gordura total no feriado, não obtiveram aderência à curva normal. Optou-se pela transformação em logaritmo (LOG10) de todos os nutrientes analisados para a realização de testes estatísticos paramétricos (ANEXO 1 e 2).

Para a comparação das médias dos nutrientes na segunda, quarta, quinta-feira em relação ao feriado, o teste utilizado foi o teste $T$ Student Bicaudal para amostras 
repetidas, com um nível de significância de 5\%. Foram feitas as figuras das médias e os respectivos intervalos de confiança (IC) segundo o dia da semana.

\subsection{Análise do consumo dos grupos de alimentos}

Inicialmente os dados processados pelo software Virtual Nutri (Philippi et al. 1996) foram transferidos para o programa Excel 2000, e os alimentos consumidos pelos 64 adolescentes durante os seis meses de estudo foram agrupados em 92 grupos (Anexo 3).

Optou-se por utilizar apenas os 20 grupos de alimentos mais freqüentes entre os adolescentes, para isso realizou-se um reagrupamento e uma freqüência de consumo dos mesmos.

Houve grupos de alimentos que estavam entre os mais freqüentes em um mês em outro não, para manter os 20 alimentos em todos os dias de análise resolveu-se trabalhar com 23 grupos.

Os grupos de alimentos obtidos foram: achocolatado em pó, açúcar, alface, arroz, batata, biscoitos, café, carne bovina, doces, salgados, feijão, carne de frango, frutas, leite, macarrão, óleos, pães, queijos, refrigerante, verduras, salgadinhos extrusados, sanduíches e bolo (Anexo 4).

Para comparação das quantidades médias (em gramas) dos alimentos consumidos pelos adolescentes ao longo da semana, aplicou-se o teste de aderência a curva normal (Kolmogorov-Smirnov). 
Nenhum dos grupos de alimentos obteve distribuição normal, mesmo quando transformados em logaritmo, dessa forma utilizou-se o teste não paramétrico Wilcoxon Signed Rank Test.

Quanto ao consumo dos alimentos primeiramente foi feito o teste de freqüência de cada grupo e suas respectivas figuras. Após a reconfiguração do banco de dados em consumiu e não consumiu, avaliou-se as mudanças no consumo dos alimentos na segunda, quarta, quinta-feira em relação ao feriado, para isso utilizou-se o teste McNemar, com um nível de significância de 5\%.

\subsection{Análise das freqüências das refeições}

Havia 6 possiveis refeições a serem realizadas: café da manhã, lanche da manhã, almoço, lanche da tarde, jantar e lanche da noite. Obteve-se a freqüência de quantos adolescentes fizeram refeição segundo o dia da semana e foram feitas suas respectivas figuras. Realizou-se o teste McNemar para avaliar se houveram mudanças no consumo dos alimentos na segunda, quarta, quinta-feira em relação ao feriado. 


\section{Aspectos éticos}

Utilizou-se banco de dados coletado no estudo "Desenvolvimento e validação de um questionário semi-quantitativo de freqüência alimentar para adolescentes", realizado por Slater (2001) que adotou os requisitos da resolução do Conselho Nacional de Saúde do Ministério da Saúde (CNS) 196, de outubro 1996. Foi submetido e aprovado peio Comitê de Ética da Faculdade de Saúde Pública da Universidade de São Paulo (Anexo 5).

Foram garantidos o consentimento livre e esclarecido, a privacidade, confidencialidade e anonimato, sendo respeitados valores sócio-culturais, esclarecimento de dúvidas. $\mathrm{O}$ trabalho não apresentou risco à população estudada, atendendo a CNS 196/96. 
RESULTADOS 


\section{Descrição da população}

\subsection{Distribuição por gênero}

As distribuições entre os gêneros para os adolescentes com 4 medidas (feriado, segunda, quarta e quinta-feira) foram de $47 \%(n=30)$ para o masculino e $53 \%(n=34)$ para o feminino respectivamente (Figura 1).

Figura 1: Distribuição percentual dos adolescentes segundo gênero de uma Escola Estadual de segundo grau do município de São Paulo, 1999.

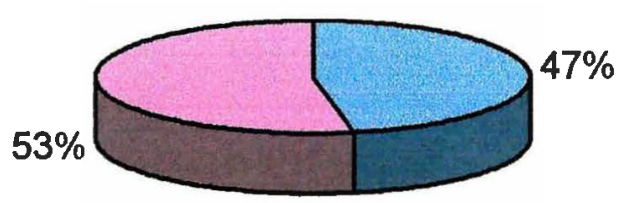




\subsection{Distribuição etária.}

A maioria dos adolescentes, no início do estudo, encontrava-se entre 15 e 16 anos de idade, com uma distribuição percentual de 47 e $22 \%$ respectivamente. A média em anos para o estágio de vida foi de 15,6 e as distribuições percentuais em anos segundo gêneros mantiveram-se semelhantes (Tabela 1).

Tabela 1: Distribuição percentual e numérica dos adolescentes segundo estágio de vida e gênero de uma Escola Estadual de segundo grau do município de São Paulo, 1999.

\begin{tabular}{|c|c|c|c|}
\hline \multirow[b]{2}{*}{$\begin{array}{l}\text { Idade } \\
\text { (anos) }\end{array}$} & \multicolumn{2}{|c|}{ Gênero } & \multirow[b]{2}{*}{$\begin{array}{l}\text { Total } \\
(\%)\end{array}$} \\
\hline & $\begin{array}{c}\text { Feminino } \\
(\%)^{*}\end{array}$ & $\begin{array}{c}\text { Masculino } \\
(\%)^{*}\end{array}$ & \\
\hline 14 & $\begin{array}{c}5 \\
(8)\end{array}$ & $\begin{array}{c}2 \\
(3)\end{array}$ & $\begin{array}{c}7 \\
(11)\end{array}$ \\
\hline 15 & $\begin{array}{c}17 \\
(27)\end{array}$ & $\begin{array}{c}13 \\
(20)\end{array}$ & $\begin{array}{r}30 \\
(47)\end{array}$ \\
\hline 16 & $\begin{array}{c}7 \\
(11)\end{array}$ & $\begin{array}{c}7 \\
(11)\end{array}$ & $\begin{array}{c}14 \\
(22)\end{array}$ \\
\hline 17 & $\begin{array}{c}3 \\
(5)\end{array}$ & $\begin{array}{c}6 \\
(9)\end{array}$ & $\begin{array}{c}9 \\
(14)\end{array}$ \\
\hline 18 & $\begin{array}{c}2 \\
(3)\end{array}$ & $\begin{array}{c}2 \\
(3)\end{array}$ & $\begin{array}{c}4 \\
(6)\end{array}$ \\
\hline $\begin{array}{c}\text { Total } \\
\%\end{array}$ & $\begin{array}{r}\mathbf{3 4} \\
(\mathbf{5 3})\end{array}$ & $\begin{array}{r}30 \\
(47)\end{array}$ & $\begin{array}{c}64 \\
(100)\end{array}$ \\
\hline
\end{tabular}

* percentual calculado segundo o número total de adolescentes 


\section{Consumo Alimentar}

\subsection{Consumo de nutrientes}

A distribuição percentual da contribuição energética das médias dos macronutrientes, consumidos pelos adolescentes, foi superior a $15 \%$ de proteínas, não alcançou os $50 \%$ de carboidratos e ultrapassou o $30 \%$ de gorduras totais para todos os dias analisados (Tabela 2).

Tabela 2: Contribuição de energia proveniente de Proteína (g), Carboidratos (g) e Gordura total (g), consumidos pelos adolescentes no feriado, segunda, quarta e quinta-feira, de uma Escola Estadual de segundo grau do município de São Paulo, 1999.

\begin{tabular}{l|c|c|c|c|c|c|c|c}
\hline \multirow{2}{*}{ Nutrientes } & \multicolumn{2}{|c|}{ Feriado } & \multicolumn{2}{c|}{$\mathbf{2}^{\mathrm{a}}$ feira } & \multicolumn{2}{c|}{$\mathbf{4}^{\mathrm{a}}$ feira } & \multicolumn{2}{c}{$\mathbf{5}^{\mathrm{a}}$ feira } \\
\cline { 2 - 9 } & $\begin{array}{c}\text { Média } \\
(\boldsymbol{D P})\end{array}$ & $\%$ & $\begin{array}{c}\text { Média } \\
(\boldsymbol{D P P})\end{array}$ & $\%$ & $\begin{array}{c}\text { Média } \\
(\boldsymbol{D P})\end{array}$ & $\%$ & $\begin{array}{c}\text { Média } \\
(\boldsymbol{D P})\end{array}$ & $\%$ \\
\hline Energia (kcal) & 1893,7 & - & 1997,5 & - & 2047,5 & - & 1930,4 & - \\
& $(720,6)$ & & $(758,7)$ & & $(763,4)$ & & $(713,8)$ & \\
\hline Proteínas (g) & 77,8 & 16,4 & 78,8 & 15,8 & 79,1 & 15,4 & 75,0 & 15,5 \\
& $(37,5)$ & & $(34,1)$ & & $(35,6)$ & & $(35,1)$ & \\
\hline Carboidratos (g) & 232,7 & 49,1 & 242,0 & 48,5 & 255,7 & 49,9 & 231,5 & 48,0 \\
& $(91,5)$ & & $(91,0)$ & & $(95,8)$ & & $(81,5)$ & \\
\hline Gordura & 72,0 & 34,2 & 78,8 & 35,5 & 77,6 & 34,1 & 76,4 & 35,6 \\
Total (g) & $(37,0)$ & & $(38,5)$ & & $(38,2)$ & & $(39,8)$ & \\
\hline
\end{tabular}

-base de cálculo 
A média de consumo de Energia (kcal), Proteína (g), Carboidratos (g), Gordura total (g), Gordura insaturada (g), Fibras (g), Vitamina C (mg), Cálcio (mg) e Ferro (mg) encontram-se descritos na Tabela 3.

Em relação ao feriado, não houve diferença estatística no consumo de energia (kcal), proteína $(\mathrm{g})$, gordura total $(\mathrm{g})$ e ferro $(\mathrm{mg})$ na segunda, quarta e quinta-feira. $\mathrm{O}$ consumo de carboidrato foi significativamente maior na quarta-feira e não teve diferença na segunda e na quinta-feira (Tabela 3).

Com relação á gordura insaturada, verificou-se que o consumo foi estatisticamente maior na segunda e quarta-feira. Na quinta-feira ele se manteve semelhante ao feriado (Tabela 3).

O consumo de fibras foi significativamente maior para todos os dias da semana em relação ao feriado (Tabela 3). O consumo de vitamina $\mathrm{C}$ foi estatisticamente maior na segunda e na quarta-feira e manteve-se semelhante na quinta-feira em relação ao feriado. Para o cálcio, o consumo na segunda-feira foi maior que no feriado e manteve-se igual para os demais dias (Tabela 3). 
Tabela 3: Médias de Energia e dos nutrientes consumidos pelos adolescentes no feriado, segunda, quarta e quinta-feira, de uma Escola Estadual de segundo grau do município de São Paulo, 1999.

\begin{tabular}{|c|c|c|c|c|c|c|c|}
\hline \multirow[t]{2}{*}{ Nutrientes } & \multirow{2}{*}{$\begin{array}{c}\text { Feriado } \\
\text { Média } \\
\text { (DP) }\end{array}$} & \multicolumn{2}{|c|}{$2^{a}$ feira } & \multicolumn{2}{|c|}{$4^{a}$ feira } & \multicolumn{2}{|c|}{$5^{\mathrm{a}}$ feira } \\
\hline & & $\begin{array}{l}\text { Média } \\
\text { (DP) }\end{array}$ & $\mathbf{P}^{*}$ & $\begin{array}{c}\text { Média } \\
\text { (DP) }\end{array}$ & $P^{*}$ & $\begin{array}{c}\text { Média } \\
\text { (DP) }\end{array}$ & P* \\
\hline Energia (kcal) & $\begin{array}{l}1893,7 \\
(720,6)\end{array}$ & $\begin{array}{l}1997,5 \\
(758,7) \\
\end{array}$ & 0,35 & $\begin{array}{l}2047,5 \\
(763,4)\end{array}$ & 0,57 & $\begin{array}{l}1930,4 \\
(713,8)\end{array}$ & 0,12 \\
\hline Proteínas (g) & $\begin{array}{c}77,8 \\
(37,5)\end{array}$ & $\begin{array}{l}78,8 \\
(34,1)\end{array}$ & 0,38 & $\begin{array}{c}79,1 \\
(35,6)\end{array}$ & 0,49 & $\begin{array}{l}75,0 \\
(35,1)\end{array}$ & 0,71 \\
\hline Carboidratos (g) & $\begin{array}{l}232,7 \\
(91,5)\end{array}$ & $\begin{array}{l}242,0 \\
(91,0)\end{array}$ & 0,29 & $\begin{array}{l}255,7 \\
(95,8)\end{array}$ & 0,05 & $\begin{array}{l}231,5 \\
(81,5)\end{array}$ & 0,70 \\
\hline $\begin{array}{c}\text { Gordura } \\
\text { Total (g) }\end{array}$ & $\begin{array}{c}72,0 \\
(37,0)\end{array}$ & $\begin{array}{l}78,8 \\
(38,5)\end{array}$ & 0,14 & $\begin{array}{r}77,6 \\
(38,2) \\
\end{array}$ & 0,28 & $\begin{array}{r}76,4 \\
(39,8) \\
\end{array}$ & 0,34 \\
\hline $\begin{array}{l}\text { Gordura } \\
\text { Insaturada (g) }\end{array}$ & $\begin{array}{c}25,4 \\
(16,1) \\
\end{array}$ & $\begin{array}{l}34,4 \\
(20,6) \\
\end{array}$ & 0,01 & $\begin{array}{l}30,5 \\
(17,9)\end{array}$ & 0,05 & $\begin{array}{l}32,0 \\
(25,1)\end{array}$ & 0,25 \\
\hline Fibra (g) & $\begin{array}{c}9,3 \\
(5,6)\end{array}$ & $\begin{array}{l}11,4 \\
(5,8)\end{array}$ & 0,04 & $\begin{array}{l}11,8 \\
(6,6)\end{array}$ & $<0,01$ & $\begin{array}{l}10,2 \\
(7,2)\end{array}$ & $<0,01$ \\
\hline Vitamina C (mg) & $\begin{array}{l}56,0 \\
(50,0)\end{array}$ & $\begin{array}{c}64,9 \\
(59,0)\end{array}$ & 0,05 & $\begin{array}{r}76,7 \\
(70,8)\end{array}$ & 0,03 & $\begin{array}{c}69,4 \\
(110,4)\end{array}$ & 0,65 \\
\hline Cálcio (mg) & $\begin{array}{l}580,0 \\
(400,6)\end{array}$ & $\begin{array}{r}629,9 \\
(336,0)\end{array}$ & 0,05 & $\begin{array}{r}635,5 \\
(438,5) \\
\end{array}$ & 0,12 & $\begin{array}{l}496,1 \\
(212,1)\end{array}$ & 0,82 \\
\hline Ferro (mg) & $\begin{array}{l}11,3 \\
(5,4)\end{array}$ & $\begin{array}{l}11,6 \\
(5,0)\end{array}$ & 0,28 & $\begin{array}{l}12,0 \\
(5,8)\end{array}$ & 0,21 & $\begin{array}{l}11,1 \\
(6,1)\end{array}$ & 0,60 \\
\hline
\end{tabular}

$D P=$ Desvio Padrão *analises feitas em logaritmo

Para uma melhor visualização dos dados descritos anteriormente, estes estão representados graficamente nas figuras $2,3,4,5,6,7,8,9,10$. 
A figura 2 mostra que as variações em logaritmo das médias de energia consumidas pelos adolescentes no feriado, segunda, quarta e quinta-feira não possuíram diferenças estatisticamente significantes para um intervalo de confiança de 95\%.

Figura 2: Consumo de energia dos adolescentes no feriado, segunda, quarta e quinta-feira, de uma Escola Estadual de segundo grau do município de São Paulo, 1999.

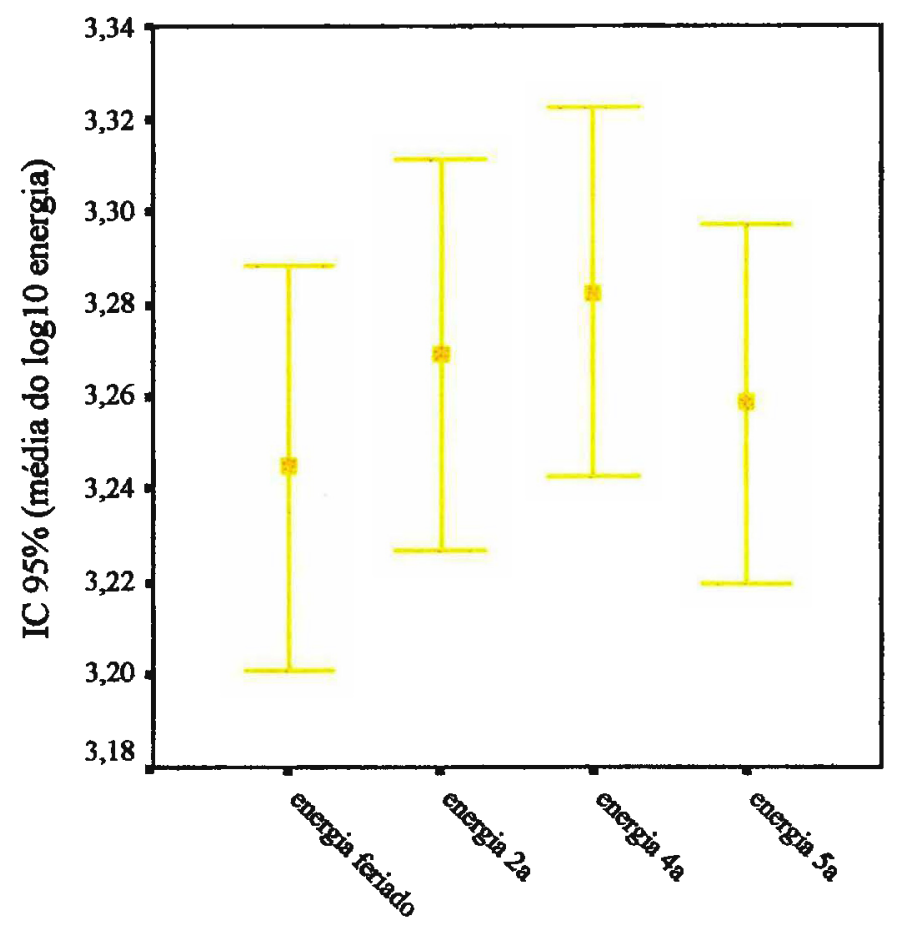


As médias do LOG10 de proteína, para um intervalo de confiança de 95\%, consumidas pelos adolescentes nos quatro momentos de medição (feriado, segunda, quarta e quinta-feira) mantiveram-se semelhantes (Figura 3).

Figura 3: Consumo de proteína dos adolescentes no feriado, segunda, quarta e quinta-feira, de uma Escola Estadual de segundo grau do município de São Paulo, 1999.

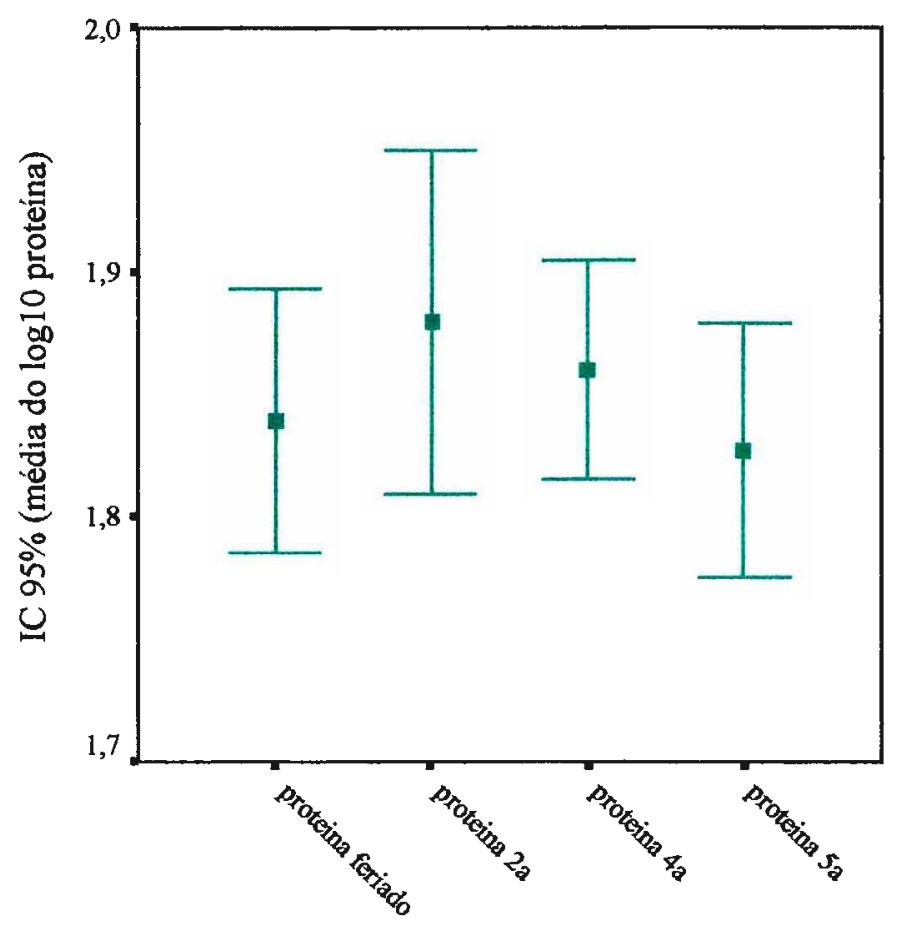


Com relação à gordura total as médias no feriado, segunda, quarta e quintafeira, calculadas em LOG10 e intervalo de confiança de 95\%, consumidas pelos adolescentes não possuíram diferenças significantes (Figura 4).

Figura 4: Consumo de gordura total dos adolescentes no feriado, segunda, quarta e quinta-feira, de uma Escola Estadual de segundo grau do município de São Paulo, 1999.

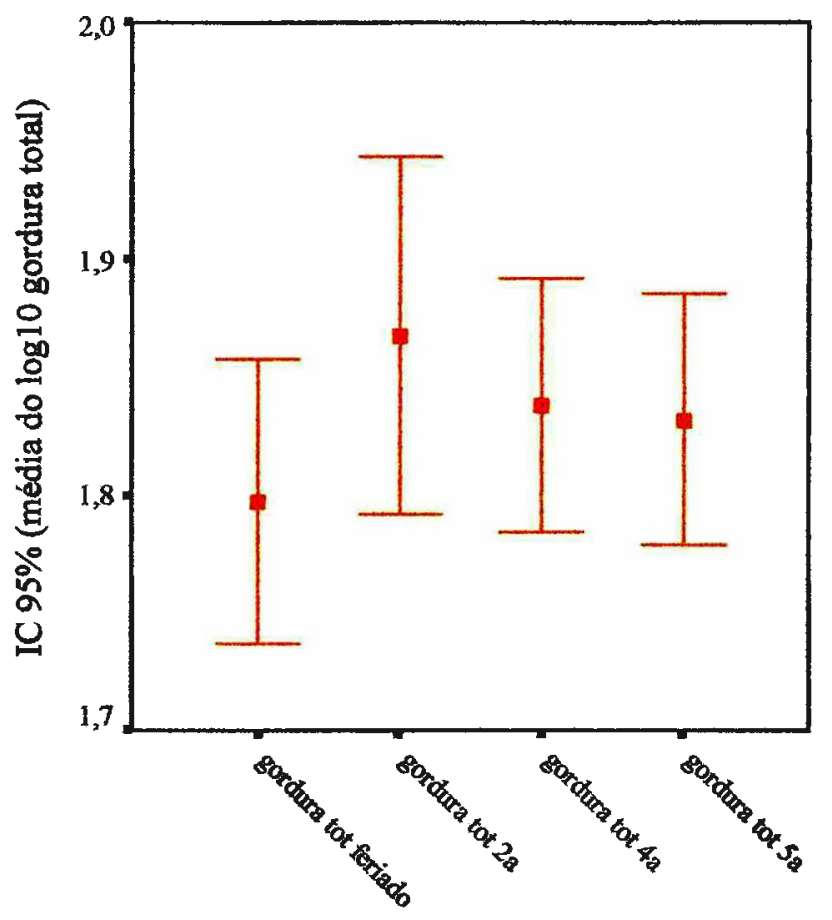


Também não houve diferenças significantes entre os LOG10 das médias de ferro entre os dias da semana em relação ao feriado para um intervalo de confiança de $95 \%$ (Figura 5).

Figura 5: Consumo de ferro dos adolescentes no feriado, segunda, quarta e quintafeira, de uma Escola Estadual de segundo grau do município de São Paulo, 1999.

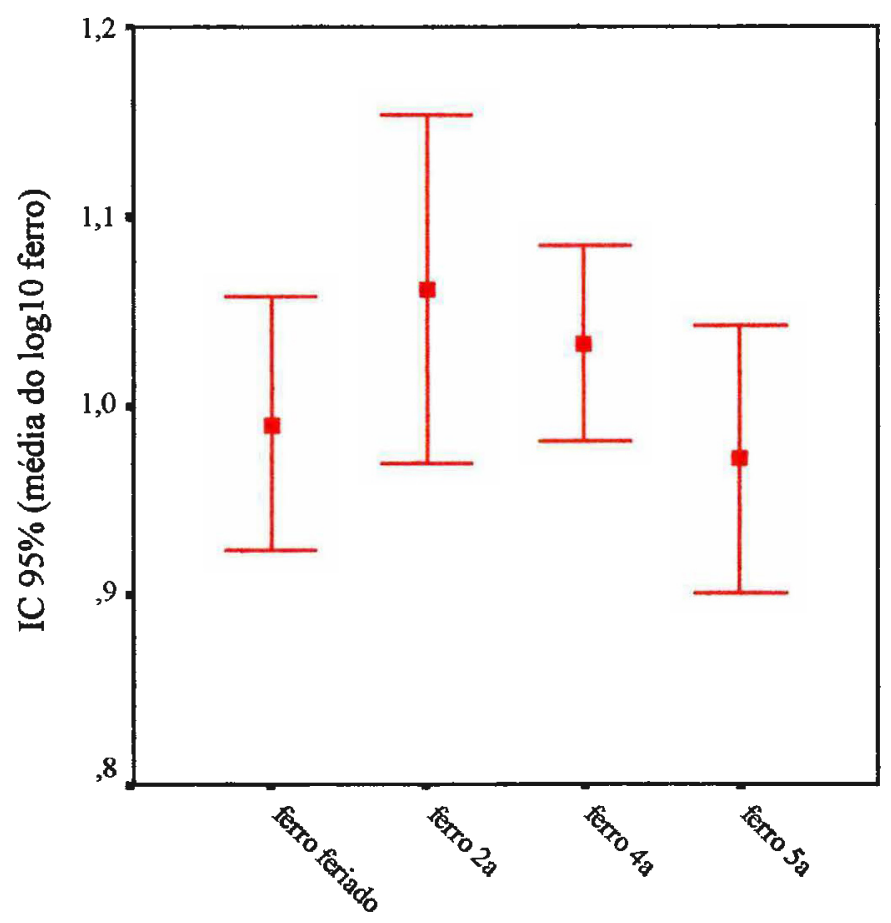


As médias de consumo de carboidratos calculadas em LOG10 e intervalo de confiança de $95 \%$, não obtiveram diferenças estatísticas entre a segunda e a quintafeira em relação ao feriado. Na quarta-feira a média foi significativamente $(p=0,05)$ maior do que no feriado (Figura 6).

Figura 6: Consumo de carboidrato dos adolescentes no feriado, segunda, quarta e quinta-feira, de uma Escola Estadual de segundo grau do município de São Paulo, 1999.

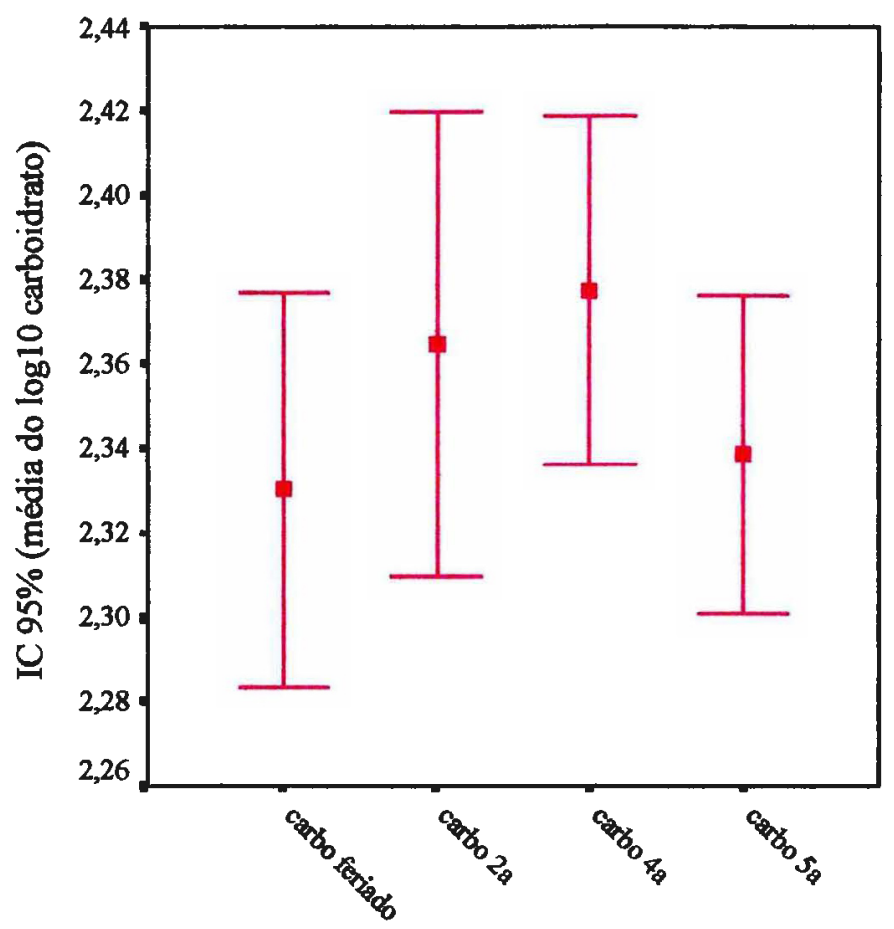


O consumo médio em LOG10 de gordura insaturada obteve um aumento significativo na segunda-feira $(p=0,01)$ e na quarta-feira $(p=0,05)$ em relação ao feriado. Na quinta-feira o consumo manteve-se semelhante ao feriado (Figura 7).

Figura 7: Consumo de gordura insaturada dos adolescentes no feriado, segunda, quarta e quinta-feira, de uma Escola Estadual de segundo grau do município de São Paulo, 1999.

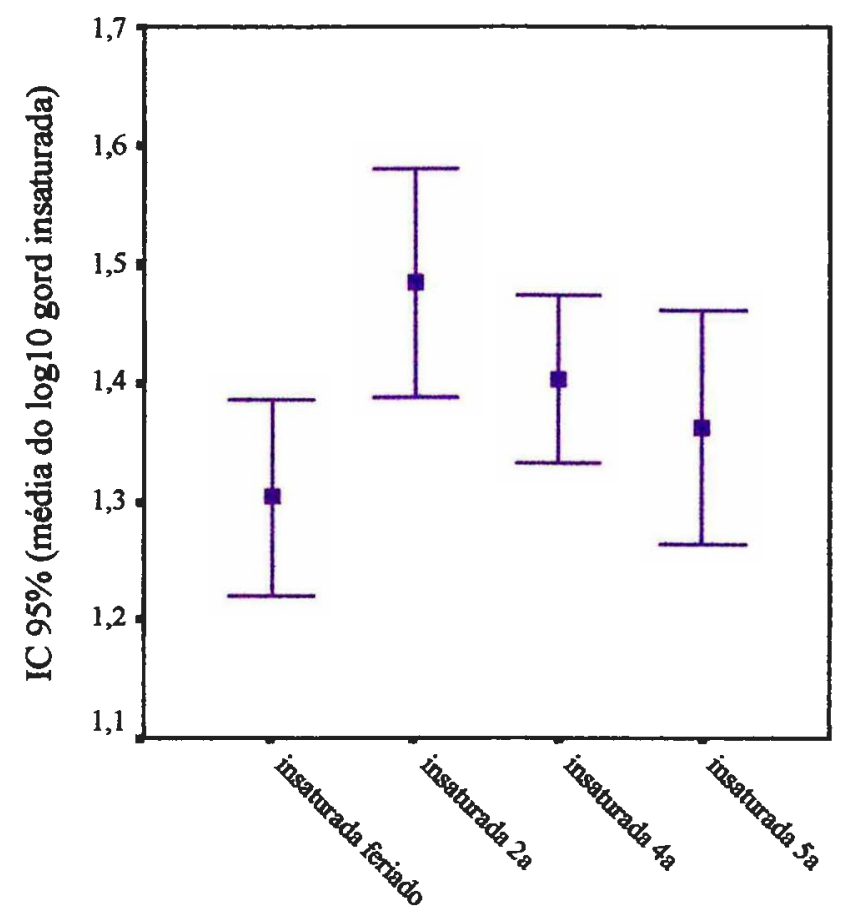


A média do LOG10 de fibras consumidas pelos adolescentes obteve um aumento significativo em todos os dias da semana em relação ao feriado variando de 0,85 a 1,30, para um intervalo de confiança de 95\% (Figura 8).

Figura 8: Consumo de fibra dos adolescentes no feriado, segunda, quarta e quintafeira, de uma Escola Estadual de segundo grau do município de São Paulo, 1999.

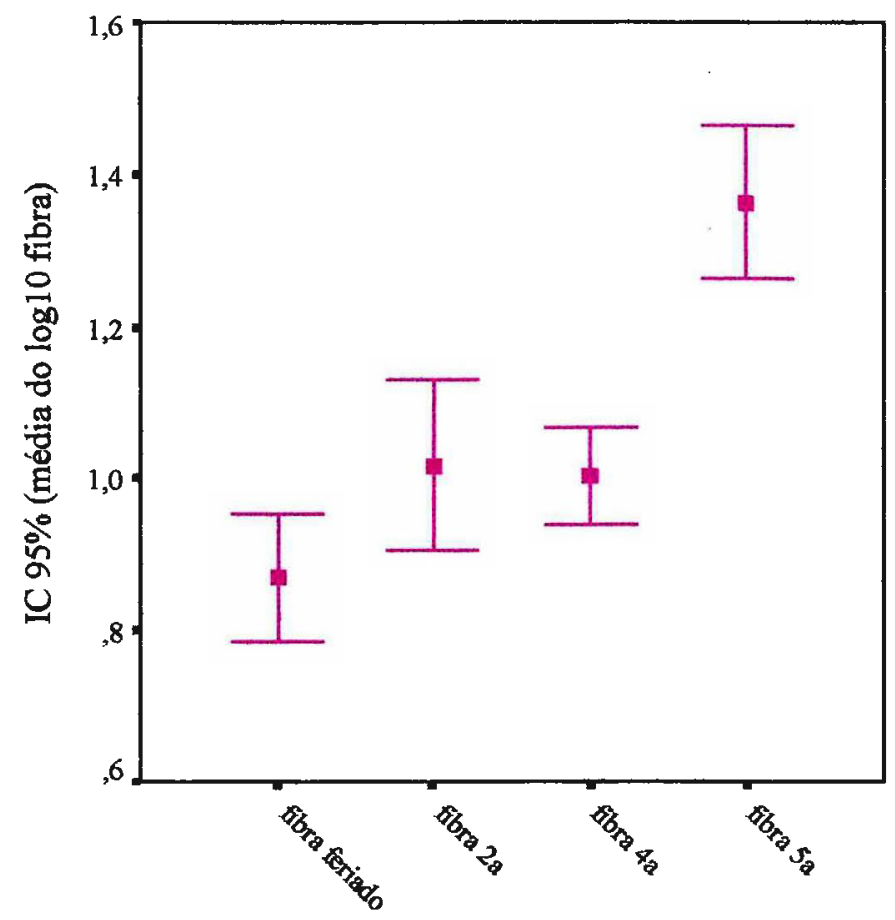


O consumo de vitamina $\mathrm{C}$ foi maior na segunda $(p=0,05)$ e na quarta-feira $(p=0,03)$. A Figura 9 mostra a variação do LOG10 da média de vitamina C para um intervalo de confiança de $95 \%$

Figura 9: Consumo de vitamina $\mathrm{C}$ dos adolescentes no feriado, segunda, quarta $\mathrm{e}$ quinta-feira, de uma Escola Estadual de segundo grau do município de São Paulo, 1999.

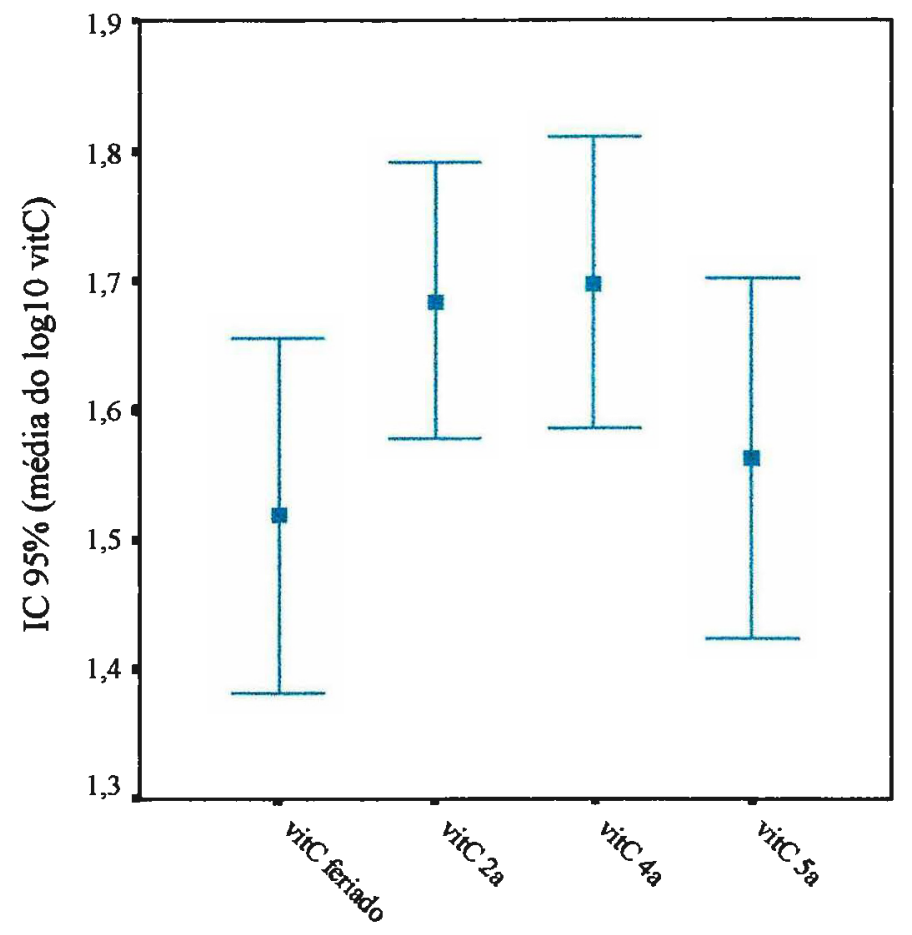


O consumo médio de cálcio calculado em LOG10 entre os adolescentes obteve um aumento $(p=0,05)$ na segunda-feira em relação ao feriado, para os outros dias as médias consumidas se mantiveram iguais (Figura 10).

Figura 10: Consumo de cálcio dos adolescentes no feriado, segunda, quarta e quintafeira, de uma Escola Estadual de segundo grau do município de São Paulo, 1999.

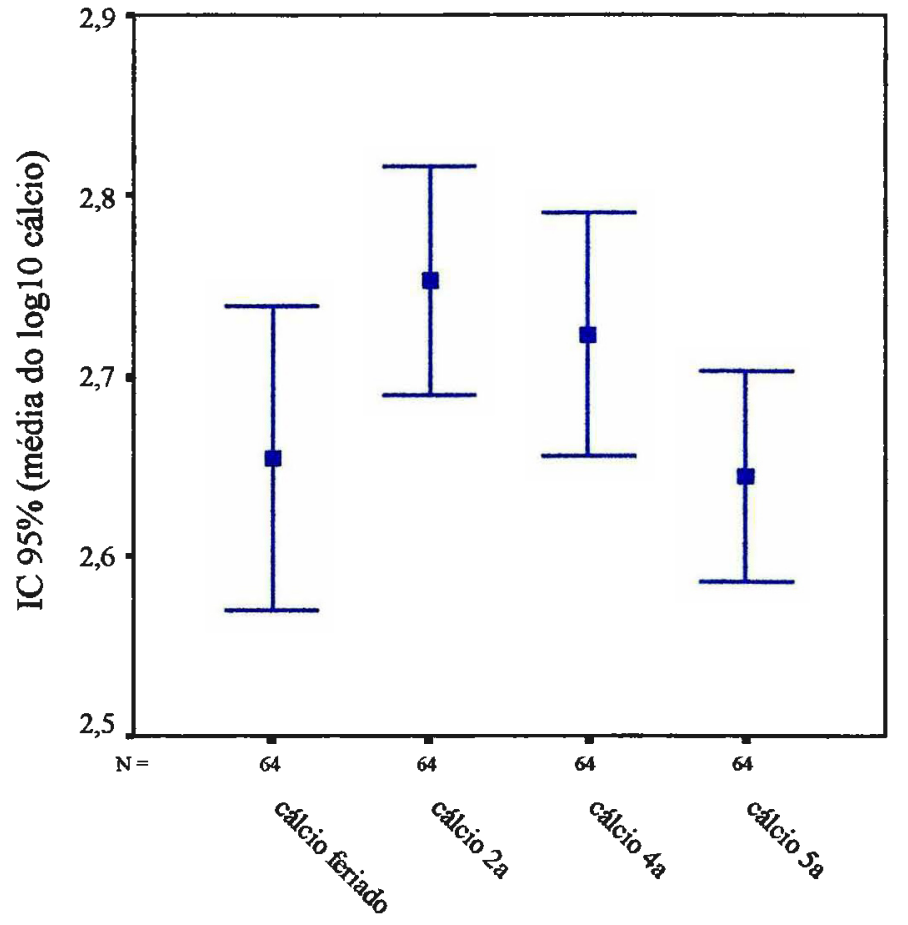




\subsection{Consumo dos grupos alimentares}

\subsubsection{Média em gramas}

As Tabelas 4 e 5 descrevem a média de consumo em gramas dos 23 grupos de alimentos (achocolatado em pó, açúcar, folhas, arroz, batata, biscoitos, café, carne bovina, doces, salgados, feijão, carne de frango, frutas, leite, macarrão, manteiga, pães, queijos, refrigerante, verduras, salgadinhos extrusados, sanduíches e bolo) consumidos pelos adolescentes nos 4 momentos de medição. Quase todos os alimentos possuíram uma quantidade de consumo semelhante entre os dias da semana em relação ao feriado, com exceção da alface e da carne bovina, que foi significantemente maior na segunda-feira. 
Tabela 4: Médias em gramas de grupos alimentares consumidos pelos adolescentes no feriado, segunda, quarta e quinta-feira, de uma Escola Estadual de segundo grau do município de São Paulo, 1999.

\begin{tabular}{|c|c|c|c|c|c|c|c|}
\hline \multirow[b]{2}{*}{$\begin{array}{c}\text { Grupos } \\
\text { de alimentos }\end{array}$} & \multirow{2}{*}{$\begin{array}{c}\text { Feriado } \\
\text { Média } \\
\text { (DP) }\end{array}$} & \multicolumn{2}{|c|}{ Segunda-feira } & \multicolumn{2}{|c|}{ Quarta-feira } & \multicolumn{2}{|c|}{ Quinta-feira } \\
\hline & & $\begin{array}{c}\text { Média } \\
(D P)\end{array}$ & $P$ & $\begin{array}{c}\text { Média } \\
\text { (DP) }\end{array}$ & $P$ & $\begin{array}{c}\text { Média } \\
\text { (DP) }\end{array}$ & $P$ \\
\hline $\begin{array}{c}\text { Achocolatado } \\
\text { em pó } \\
\end{array}$ & $\begin{array}{l}27,6 \\
(10,4) \\
\end{array}$ & $\begin{array}{l}29,9 \\
(14,0) \\
\end{array}$ & 0,19 & $\begin{array}{l}27,7 \\
(14,1) \\
\end{array}$ & 0,97 & $\begin{array}{r}27,3 \\
(13,4) \\
\end{array}$ & 0,72 \\
\hline Açúcar & $\begin{array}{r}35,0 \\
(15,1)\end{array}$ & $\begin{array}{r}41,6 \\
(25,9)\end{array}$ & 0,12 & $\begin{array}{c}37,5 \\
(22,6)\end{array}$ & 0,62 & $\begin{array}{c}28,0 \\
(13,5)\end{array}$ & 0,54 \\
\hline Alface & $\begin{array}{l}35,8 \\
(16,3) \\
\end{array}$ & $\begin{array}{l}46,7 \\
(26,8) \\
\end{array}$ & 0,03 & $\begin{array}{l}33,4 \\
(20,8) \\
\end{array}$ & 0,50 & $\begin{array}{r}47,5 \\
(23,4) \\
\end{array}$ & 0,69 \\
\hline Arroz & $\begin{array}{l}176,0 \\
(107,1)\end{array}$ & $\begin{array}{l}175,4 \\
(88,5)\end{array}$ & 0,97 & $\begin{array}{r}178,6 \\
(103,5)\end{array}$ & 0,19 & $\begin{array}{l}168,9 \\
(93,2)\end{array}$ & 0,52 \\
\hline Batata & $\begin{array}{r}80,7 \\
(47,4)\end{array}$ & $\begin{array}{r}82,2 \\
(29,4)\end{array}$ & 0,65 & $\begin{array}{c}74,1 \\
(42,7)\end{array}$ & \# & $\begin{array}{l}103,7 \\
(56,8)\end{array}$ & 0,34 \\
\hline Biscoitos & $\begin{array}{l}96,0 \\
(72,3)\end{array}$ & $\begin{array}{c}89,2 \\
(68,4)\end{array}$ & 0,26 & $\begin{array}{r}82,9 \\
(61,5) \\
\end{array}$ & 0,69 & $\begin{array}{l}102,7 \\
(78,2)\end{array}$ & 0,18 \\
\hline Café & $\begin{array}{r}62,0 \\
(32,4) \\
\end{array}$ & $\begin{array}{r}70,0 \\
(51,4) \\
\end{array}$ & 0,28 & $\begin{array}{l}77,9 \\
(71,2) \\
\end{array}$ & 1,00 & $\begin{array}{l}89,2 \\
(72,6)\end{array}$ & 0,32 \\
\hline Carne bovina & $\begin{array}{l}123,0 \\
(57,5)\end{array}$ & $\begin{array}{l}145,6 \\
(74,7)\end{array}$ & 0,05 & $\begin{array}{l}126,4 \\
(62,3)\end{array}$ & 0,28 & $\begin{array}{l}160,3 \\
(87,6)\end{array}$ & 0,21 \\
\hline Doces & $\begin{array}{r}87,6 \\
(68,1)\end{array}$ & $\begin{array}{c}84,5 \\
(173,8)\end{array}$ & 0,59 & $\begin{array}{l}52,6 \\
(54,8)\end{array}$ & 0,71 & $\begin{array}{c}66,4 \\
(44,5)\end{array}$ & 0,18 \\
\hline Salgados & $\begin{array}{l}100,7 \\
(53,4) \\
\end{array}$ & $\begin{array}{l}123,2 \\
(54,1) \\
\end{array}$ & 1,00 & $\begin{array}{l}117,5 \\
(54,4) \\
\end{array}$ & 0,65 & $\begin{array}{r}97,7 \\
(34,4) \\
\end{array}$ & 0,28 \\
\hline
\end{tabular}

* não havia casos suficientes para realizar o teste, \# não possui valor de significância. 
Tabela 5: Médias em gramas de grupos alimentares consumidos pelos adolescentes no feriado, segunda, quarta e quinta-feira, de uma Escola Estadual de segundo grau do município de São Paulo, 1999.

\begin{tabular}{|c|c|c|c|c|c|c|c|}
\hline \multirow[b]{2}{*}{$\begin{array}{c}\text { Grupos } \\
\text { de alimentos }\end{array}$} & \multirow{2}{*}{\begin{tabular}{|c|} 
Feriado \\
$\begin{array}{c}\text { Média } \\
(D P)\end{array}$ \\
\end{tabular}} & \multicolumn{2}{|c|}{ Segunda-feira } & \multicolumn{2}{|c|}{ Quarta-feira } & \multicolumn{2}{|c|}{ Quinta-feira } \\
\hline & & $\begin{array}{c}\text { Média } \\
\text { (DP) }\end{array}$ & $P$ & $\begin{array}{c}\text { Média } \\
\text { (DP) }\end{array}$ & $\underline{P}$ & $\begin{array}{c}\text { Média } \\
\text { (DP) }\end{array}$ & $P$ \\
\hline Feijão & $\begin{array}{l}152,4 \\
(63,0)\end{array}$ & $\begin{array}{l}162,3 \\
(75,5)\end{array}$ & 0,71 & $\begin{array}{l}146,0 \\
(75,4)\end{array}$ & 0,95 & $\begin{array}{l}157,4 \\
(94,2)\end{array}$ & 0,31 \\
\hline Carne de frango & $\begin{array}{l}100,6 \\
(31,9)\end{array}$ & $\begin{array}{l}122,4 \\
(48,1)\end{array}$ & 0,59 & $\begin{array}{l}131,4 \\
(64,1)\end{array}$ & 0,65 & $\begin{array}{l}138,7 \\
(59,1)\end{array}$ & 0,18 \\
\hline Frutas & $\begin{array}{l}228,8 \\
(143,6) \\
\end{array}$ & $\begin{array}{l}250,7 \\
(183,9)\end{array}$ & 0,24 & $\begin{array}{l}305,9 \\
(211,2)\end{array}$ & 0,14 & $\begin{array}{l}267,2 \\
(149,3) \\
\end{array}$ & 1,00 \\
\hline Leite & $\begin{array}{l}284,5 \\
(137,6)\end{array}$ & $\begin{array}{l}287,7 \\
(121,5)\end{array}$ & 0,33 & $\begin{array}{l}323,5 \\
(205,8)\end{array}$ & 0,24 & $\begin{array}{l}257,2 \\
(118,7) \\
\end{array}$ & 0,43 \\
\hline Macarrão & $\begin{array}{r}206,9 \\
(126,9)\end{array}$ & $\begin{array}{l}140,2 \\
(93,2)\end{array}$ & 0,71 & $\begin{array}{l}242,9 \\
(114,9)\end{array}$ & 1,00 & $\begin{array}{l}235,5 \\
(216,6) \\
\end{array}$ & 0,89 \\
\hline Óleos & $\begin{array}{l}21,1 \\
(26,8)\end{array}$ & $\begin{array}{r}14,1 \\
(93,2) \\
\end{array}$ & 0,27 & $\begin{array}{l}21,6 \\
(17,0)\end{array}$ & 0,56 & $\begin{array}{r}16,3 \\
(15,8) \\
\end{array}$ & 0,65 \\
\hline Pães & $\begin{array}{r}82,8 \\
(43,6) \\
\end{array}$ & $\begin{array}{r}84,7 \\
(40,4) \\
\end{array}$ & 0,48 & $\begin{array}{r}88,6 \\
(45,8) \\
\end{array}$ & 0,23 & $\begin{array}{r}83,2 \\
(43,9) \\
\end{array}$ & 0,86 \\
\hline Queijos & $\begin{array}{l}43,5 \\
(31,9)\end{array}$ & $\begin{array}{l}33,5 \\
(18,1)\end{array}$ & 0,11 & $\begin{array}{r}43,5 \\
(32,5) \\
\end{array}$ & 0,78 & $\begin{array}{l}36,1 \\
(19,0)\end{array}$ & 0,34 \\
\hline Refrigerante & $\begin{array}{l}476,0 \\
(216,6) \\
\end{array}$ & $\begin{array}{l}503,6 \\
(279,1) \\
\end{array}$ & 0,34 & $\begin{array}{l}462,9 \\
(218,5)\end{array}$ & 0,40 & $\begin{array}{l}435,4 \\
(186,6)\end{array}$ & 0,28 \\
\hline Verduras & $\begin{array}{r}67,3 \\
(50,1) \\
\end{array}$ & $\begin{array}{r}94,4 \\
(69,6) \\
\end{array}$ & 0,50 & $\begin{array}{r}70,7 \\
(35,3)\end{array}$ & 0,40 & $\begin{array}{r}72,1 \\
(33,8)\end{array}$ & 0,48 \\
\hline $\begin{array}{c}\text { Salgadinhos } \\
\text { extrusados }\end{array}$ & $\begin{array}{r}78,5 \\
(52,7) \\
\end{array}$ & $\begin{array}{r}62,9 \\
(52,3) \\
\end{array}$ & * & $\begin{array}{r}49,9 \\
(21,6) \\
\end{array}$ & * & $\begin{array}{r}68,2 \\
(38,7) \\
\end{array}$ & * \\
\hline Sanduíches & $\begin{array}{l}177,5 \\
(88,9)\end{array}$ & $\begin{array}{l}181,4 \\
(68,8) \\
\end{array}$ & 0,32 & $\begin{array}{l}138,0 \\
(77,3) \\
\end{array}$ & 0,18 & $\begin{array}{l}238,1 \\
(117,7) \\
\end{array}$ & $\#$ \\
\hline Bolo & $\begin{array}{l}105,0 \\
(32,1)\end{array}$ & $\begin{array}{r}77,3 \\
(43,0) \\
\end{array}$ & 0,07 & $\begin{array}{l}127,7 \\
(66,4) \\
\end{array}$ & 0,65 & $\begin{array}{l}102,3 \\
(56,1) \\
\end{array}$ & 0,59 \\
\hline
\end{tabular}

* não havia casos suficientes para realizar o teste, \# não possui valor de significância. 


\subsubsection{Freqüência}

O percentual de adolescentes que consumiram o achocolatado em pó no feriado foi de $45 \%(n=29)$, na segunda-feira foi de $48 \%(n=31)$, na quarta-feira de $47 \%(n=30)$ e na quinta-feira $53 \%(n=34)$. O grupo do açúcar obteve os respectivos valores: $47 \%(n=30), 55 \%(n=35), 33 \%(n=26)$ e $41 \%(n=26)$ (Figura 11).

Em relação ao consumo do grupo do leite $63 \%(n=40)$ dos adolescentes consumiram esse grupo no feriado, $72 \%(n=46)$ na segunda-feira, $67 \%(n=43)$ na quarta-feira e $72 \%(n=46)$ na quinta-feira. O consumo do grupo do café foi de $16 \%$ $(n=10)$ no feriado e na quarta-feira, e $20 \%(n=14)$ e $25 \%(n=16)$ na segunda e quintafeira (Figura 11). Para todos os grupos citados alimentos não houve diferenças significativas no consumo durante o feriado e os dias da semana (Tabela 6).

Figura 11: Distribuição da freqüência do consumo de achocolatado em pó, açúcar, leite e café, dos adolescentes no feriado, segunda, quarta e quinta-feira, de uma Escola Estadual de segundo grau do município de São Paulo, 1999.

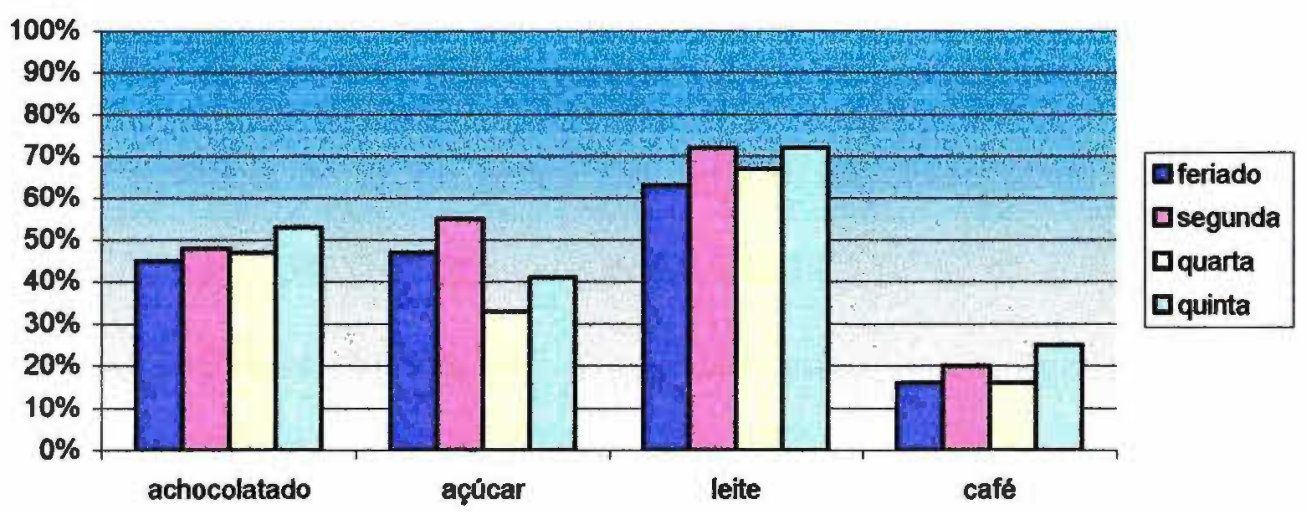


Tabela 6: Distribuição das mudanças entre os adolescentes que deixaram ou passaram a consumir os grupos alimentares no feriado, segunda, quarta e quintafeira, de uma Escola Estadual de segundo grau do município de São Paulo, 1999.

\begin{tabular}{|c|c|c|c|c|c|c|c|c|c|c|c|}
\hline \multirow{3}{*}{ Grupos } & \multicolumn{2}{|c|}{ Feriado } & \multicolumn{3}{|c|}{ Segunda } & \multicolumn{3}{|c|}{ Quarta } & \multicolumn{3}{|c|}{ Quinta } \\
\hline & \multicolumn{2}{|c|}{ Consumo } & \multicolumn{3}{|c|}{ Mudança } & \multicolumn{3}{|c|}{ Mudança } & \multicolumn{3}{|c|}{ Mudança } \\
\hline & $\begin{array}{l}\text { Sim } \\
(\%)\end{array}$ & $\begin{array}{l}\text { Não } \\
\text { (\%) }\end{array}$ & $\begin{array}{c}- \\
(x \%)\end{array}$ & $\begin{array}{c}+ \\
(x \%)\end{array}$ & $\mathbf{P}$ & $\begin{array}{c}- \\
(x \%)\end{array}$ & $\begin{array}{c}+ \\
(\alpha \%)\end{array}$ & $\mathbf{P}$ & $\begin{array}{c}- \\
(x \%)\end{array}$ & $\begin{array}{c}+ \\
(\alpha \%)\end{array}$ & $\mathbf{P}$ \\
\hline $\begin{array}{c}\text { Achocolatado } \\
\text { em pó }\end{array}$ & $\begin{array}{c}29 \\
(45)\end{array}$ & $\begin{array}{c}35 \\
(55)\end{array}$ & $\begin{array}{c}8 \\
(28)\end{array}$ & $\begin{array}{c}10 \\
(29)\end{array}$ & 0,81 & $\begin{array}{c}10 \\
(34)\end{array}$ & $\begin{array}{c}11 \\
(31)\end{array}$ & 1,00 & $\begin{array}{c}9 \\
(31)\end{array}$ & $\begin{array}{c}14 \\
(40)\end{array}$ & 0,40 \\
\hline Açúcar & $\begin{array}{c}30 \\
(47)\end{array}$ & $\begin{array}{c}34 \\
(53)\end{array}$ & $\begin{array}{c}9 \\
(30)\end{array}$ & $\begin{array}{c}14 \\
(41)\end{array}$ & 0,40 & $\begin{array}{c}14 \\
(47)\end{array}$ & $\begin{array}{c}5 \\
(15)\end{array}$ & 0,06 & $\begin{array}{c}15 \\
(50)\end{array}$ & $\begin{array}{l}11 \\
(32)\end{array}$ & $0,56^{*}$ \\
\hline Leite & $\begin{array}{c}40 \\
(63)\end{array}$ & \begin{tabular}{|c|}
24 \\
$(38)$
\end{tabular} & $\begin{array}{c}5 \\
(13)\end{array}$ & $\begin{array}{c}11 \\
(46)\end{array}$ & 0,21 & $\begin{array}{c}6 \\
(15)\end{array}$ & $\begin{array}{c}9 \\
(38)\end{array}$ & 0,61 & $\begin{array}{c}6 \\
(15)\end{array}$ & $\begin{array}{c}12 \\
(50)\end{array}$ & 0,24 \\
\hline Café & $\begin{array}{c}10 \\
(16)\end{array}$ & $\begin{array}{c}54 \\
(84)\end{array}$ & $\begin{array}{c}7 \\
(70)\end{array}$ & $\begin{array}{c}11 \\
(20)\end{array}$ & 0,48 & $\begin{array}{c}8 \\
(80)\end{array}$ & $\begin{array}{c}8 \\
(15)\end{array}$ & 1,00 & $\begin{array}{c}6 \\
(60)\end{array}$ & $\begin{array}{l}12 \\
(22)\end{array}$ & 0,24 \\
\hline
\end{tabular}

-número de indivíduos que deixaram de comer; + número de indivíduos que passaram a comer;

*symp. Sig; $\chi \%$ calculada em relação aos adolescentes que consumiram no feriado

O consumo do grupo do arroz entre os adolescentes obteve uma freqüência no feriado, segunda, quarta e quinta-feira de respectivamente $66 \%(n=42), 83 \%(n=53)$, $81 \%(n=52)$ e $77 \%(n=49)$ (Figura 12). Suas mudanças foram significativas na segunda e na quarta-feira, ou seja, um número maior de adolescentes passou a consumir o alimento nestes dias. $\mathrm{Na}$ quinta-feira o consumo foi semelhante ao feriado (Tabela 7).

A freqüência do grupo batata não foi tão acentuada sendo cerca de $16 \%$ $(n=10)$ no feriado, $23 \%(n=15)$ na segunda-feira, $14 \%(n=9)$ na quarta-feira e $32 \%$ $(n=14)$ na quinta-feira (Figura 12). Sendo seu consumo significativamente maior apenas na quinta-feira em relação ao feriado (Tabela 7). 
O grupo do feijão obteve um consumo no feriado foi de $52 \%(n=33)$, na segunda e quarta foi de $67 \%(n=43)$ e na quinta $61 \% 52 \%(n=39)$ e obteve um número maior de adolescentes que passaram a consumir o alimento na segunda $\mathrm{e}$ quarta-feira, mantendo-se sem mudanças na quinta-feira, em relação ao feriado (Figura 12) e (Tabela 7).

As frequências do grupo de carne bovinas para os mesmos dias foram de respectivamente $63 \%(n=40), 64 \%(n=41), 58 \%(n=37), 61 \%(n=39)$, não havendo diferenças estatisticamente significativas entre os dias de consumo (Figura 12) e (Tabela 7). O grupo de carne de frango obteve um consumo de $20 \%(n=13)$ no feriado, $19 \%(n=12)$ na segunda e quinta-feira e $25 \%(n=16)$ na quarta-feira, entre os adolescentes estudados, também não havendo diferença significativa entre o consumo no feriado e nos dias da semana (Figura 12) e (Tabela 7).

Figura 12: Distribuição da freqüência do consumo arroz, batata, feijão, carne bovina e de frango dos adolescentes no feriado, segunda, quarta e quinta-feira, de uma Escola Estadual de segundo grau do município de São Paulo, 1999.

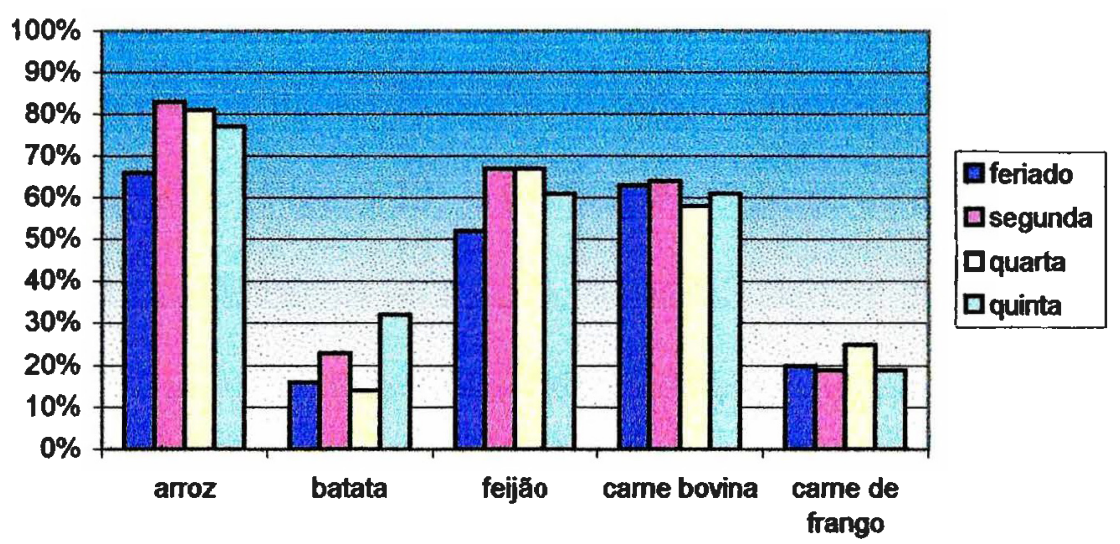


Tabela 7: Distribuição das mudanças entre os adolescentes que deixaram ou passaram a consumir os grupos alimentares no feriado, segunda, quarta e quintafeira, de uma Escola Estadual de segundo grau do município de São Paulo, 1999.

\begin{tabular}{|c|c|c|c|c|c|c|c|c|c|c|c|}
\hline \multirow{3}{*}{ Grupos } & \multicolumn{2}{|c|}{ Feriado } & \multicolumn{3}{|c|}{ Segunda } & \multicolumn{3}{|c|}{ Quarta } & \multicolumn{3}{|c|}{ Quinta } \\
\hline & \multicolumn{2}{|c|}{ Consumo } & \multicolumn{3}{|c|}{ Mudança } & \multicolumn{3}{|c|}{ Mudança } & \multicolumn{3}{|c|}{ Mudança } \\
\hline & $\begin{array}{l}\text { Sim } \\
(\%)\end{array}$ & $\begin{array}{l}\text { Não } \\
(\%)\end{array}$ & $\begin{array}{c}- \\
(x \%)\end{array}$ & $\begin{array}{c}+ \\
(x \%)\end{array}$ & $\mathbf{P}$ & $\begin{array}{c}- \\
(x \%)\end{array}$ & $\begin{array}{c}+ \\
(\chi \%)\end{array}$ & $\mathbf{P}$ & $\begin{array}{c}- \\
(x \%)\end{array}$ & $\begin{array}{c}+ \\
(\chi \%)\end{array}$ & $\mathbf{P}$ \\
\hline Arroz & $\begin{array}{c}42 \\
(66) \\
\end{array}$ & $\begin{array}{c}22 \\
(34)\end{array}$ & $\begin{array}{c}3 \\
(7)\end{array}$ & $\begin{array}{c}14 \\
(64)\end{array}$ & 0,01 & \begin{tabular}{|c|}
6 \\
$(14)$ \\
\end{tabular} & $\begin{array}{c}16 \\
(73) \\
\end{array}$ & 0,05 & $\begin{array}{c}8 \\
(19)\end{array}$ & $\begin{array}{c}15 \\
(68) \\
\end{array}$ & 0,21 \\
\hline Batata & $\begin{array}{c}10 \\
(16)\end{array}$ & $\begin{array}{c}54 \\
(84)\end{array}$ & $\begin{array}{c}8 \\
(80)\end{array}$ & $\begin{array}{c}13 \\
(24)\end{array}$ & 0,38 & \begin{tabular}{|c|}
9 \\
$(90)$
\end{tabular} & $\begin{array}{c}8 \\
(15)\end{array}$ & 1,00 & $\begin{array}{c}5 \\
(50)\end{array}$ & $\begin{array}{c}16 \\
(30)\end{array}$ & 0,03 \\
\hline Feijão & $\begin{array}{c}33 \\
(52) \\
\end{array}$ & $\begin{array}{c}31 \\
(48)\end{array}$ & $\begin{array}{c}6 \\
(18) \\
\end{array}$ & $\begin{array}{c}16 \\
(52) \\
\end{array}$ & 0,05 & $\begin{array}{c}3 \\
(9)\end{array}$ & $\begin{array}{c}13 \\
(42) \\
\end{array}$ & 0,02 & $\begin{array}{c}10 \\
(30)\end{array}$ & $\begin{array}{c}16 \\
(52) \\
\end{array}$ & $0,33^{*}$ \\
\hline Carne bovina & $\begin{array}{l}40 \\
(63)\end{array}$ & $\begin{array}{c}24 \\
(38)\end{array}$ & $\begin{array}{c}13 \\
(33)\end{array}$ & $\begin{array}{c}14 \\
(58)\end{array}$ & $1,00^{*}$ & $\begin{array}{c}16 \\
(40)\end{array}$ & $\begin{array}{c}13 \\
(54)\end{array}$ & $0,71^{*}$ & $\begin{array}{c}13 \\
(33)\end{array}$ & $\begin{array}{c}12 \\
(50)\end{array}$ & 1,00 \\
\hline $\begin{array}{l}\text { Carne de } \\
\text { frango }\end{array}$ & $\begin{array}{c}13 \\
(20)\end{array}$ & $\begin{array}{c}51 \\
(80)\end{array}$ & $\begin{array}{c}10 \\
(77)\end{array}$ & $\begin{array}{c}9 \\
(18)\end{array}$ & 1,00 & \begin{tabular}{|c|}
9 \\
$(69)$
\end{tabular} & $\begin{array}{c}12 \\
(24)\end{array}$ & 0,66 & $\begin{array}{c}11 \\
(85)\end{array}$ & $\begin{array}{c}10 \\
(20)\end{array}$ & 1,00 \\
\hline
\end{tabular}

-número de indivíduos que deixaram de comer; + número de indivíduos que passaram a comer;

*symp. Sig; $\chi \%$ calculada em relação aos adolescentes que consumiram no feriado

Ao se analisar o consumo do grupo de biscoitos verificou-se que $33 \%(n=21)$ dos adolescentes o fazem no feriado, $27 \%(n=17)$ na segunda-feira, $28 \%(n=18)$ na quarta-feira e $34 \%(n=22)$ na quinta-feira. O grupo de pães obteve um consumo acima de $50 \%$ para todos os dias analisados. A freqüência do grupo do bolo foi de $19 \%(n=12)$ no feriado, $22 \%(n=14)$ na segunda-feira, $14 \%(n=9)$ na quarta e quintafeira. Para todos esses grupos não houve diferença estatística entre o consumo no feriado e nos dias úteis (Figura 13) e (Tabela 8). O grupo do macarrão o consumo alimentar entre os adolescentes no feriado, segunda, quarta e quinta-feira foram de $41 \%(n=26), 14 \%(n=9), 25 \%(n=16)$ e $28 \%(n=18)$ respectivamente. Seu consumo obteve uma significativa queda na segunda e quarta-feira mantendo-se na quintafeira (Figura 13) e (Tabela 8). 
Figura 13: Distribuição da freqüência do consumo biscoitos, pães, bolo e macarrão dos adolescentes no feriado, segunda, quarta e quinta-feira, de uma Escola Estadual de segundo grau do município de São Paulo, 1999.

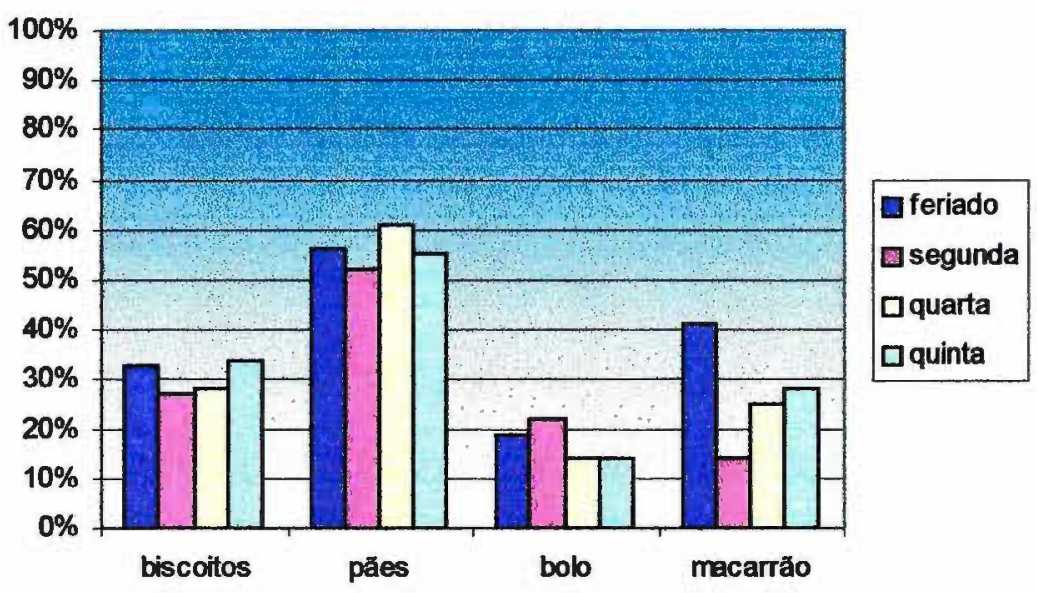

Tabela 8: Distribuição das mudanças entre os adolescentes que deixaram ou passaram a consumir os grupos alimentares no feriado, segunda, quarta e quintafeira, de uma Escola Estadual de segundo grau do município de São Paulo, 1999.

\begin{tabular}{|c|c|c|c|c|c|c|c|c|c|c|c|}
\hline \multirow{3}{*}{ Grupos } & \multicolumn{2}{|c|}{ Feriado } & \multicolumn{3}{|c|}{ Segunda } & \multicolumn{3}{|c|}{ Quarta } & \multicolumn{3}{|c|}{ Quinta } \\
\hline & \multicolumn{2}{|c|}{ Consumo } & \multicolumn{3}{|c|}{ Mudança } & \multicolumn{3}{|c|}{ Mudança } & \multicolumn{3}{|c|}{ Mudança } \\
\hline & $\begin{array}{l}\text { Sim } \\
\text { (\%) }\end{array}$ & $\begin{array}{l}\text { Não } \\
\text { (\%) }\end{array}$ & $\begin{array}{c}- \\
(x \%)\end{array}$ & $\begin{array}{c}+ \\
(\chi \%)\end{array}$ & $\mathbf{P}$ & $\begin{array}{c}- \\
(x \%)\end{array}$ & $\begin{array}{c}+ \\
(\chi \%)\end{array}$ & $\mathbf{P}$ & $\begin{array}{c}- \\
(x \%)\end{array}$ & $\begin{array}{c}+ \\
(\alpha \%)\end{array}$ & $\mathbf{P}$ \\
\hline Biscoitos & $\begin{array}{c}21 \\
(33)\end{array}$ & $\begin{array}{c}43 \\
\text { (67) }\end{array}$ & $\begin{array}{c}13 \\
(62)\end{array}$ & $\begin{array}{c}9 \\
(21)\end{array}$ & 0,52 & $\begin{array}{c}15 \\
(71)\end{array}$ & $\begin{array}{c}12 \\
(28)\end{array}$ & $0,70^{*}$ & $\begin{array}{c}13 \\
(62)\end{array}$ & $\begin{array}{c}14 \\
(33)\end{array}$ & $1,00^{*}$ \\
\hline Pães & $\begin{array}{c}36 \\
(56)\end{array}$ & $\begin{array}{c}28 \\
(44)\end{array}$ & $\begin{array}{c}12 \\
(33)\end{array}$ & $\begin{array}{c}9 \\
(32)\end{array}$ & 0,66 & $\begin{array}{c}11 \\
(31)\end{array}$ & $\begin{array}{c}14 \\
(50)\end{array}$ & 0,69 & $\begin{array}{c}15 \\
(42)\end{array}$ & $\begin{array}{c}14 \\
(50)\end{array}$ & $1,00^{*}$ \\
\hline Bolo & $\begin{array}{c}12 \\
(19)\end{array}$ & $\begin{array}{c}52 \\
(81)\end{array}$ & $\begin{array}{c}8 \\
(67)\end{array}$ & $\begin{array}{c}10 \\
(19)\end{array}$ & 0,81 & $\begin{array}{c}10 \\
(83)\end{array}$ & $\begin{array}{c}7 \\
(13)\end{array}$ & 0,63 & $\begin{array}{c}8 \\
(67)\end{array}$ & $\begin{array}{c}5 \\
(10)\end{array}$ & 0,58 \\
\hline Macarrão & $\begin{array}{c}26 \\
(41)\end{array}$ & $\begin{array}{c}38 \\
(59)\end{array}$ & $\begin{array}{c}22 \\
(85)\end{array}$ & $\begin{array}{c}5 \\
(13)\end{array}$ & $\underset{*}{<0,01}$ & $\begin{array}{c}18 \\
(69)\end{array}$ & $\begin{array}{c}8 \\
(21)\end{array}$ & $0,08^{*}$ & $\begin{array}{c}18 \\
(69)\end{array}$ & $\begin{array}{c}10 \\
(26)\end{array}$ & $0,19^{*}$ \\
\hline
\end{tabular}


No feriado $19 \%(n=12)$ dos adolescentes estudados consumiram alimentos do grupo da alface, na segunda-feira o número foi de $36 \%(n=23)$, na quarta-feira $30 \%$ $(n=19)$ e na quinta-feira $20 \%(n=13)$ (Figura 14). Na segunda-feira houve uma diferença estatística no consumo do grupo alface, em relação ao feriado, pois 14 indivíduos passaram a ingerir o alimento e apenas 3 deixaram de consumi-lo neste dia. Com relação aos outros dias da semana as mudanças ocorridas mantiveram-se semelhantes (Tabela 9).

Para o grupo de verduras os percentuais foram de $35 \%(n=22), 33 \%(n=21)$, $36 \%(n=23)$ e $34 \%(n=22)$, para os mesmos dias citados. A freqüência de consumo do grupo de frutas foi de $31 \%(n=20)$ tanto no feriado como na quinta-feira e de $36 \%$ $(n=23)$ na segunda-feira e $44 \%(n=28)$ na quarta-feira. Tanto o grupo de verduras como o de frutas mantiveram um consumo semelhante para todos os dias analisados (Figura 14) e (Tabela 9). 
Figura 14: Distribuição da frequuência do consumo alface, verduras e frutas dos adolescentes no feriado, segunda, quarta e quinta-feira, de uma Escola Estadual de segundo grau do município de São Paulo, 1999.

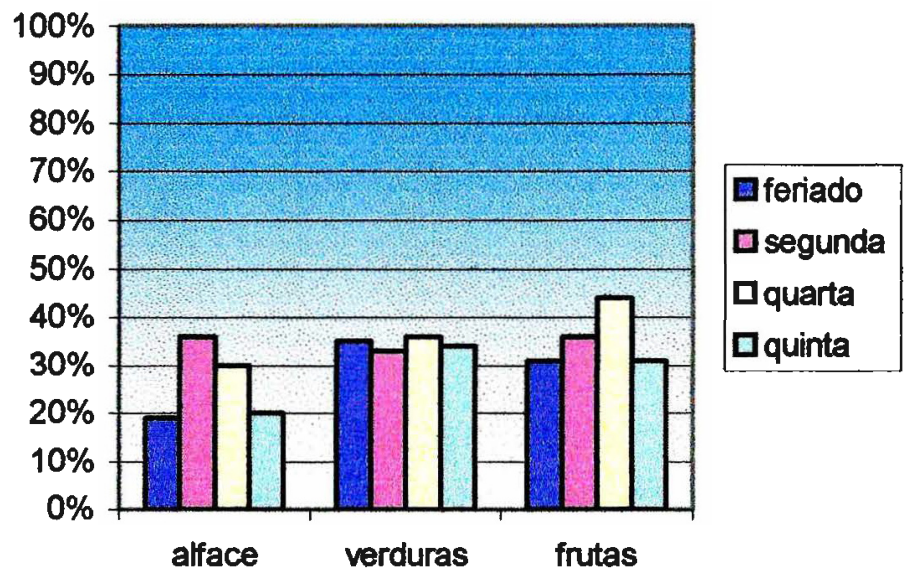

Tabela 9: Distribuição das mudanças entre os adolescentes que deixaram ou passaram a consumir os grupos alimentares no feriado, segunda, quarta e quintafeira, de uma Escola Estadual de segundo grau do município de São Paulo, 1999.

\begin{tabular}{|c|c|c|c|c|c|c|c|c|c|c|c|}
\hline \multirow[b]{3}{*}{ Grupos } & \multicolumn{2}{|c|}{ Feriado } & \multicolumn{3}{|c|}{ Segunda } & \multicolumn{3}{|c|}{ Quarta } & \multicolumn{3}{|c|}{ Quinta } \\
\hline & \multicolumn{2}{|c|}{ Consumo } & \multicolumn{3}{|c|}{ Mudança } & \multicolumn{3}{|c|}{ Mudanca } & \multicolumn{3}{|c|}{ Mudança } \\
\hline & $\begin{array}{l}\text { Sim } \\
(\%)\end{array}$ & $\begin{array}{l}\text { Não } \\
\text { (\%) }\end{array}$ & $\begin{array}{c}- \\
(x \%)\end{array}$ & $\begin{array}{c}+ \\
(\alpha \%)\end{array}$ & $\mathbf{P}$ & $\overline{(x \%)}$ & $\begin{array}{c}+ \\
(\alpha \%)\end{array}$ & $\mathbf{P}$ & $\begin{array}{c}- \\
(\chi \%)\end{array}$ & $\begin{array}{c}+ \\
(\alpha \%)\end{array}$ & $\mathbf{P}$ \\
\hline Alface & $\begin{array}{c}12 \\
(19)\end{array}$ & $\begin{array}{c}52 \\
(81)\end{array}$ & $\begin{array}{c}3 \\
(25)\end{array}$ & $\begin{array}{c}14 \\
(27)\end{array}$ & 0,01 & $\begin{array}{c}5 \\
(42)\end{array}$ & $\begin{array}{c}12 \\
(23)\end{array}$ & 0,14 & $\begin{array}{c}6 \\
(50)\end{array}$ & $\begin{array}{c}7 \\
(13)\end{array}$ & 1,00 \\
\hline Verduras & $\begin{array}{c}22 \\
(34)\end{array}$ & $\begin{array}{c}42 \\
(66)\end{array}$ & $\begin{array}{c}14 \\
(64)\end{array}$ & $\begin{array}{c}13 \\
(31) \\
\end{array}$ & $1,00^{*}$ & $\begin{array}{c}13 \\
(59) \\
\end{array}$ & $\begin{array}{c}14 \\
\text { (33) }\end{array}$ & $1,00^{*}$ & $\begin{array}{c}14 \\
(64)\end{array}$ & $\begin{array}{c}14 \\
\text { (33) }\end{array}$ & $1,00 *$ \\
\hline Frutas & $\begin{array}{c}44 \\
(69)\end{array}$ & $\begin{array}{c}20 \\
(31)\end{array}$ & $\begin{array}{c}10 \\
(23)\end{array}$ & $\begin{array}{c}13 \\
(65)\end{array}$ & 0,68 & $\begin{array}{c}9 \\
(20)\end{array}$ & $\begin{array}{c}17 \\
(85)\end{array}$ & $0,17 *$ & $\begin{array}{c}9 \\
(20)\end{array}$ & $\begin{array}{c}9 \\
(45)\end{array}$ & 1,00 \\
\hline
\end{tabular}

-número de individuos que deixaram de comer; + número de indivíduos que passaram a comer;

* symp. Sig; $\chi \%$ calculada em relação aos adolescentes que consumiram no feriado 
O consumo alimentar do grupo dos óleos para os dias estudados no feriado, segunda, quarta e quinta-feira foram de $45 \%(n=29), 44 \%(n=28), 48 \%(n=31), 44 \%$ $(n=28)$, respectivamente entre os indivíduos. Para o grupo dos queijos, $25 \%(n=16)$ dos adolescentes consumiram um item alimentar desse grupo no feriado, $20 \%(n=13)$ na segunda e quarta-feira e $16 \%(n=10)$ na quinta-feira. Não houve diferenças estatísticas no consumo de óleos e queijos entre o feriados e os dias da semana (Figura 15) e (Tabela 10).

Figura 15: Distribuição da freqüência do consumo óleos e queijos dos adolescentes no feriado, segunda, quarta e quinta-feira, de uma Escola Estadual de segundo grau do município de São Paulo, 1999.

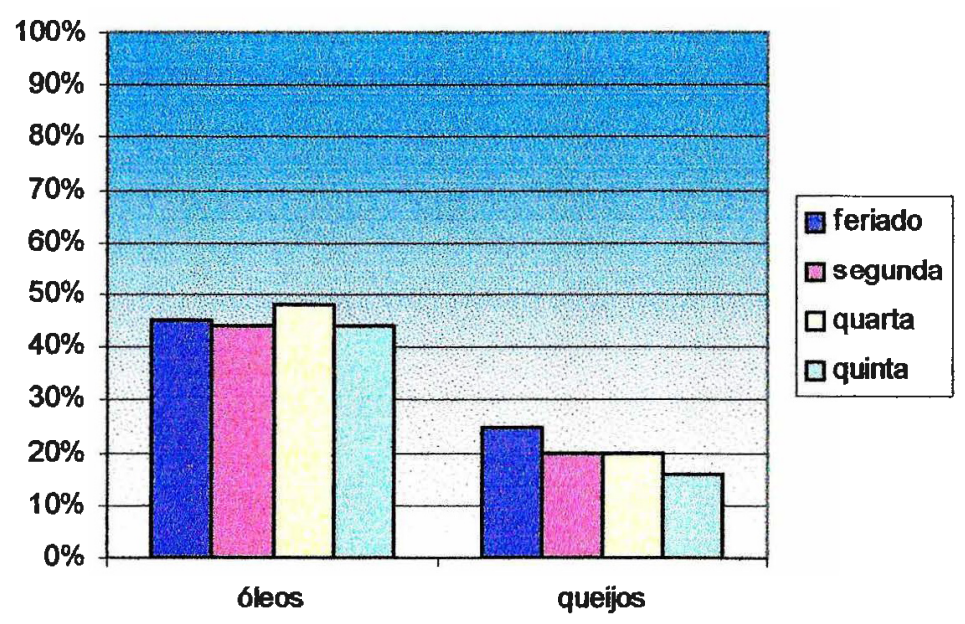


Tabela 10: Distribuição das mudanças entre os adolescentes que deixaram ou passaram a consumir os grupos alimentares no feriado, segunda, quarta e quintafeira, de uma Escola Estadual de segundo grau do município de São Paulo, 1999.

\begin{tabular}{|c|c|c|c|c|c|c|c|c|c|c|c|}
\hline \multirow{3}{*}{ Grupos } & \multicolumn{2}{|c|}{ Feriado } & \multicolumn{3}{|c|}{ Segunda } & \multicolumn{3}{|c|}{ Quarta } & \multicolumn{3}{|c|}{ Quinta } \\
\hline & \multicolumn{2}{|c|}{ Consumo } & \multicolumn{3}{|c|}{ Mudança } & \multicolumn{3}{|c|}{ Mudança } & \multicolumn{3}{|c|}{ Mudança } \\
\hline & $\begin{array}{c}\text { Sim } \\
(\%)\end{array}$ & $\begin{array}{c}\text { Não } \\
(\%)\end{array}$ & $\begin{array}{c}- \\
(\chi \%)\end{array}$ & $\begin{array}{c}+ \\
(\chi \%)\end{array}$ & $\mathbf{P}$ & $\begin{array}{c}- \\
(x \%)\end{array}$ & $\begin{array}{c}+ \\
(x \%)\end{array}$ & $\mathbf{P}$ & $\begin{array}{c}- \\
(\chi \%)\end{array}$ & $\begin{array}{c}+ \\
(\chi \%)\end{array}$ & $\mathbf{P}$ \\
\hline Óleos & $\begin{array}{c}29 \\
(45)\end{array}$ & $\begin{array}{c}35 \\
(55) \\
\end{array}$ & $\begin{array}{c}13 \\
(45)\end{array}$ & $\begin{array}{c}12 \\
(34)\end{array}$ & $\overline{1,00}$ & $\begin{array}{c}9 \\
(31)\end{array}$ & $\begin{array}{c}11 \\
(31)\end{array}$ & 0,82 & $\begin{array}{c}15 \\
(52)\end{array}$ & $\begin{array}{c}14 \\
(40)\end{array}$ & $1,00 *$ \\
\hline Queijos & $\begin{array}{c}16 \\
(25)\end{array}$ & $\begin{array}{c}48 \\
(75)\end{array}$ & $\begin{array}{c}10 \\
(63)\end{array}$ & $\begin{array}{c}7 \\
(15)\end{array}$ & 0,63 & $\begin{array}{c}12 \\
(75)\end{array}$ & $\begin{array}{c}9 \\
(19)\end{array}$ & 0,66 & $\begin{array}{c}15 \\
(94)\end{array}$ & $\begin{array}{c}9 \\
(19)\end{array}$ & 0,31 \\
\hline
\end{tabular}

-número de indivíduos que deixaram de comer; + número de indivíduos que passaram a comer; *symp. Sig; $\chi \%$ calculada em relação aos adolescentes que consumiram no feriado

Entre os 64 adolescentes estudados, $39 \%(n=25)$ consumiram refrigerante no feriado, na segunda-feira o percentual foi de $22 \%(n=14)$, na quarta e quinta-feira foi de $36 \%(n=23)$, seu consumo caiu na segunda-feira em relação ao feriado (Figura 16) e (Tabela 11).

O grupo dos salgados apenas $9 \%(\mathrm{n}=6)$ dos indivíduos consumiram esse item alimentar no feriado, na segunda-feira o percentual foi de $33 \%(\mathrm{n}=21)$, na quartafeira $40 \%(n=25)$ e na quinta-feira $31 \%(n=20)$, ou seja, este grupo obteve um consumo estatisticamente maior para todos os dias úteis (Figura 16) e (Tabela 11).

O consumo do grupo de salgadinhos extrusados foi inferior a 15 adolescentes para todos os dias sendo que as porcentagens de consumo foram de $6 \%(n=4), 11 \%$ $(n=7), 8 \% \quad(n=5)$ e $17 \% \quad(n=11)$ no feriado, segunda, quarta e quinta-feira 
respectivamente. Os valores de consumo do grupo dos sanduíches foram de $16 \%$ $(n=10)$ no feriado, $19 \%(n=12)$ segunda e quarta-feira, e $11 \%(n=7)$ na quinta-feira.

O grupo dos doces obteve uma freqüência de consumo no feriado, segunda, quarta e quinta-feira de respectivamente $19 \%(n=12), 17 \%(n=11), 23 \%(n=15), 14 \%$ $(\mathrm{n}=9)$ (Figura 16).

Não houve diferença estatisticamente significativa no consumo de salgadinhos extrusados, sanduíches e doces entre todos os dias analisados (Tabela 11).

Figura 16: Distribuição da freqüência do consumo refrigerante, salgado, salgadinho, sanduíches e doces dos adolescentes no feriado, segunda, quarta e quinta-feira, de uma Escola Estadual de segundo grau do município de São Paulo, 1999.

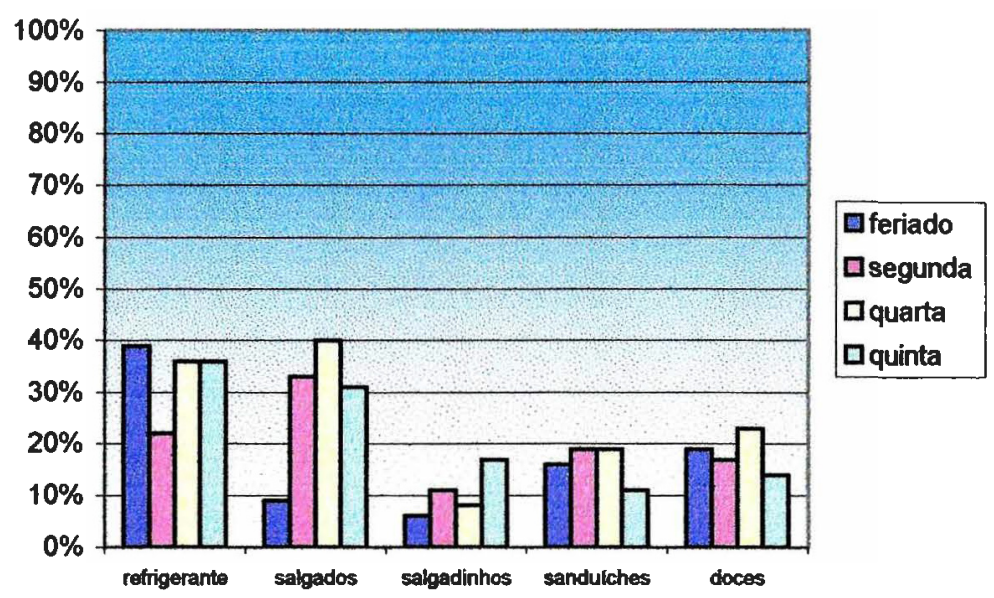


Tabela 11: Distribuição das mudanças entre os adolescentes que deixaram ou passaram a consumir os grupos alimentares no feriado, segunda, quarta e quintafeira, de uma Escola Estadual de segundo grau do município de São Paulo, 1999.

\begin{tabular}{|c|c|c|c|c|c|c|c|c|c|c|c|}
\hline \multirow{3}{*}{ Grupos } & \multirow{2}{*}{\multicolumn{2}{|c|}{$\frac{\text { Feriado }}{\text { Consumo }}$}} & \multicolumn{3}{|c|}{ Segunda } & \multicolumn{3}{|c|}{ Quarta } & \multicolumn{3}{|c|}{ Quinta } \\
\hline & & & \multicolumn{3}{|c|}{ Mudança } & \multicolumn{3}{|c|}{ Mudança } & \multicolumn{3}{|c|}{ Mudança } \\
\hline & $\begin{array}{l}\text { Sim } \\
(\%)\end{array}$ & $\begin{array}{l}\text { Não } \\
(\%)\end{array}$ & $\overline{-}$ & $\begin{array}{c}+ \\
(x \%)\end{array}$ & $\mathbf{P}$ & $\begin{array}{c}- \\
(x \%)\end{array}$ & $\begin{array}{c}+ \\
(\chi \%)\end{array}$ & $\mathbf{P}$ & $\dot{-}$ & $\begin{array}{c}+ \\
(x \%)\end{array}$ & $\mathbf{P}$ \\
\hline Refrigerante & $\begin{array}{c}25 \\
(39) \\
\end{array}$ & $\begin{array}{c}39 \\
(61) \\
\end{array}$ & $\begin{array}{c}19 \\
(76)\end{array}$ & $\begin{array}{c}8 \\
(21) \\
\end{array}$ & $0,05^{*}$ & $\begin{array}{c}14 \\
(56) \\
\end{array}$ & $\begin{array}{c}12 \\
(31) \\
\end{array}$ & $0,84^{*}$ & $\begin{array}{c}16 \\
(64) \\
\end{array}$ & $\begin{array}{c}14 \\
(36) \\
\end{array}$ & $0,85^{*}$ \\
\hline Salgados & $\begin{array}{c}6 \\
(9) \\
\end{array}$ & $\begin{array}{c}58 \\
(91) \\
\end{array}$ & $\begin{array}{c}1 \\
(17)\end{array}$ & $\begin{array}{c}16 \\
(28) \\
\end{array}$ & $<0,01$ & $\begin{array}{c}3 \\
(50) \\
\end{array}$ & $\begin{array}{c}22 \\
(38)\end{array}$ & $<0,01$ & $\begin{array}{c}3 \\
(50)\end{array}$ & \begin{tabular}{|c|}
17 \\
$(29)$
\end{tabular} & $<0,01$ \\
\hline $\begin{array}{l}\text { Salgadinhos } \\
\text { extrusados }\end{array}$ & $\begin{array}{c}4 \\
(6)\end{array}$ & $\begin{array}{c}60 \\
(94)\end{array}$ & $\begin{array}{c}4 \\
(100)\end{array}$ & $\begin{array}{c}6 \\
(10)\end{array}$ & 0,75 & $\begin{array}{c}4 \\
(100 \\
\quad\end{array}$ & $\begin{array}{c}5 \\
(8)\end{array}$ & 1,00 & $\begin{array}{c}4 \\
(100)\end{array}$ & $\begin{array}{c}11 \\
(18)\end{array}$ & 0,12 \\
\hline Sanduíches & $\begin{array}{c}10 \\
(16) \\
\end{array}$ & $\begin{array}{c}54 \\
(84) \\
\end{array}$ & $\begin{array}{c}8 \\
(80) \\
\end{array}$ & $\begin{array}{c}10 \\
(19)\end{array}$ & 0,81 & $\begin{array}{c}8 \\
(80) \\
\end{array}$ & $\begin{array}{c}10 \\
(19) \\
\end{array}$ & 0,81 & $\begin{array}{c}9 \\
(90) \\
\end{array}$ & $\begin{array}{c}6 \\
(11) \\
\end{array}$ & 0,61 \\
\hline Doces & $\begin{array}{c}52 \\
(81)\end{array}$ & $\begin{array}{c}12 \\
(19)\end{array}$ & $\begin{array}{c}9 \\
(17)\end{array}$ & $\begin{array}{c}8 \\
(67)\end{array}$ & 1,00 & $\begin{array}{c}8 \\
(15)\end{array}$ & $\begin{array}{c}11 \\
(92)\end{array}$ & 0,65 & $\begin{array}{c}9 \\
(17)\end{array}$ & $\begin{array}{c}6 \\
(50)\end{array}$ & 0,61 \\
\hline
\end{tabular}

-número de indivíduos que deixaram de comer; + número de indivíduos que passaram a comer;

*symp. Sig; $\chi \%$ calculada em relação aos adolescentes que consumiram no feriado 


\section{Consumo das refeições}

As Figuras 17, 18, 19, 20, 21 e 22 mostram a freqüência de consumo das 6 refeições estudadas (café da manhã, lanche da manhã, almoço, lanche da tarde, jantar e lanche da noite) entre os adolescentes do estudo.

O percentual de consumo do café da manhã foi de $42 \%(n=27)$ no feriado, $88 \%(n=56)$ na segunda-feira, $83 \%(n=53)$ na quarta-feira e $85 \%(n=55)$ na quintafeira (Figura 17).

Figura 17: Distribuição da freqüência de consumo do café da manhã no feriado, segunda, quarta e quinta-feira, de uma Escola Estadual de segundo grau do município de São Paulo, 1999.

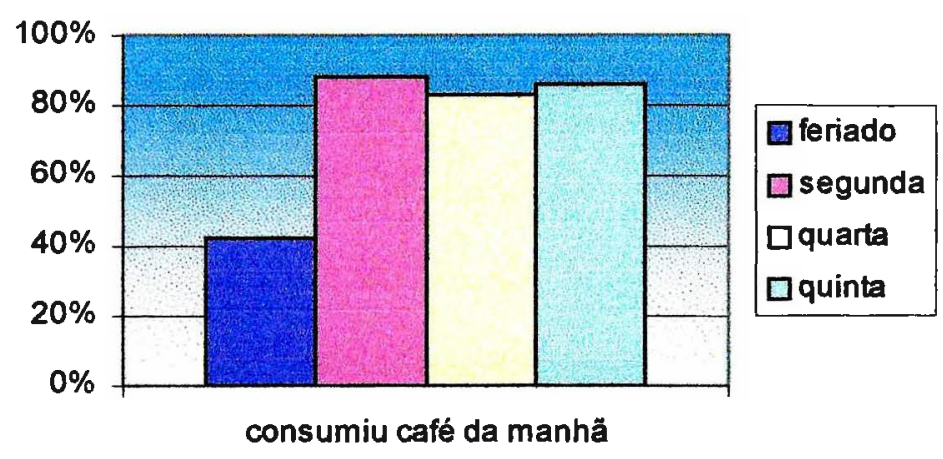

Com relação ao lanche da manhã as porcentagens de realização da refeição no feriado, segunda, quarta e quinta-feira foram de respectivamente $56 \%(n=36), 47 \%$ $(n=30), 45 \%(n=29), 44 \%(n=28)$ (Figura 18). 
Figura 18: Distribuição da frequência de consumo do lanche da manhã no feriado, segunda, quarta e quinta-feira, de uma Escola Estadual de segundo grau do município de São Paulo, 1999.

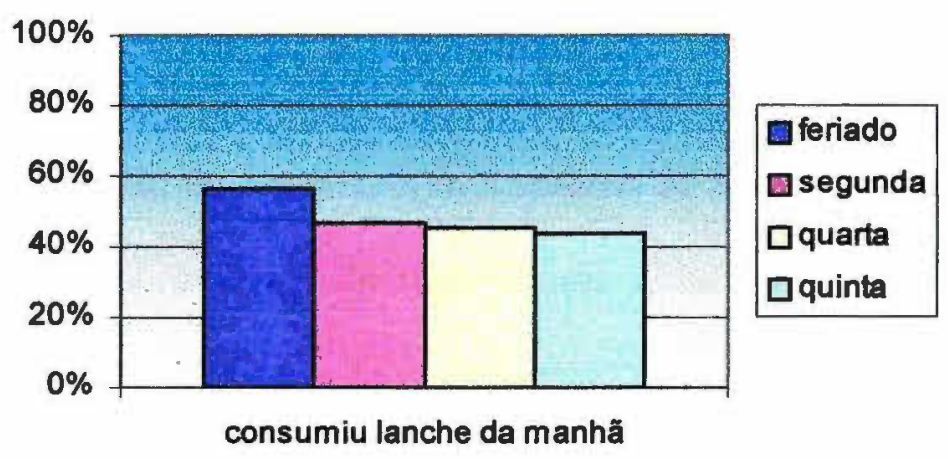

O consumo do almoço foi acima de $90 \%$ em todos os dias de análise, sendo seus valores especificamente: $94 \%(n=60)$ no feriado, $95 \%(n=61)$ na segunda-feira, $97 \%(n=62)$ na quarta-feira e $91 \%(n=58)$ na quinta-feira (Figura 19).

Figura 19: Distribuição da frequeência de consumo do almoço no feriado, segunda, quarta e quinta-feira, de uma Escola Estadual de segundo grau do município de São Paulo, 1999.

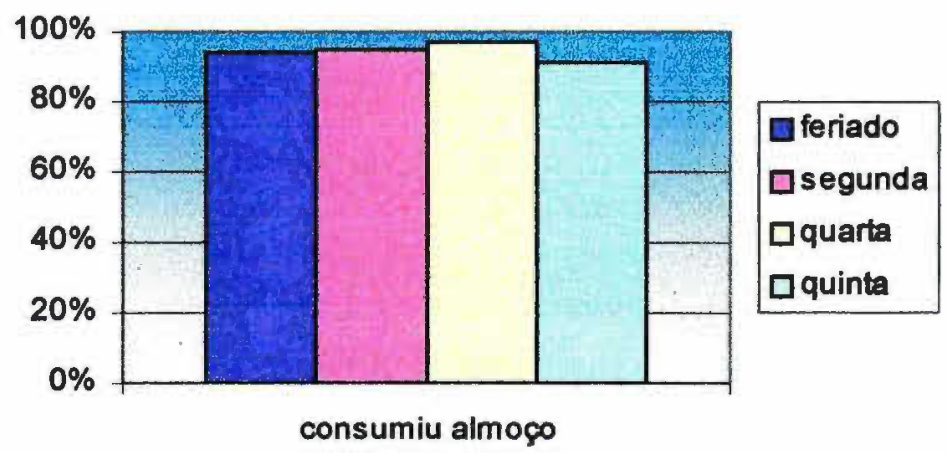


Para o lanche da tarde os percentuais de consumo da refeição foram de $52 \%$ $(n=33)$ no feriado, 64\% $(n=41)$ na segunda, $67 \%(n=43)$ na quarta e $69 \%(n=44)$ na quinta (Figura 20). A freqüência de consumo do jantar manteve-se acima dos $80 \%$ para os dias analisados, $86 \%(n=55)$ no feriado e na segunda-feira, $83 \%(n=53)$ na quarta-feira e $84 \%(n=54)$ na quinta-feira (Figura 21).

Figura 20: Distribuição da freqüência de consumo do lanche da tarde no feriado, segunda, quarta e quinta-feira, de uma Escola Estadual de segundo grau do município de São Paulo, 1999.

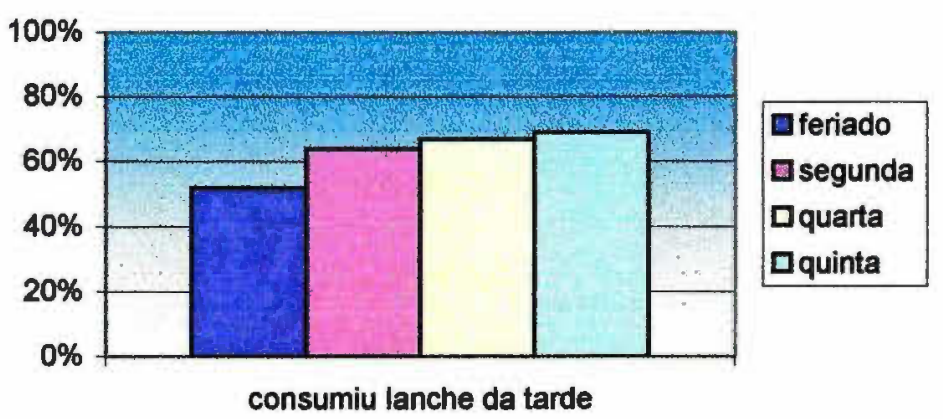

Figura 21: Distribuição da frequêencia de consumo do jantar no feriado, segunda, quarta e quinta-feira, de uma Escola Estadual de segundo grau do município de São Paulo, 1999.

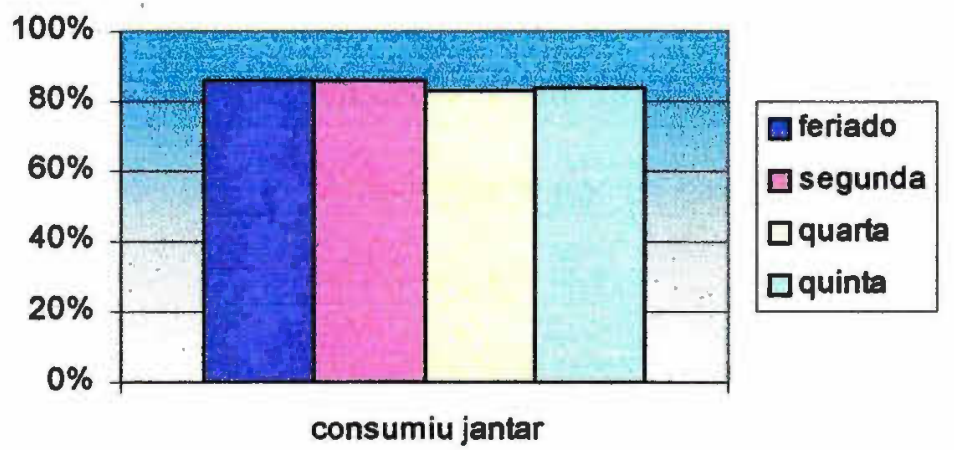


O consumo do lanche da noite foi o menos freqüente em relação a todas as outras refeições sendo os percentuais $20 \%(n=13)$ no feriado, $25 \%(n=16)$ na segunda-feira, $28 \%(\mathrm{n}=18)$ na quarta-feira e $19 \%(\mathrm{n}=12)$ na quinta-feira (Figura 22 ).

Figura 22: Distribuição da frequuência de consumo do lanche da noite no feriado, segunda, quarta e quinta-feira, de uma Escola Estadual de segundo grau do município de São Paulo, 1999.

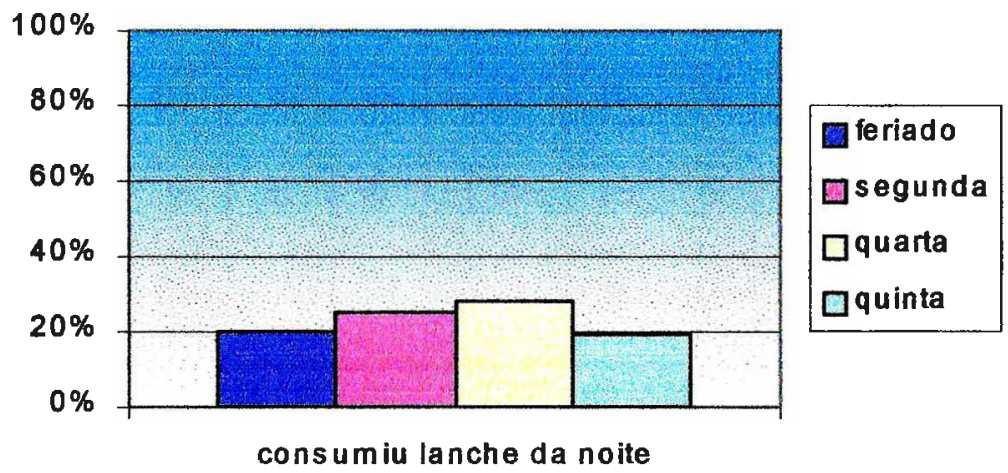

Não houve diferença significativa entre o consumo do lanche da manhã, almoço, jantar e lanche da noite em todos os dias de análise. Com relação ao café da manhã o consumo foi significativamente menor no feriado em relação aos dias da semana, e a ingestão do lanche da tarde foi maior na quinta-feira, e se manteve nos outros dias (Tabela 12). 
Tabela 12: Distribuição de mudanças dos adolescentes que deixaram ou passaram a consumir as refeições no feriado, segunda, quarta e quinta-feira, de uma Escola Estadual de segundo grau do município de São Paulo, 1999.

\begin{tabular}{|c|c|c|c|c|c|c|c|c|c|c|c|}
\hline \multirow[t]{3}{*}{ Grupo } & \multicolumn{2}{|c|}{ Feriado } & \multicolumn{3}{|c|}{ Segunda } & \multicolumn{3}{|c|}{ Quarta } & \multicolumn{3}{|c|}{ Quinta } \\
\hline & \multicolumn{2}{|c|}{ Consumo } & \multicolumn{3}{|c|}{ Mudança } & \multicolumn{3}{|c|}{ Mudança } & \multicolumn{3}{|c|}{ Mudança } \\
\hline & Sim & Não & - & + & $\mathrm{P}$ & - & + & $\mathrm{P}$ & - & + & $\mathbf{P}$ \\
\hline $\begin{array}{l}\text { Café da } \\
\text { manhã }\end{array}$ & 27 & 37 & 4 & 33 & $<0,01^{*}$ & 4 & 30 & $<0,01 *$ & 5 & 33 & $<0,01 *$ \\
\hline $\begin{array}{l}\text { Lanche da } \\
\text { manhã }\end{array}$ & 36 & 28 & 18 & 12 & $0,36^{*}$ & 20 & 13 & $0,30^{*}$ & 20 & 12 & 0,22 \\
\hline Almoço & 4 & 60 & 2 & 3 & 1,00 & 2 & 4 & 0,69 & 5 & 3 & 0,73 \\
\hline $\begin{array}{l}\text { Lanche da } \\
\text { tarde }\end{array}$ & 33 & 31 & 10 & 18 & $0,19 *$ & 10 & 20 & $0,10^{*}$ & 7 & 18 & 0,04 \\
\hline Jantar & 55 & 9 & 6 & 6 & 1,00 & 10 & 8 & 0,81 & 10 & 9 & 1,00 \\
\hline $\begin{array}{l}\text { Lanche da } \\
\text { noite }\end{array}$ & 13 & 51 & 7 & 10 & 0,63 & 9 & 14 & 0,40 & 11 & 10 & 1,00 \\
\hline
\end{tabular}

-número de indivíduos que deixaram de comer; + número de indivíduos que passaram a comer

* symp. Sig

$\chi \%$ calculada em relação aos adolescentes que consumiram no feriado

Ao se relacionar à frequêência de consumo dos lanches entre os horários de consumo (manhã, tarde e noite), verificou-se que na segunda, quarta e quinta-feira o lanche da tarde foi o mais freqüente, tendo um consumo de $64 \%(n=41), 67 \%(n=43)$ e $69 \%(n=44)$ respectivamente. O lanche da manhã, para todos os dias de análise, obteve freqüências entre $44 \%$ e $50 \%$ de consumo, já o lanche da noite não ultrapassou os $28 \%(n=18)$ de freqüência de consumo (Figura 23). 
Figura 23: Distribuição de freqüência do consumo do lanche da noite no feriado, segunda, quarta e quinta-feira, de uma Escola Estadual de segundo grau do município de São Paulo, 1999.

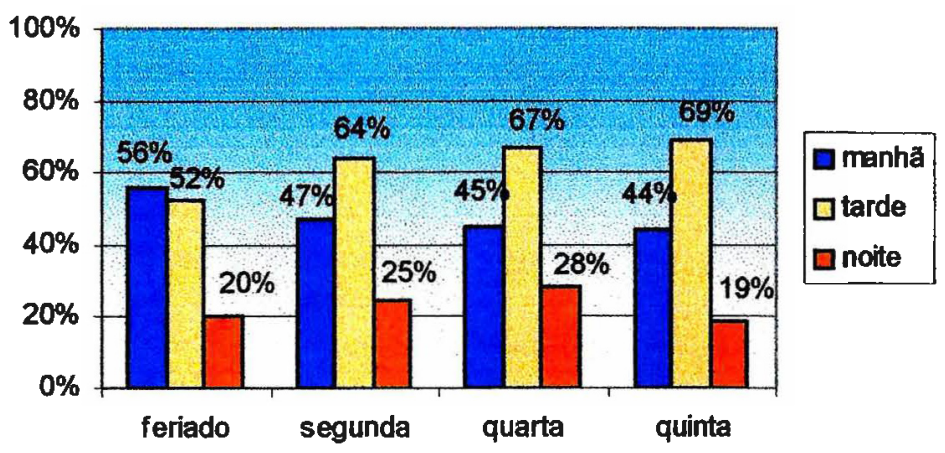

Ao analisar a relação de consumo entre os lanches, verificou-se que no feriado não houve diferença entre o número de mudanças do lanche da manhã em relação ao da tarde, porém ambos foram significativamente maiores em relação á noite $(p<0,01)$.

Na segunda-feira o consumo do lanche da manhã foi maior em relação ao lanche da noite $(p=0,02)$, assim como o lanche da tarde, que também obteve um consumo maior $(p<0,01)$. As mudanças entre manhã e tarde mantiveram-se semelhantes.

$\mathrm{Na}$ quarta o consumo do lanche da tarde foi estatisticamente maior do que o da manhã $(p=0,02)$ e o da noite $(p<0,01)$. O lanche da manhã foi maior que o da noite $(p=0,05)$. O mesmo ocorreu na quinta feira tendo níveis de significância de $p<0,01$ do lanche da tarde para manhã; $p<0,01$ do lanche da manhã para noite e $p<0,01$ do lanche da tarde para noite. 
DISCUSSÃO 
O padrão alimentar adquirida na adolescência possui uma tendência a se perpetuar na idade adulta, portanto aumentando as chances da manutenção de dietas de risco (excesso de gorduras e açúcares e baixo teor de fibras e de ácidos poliinsaturados). Conseqüentemente pode haver um aumento de doenças como: obesidade, doenças cardíacas e diabetes tipo II (Popkin 1993; Cavadini et al 2000; Lien 2001). Estudos sobre o consumo alimentar de adolescentes nos possibilitam conhecer de seus hábitos, e auxilia nas políticas de intervenções para a saúde.

O presente estudo, apesar de não possuir uma amostra representativa da população, é realizado com adolescentes em um período longo de tempo (6 meses), característica importante para se caracterizar hábitos alimentares. Ainda há referências alimentares de consumo em um dia de consumo atípico, representado pelo feriado. Esses dados podem ser extrapolados para os finais de semana e auxiliam no planejamento nutritivo de dias como sábado ou domingo.

Para uma melhor compreensão, discussão será conduzida segundo os nutrientes estudados, energia, proteínas, carboidratos, gordura total, gordura insaturada, fibras, vitamina $\mathrm{C}$, cálcio e ferro, pois todos as variáveis de estudo (influência do dia da semana, média de consumo, freqüência dos alimentos) estão interligadas. Optou-se por desvincular o item refeição dos anteriores, mas ele também terá uma discussão aprofundada. 


\section{Energia}

A quantidade de energia consumida pelos adolescentes é um importante aspecto a ser considerado. Cavadini et al $\left(2000^{\mathrm{a}}\right)$, compararam o consumo energético de adolescentes (11 a 18 anos), por meio de questionário 24 horas, em quatro momentos, $1965 ; 1977 ; 1989-91$ e $1994-96$, e constataram uma redução de $17 \%$ na ingestão energética do grupo populacional ao longo dos anos. Apesar disso, entre os dois últimos períodos estudados (91 e 96), houve um aumento de $9 \%$ na média de ingestão. O mesmo tipo de estudo realizado na Catalonia entre 1983 e 1993 mostrou uma diminuição de 6 a $9 \%$ do consumo de energia entre adolescentes de 15 a 19 anos (Arija et al 1996).

Em oposição a esses dados, Nielsen et al (2002) mostraram um aumento no consumo de energia entre os indivíduos de 2 a 18 anos, entre 1977 a 1996 de aproximadamente $6,4 \%$, sendo essa mesma tendência encontrada em outros grupos etários, 19 a 39 anos e 40 a 59 anos, com índices de $18,4 \%$ e $11,8 \%$ respectivamente.

No presente estudo o consumo se manteve semelhante ao longo dos seis meses de estudo, mas tanto o tempo como o tamanho da amostra impossibilita maiores conclusões quanto à variação da ingestão energética dos adolescentes. Devem ser viabilizados estudos de coorte para verificar que tipo de tendência, decréscimo ou aumento, do consumo energético ocorre no Brasil.

A constância de ingestão de energia pode ser considerada um fator positivo, pois se estiver dentro das recomendações utilizadas atualmente (DRIs), influenciaram na manutenção corpórea e na saúde dos adolescentes estudados, à medida que eles, provavelmente, já passaram do seu pico de maturação sexual, que 
ocorre entre 11 e 12 anos nas meninas e entre 13 e 14 anos nos meninos e que coincidi com o período de maior consumo energético (Clavien et al 1996; Giovannini et al. 2000; DRI 2001).

A adequação energética é um aspecto que deve ser considerado. Gama (1999) verificou em estudo com 724 adolescentes que $1 / 3$ não atingiu a recomendação de energia segundo a RDAs (1989), e que o maior número de inadequações estavam entre aqueles que estudavam em escolas estaduais. O mesmo pode estar ocorrendo no presente estudo, que a apesar de não ter tido este objetivo, constatou que as médias calóricas (variando de $1893,7 \mathrm{kcal}$ a $2047,5 \mathrm{kcal}$ ) dos adolescentes diferem numericamente de valores encontrados na literatura (variando de $2591 \mathrm{kcal}$ a 2794 kcal entre o gênero masculino e 2018 kcal a 2156 kcal no feminino, na Inglaterra, Escócia, Suíça) (Clavien et al 1996, Crawley 1997, Belton et al 1997) (Tabela 2).

A manutenção do consumo energético entre os dias da semana e o feriado indica que a qualidade alimentar foi alterada conforme o dia analisado, ou seja, foram feitas substituições de alguns grupos alimentares por outros (Tabela 3). Este fato é evidente em relação aos salgados (pão de queijo, pão de batata, coxinha, esfiha, rissólis, pastel, bolinho de chuva, bolinha de queijo e croissant), pois foi altamente consumido durante a semana, variando de 30 a $40 \%$, e baixando para $10 \%$ no feriado (Figura 16).

Parece evidente que o consumo deste grupo de alimento está vinculado ao local de maior permanência do adolescente, pois salgados são alimentos comercializados nas cantinas das escolas, local onde o adolescente passa cerca de 5 horas durante o período das aulas. 
A substituição qualitativa do grupo dos salgados, que gerou a manutenção calórica no feriado, provavelmente, ocorreu com os grupos do feijão e do macarrão (Tabela 7, 8 e 11). A indicação desses dois grupos se deu ao fato de terem sido os únicos alimentos com aumento significativo de consumo durante o feriado, apesar das quantidades em gramas consumidas terem permanecido semelhantes em todos os dias de análise (Tabela 4).

Essas substituições devem ser consideradas positivas à medida que a qualidade nutricional desses dois alimentos é melhor do que a dos salgados, pois em 100 gramas de alimento, um pão de queijo fornece 361 (kcal) e $15 \mathrm{~g}$ de gordura, o macarrão 148 kcal e $2 \mathrm{~g}$ e o feijão e 61 kcal e $2 \mathrm{~g}$ (Philippi et al 1996).

Outro aspecto a ser considerado é que $58 \%$ dos adolescentes não tomaram o café da manhã no feriado, indicando haver uma compensação energética na refeição seguinte e assim aumentando do consumo do feijão e macarrão (Tabela 7,8 ) e (Figura 17).

Os alimentos considerados "snacks" são aqueles alimentos consumidos principalmente nos intervalos das três principais refeições (café da manhã, almoço e jantar), mas levando-se em conta a qualidade nutritiva. Atualmente, esse tipo de alimento possui alta contribuição energética na alimentação não só de adolescentes como também de jovens adultos (Gama, 1999; Zizza et al 2001; Nielsen et al 2002).

Nos Estados Unidos os "snacks" mais consumidos são salgadinhos extrusados, doces, refrigerantes, bebidas lácteas e álcool (Zizza et al 2001; Nielsen et al 2002). No presente estudo, os alimentos mais freqüentemente escolhidos como "snacks" foram os salgados e refrigerantes, e diferindo do que Zizza et al (2001), 
encontraram, os grupos dos doces e os salgadinhos extrusados obtiveram uma freqüência muito baixa, não ultrapassando o número de 15 adolescentes por dia (Figura 16).

Com o aumento significativo do consumo de salgados durante a semana a a manutenção do consumo de refrigerante na maioria dos dias (feriado, quarta e quintafeira), pode-se mais uma vez associar o alto consumo à escola. Provavelmente devido à falta de supervisão dos pais, falta de opções na cantina e preferências alimentares, os adolescentes acabam ingerindo esses dois tipos de alimentos em grande quantidade podendo chegar a meio litro de refrigerante e 100 gramas de salgados, perfazendo um total calórico de 400kcal, por dia (Philippi et al 1996) (Tabela 4 e 5).

Sabe-se que a escola, nos EUA, possui uma grande influência nas escolhas alimentares dos adolescentes, possibilitando amplo acesso aos "snacks" e a alimentos ricos em gorduras. Apesar da realidade ser completamente diferente, pois nos os adolescentes americanos almoçam nas escolas, os aspectos relacionados a esse ambiente também devem ser considerados no Brasil (Story 2002).

Houve um declínio no consumo de refrigerante na segunda-feira, possivelmente, porque em nossa sociedade há uma tentativa de melhorar os hábitos alimentares no começo da semana. Essa melhoria é caracterizada pelo início de dietas restritivas ou regimes alimentares, que acometem especialmente adolescentes do gênero feminino (Barker 2000; Rolland-Cacherra et al. 2000) (Tabela 11). Outro aspecto relacionado ao sexo, é que adolescentes do gênero masculino consome 
refrigerante mais freqüentemente que do feminino, e que conforme ficam mais velhos a ingestão tende a aumentar (Cavadini et al 1999; Lien et al 2002).

Gama (1999) verificou que o consumo de refrigerante entre das adolescentes do gênero feminino, de uma escola estadual, variou 47,4 a 58,7\% e do masculino de 56,4 a $58,5 \%$ para diferentes estágios de vida.

O consumo energético proveniente dos "snacks" deve ser considerado um fator preocupante em vários aspectos. Primeiramente ingestão excessiva deste grupo alimentar está relacionada com a obesidade, e esta, às doenças crônicas não transmissíveis (Zizza et al 2001). Entre a NHANES II e III houve um aumento de 5 para $11 \%$ de obesidade entre os adolescentes de 12 a 19 anos de idade. Nos EUA o custo do tratamento da obesidade é estimado em torno de 68 bilhões de dólares, além dos gastos com propagandas de redução de peso e comidas especiais (Rosenbaum \& Leibel 1997, NCHS 2003). Em segundo lugar os adolescentes substituem grupos alimentares com uma qualidade nutritiva considerada adequada por esses alimentos pobres do ponto de vista nutricional. 


\section{Proteinas}

A distribuição percentual de contribuição de energia proveniente da proteína ultrapassou $15 \%$ em todos os dias analisados (Tabela 2), característica comumente encontrada na literatura (Nuzzo 1998; Dunker 1999, Gama 1999). Giovannini et al (2000) afirmam que a proporção de energia proveniente de proteínas deve se manter entre 12 a 14\%. Segundo as DRIs (2002) a distribuição aceitável de proteínas no estágio de vida entre 14 e 18 anos, para ambos os gêneros, varia entre 10 a 30\%.

Dentro do grupo de alimentos considerados fonte de proteínas, aquele mais freqüentemente consumido foi à carne bovina, variando de 58 a $64 \%$, enquanto o consumo do frango, variou de 19 a $25 \%$ de freqüência em todos os dias analisados (Figura 12). Âinda com relação à carne bovina, se observou um aumento significativo na quantidade em gramas consumida na segunda-feira, parecendo não haver nenhuma relação com qualquer outra variável do presente estudo, e assim, podendo ser considerado um acaso (Tabela 4).

Dentro dos padrões recomendados, da Pirâmide Alimentar Adaptada (PAA), se preconiza para o grupo das carnes, o consumo de 1 a 2 porções diárias. Somandose os grupos de carnes bovinos e frangos podem chegar em até 3 porções diárias, e mais uma vez ultrapassando as recomendações (Philippi et al 1999). 


\section{Carboidratos}

O consumo de carboidratos foi significativamente maior na quarta-feira em relação ao feriado, provavelmente devido ao aumento no consumo de arroz e de salgados (Tabela 3).

A ingestão do açúcar foi constante entre aos dias da semana e o feriado. Sua freqüência variou de 33 a $55 \%$ de adolescentes consumindo o alimento diariamente e a quantidade em gramas consumidas, variou de 28,0 a $41,6 \mathrm{~g}$, o equivalente a 1,25 colheres de sopa segundo a PAA. Provavelmente o seu consumo se deu em conjunto achocolatado devido suas freqüências semelhantes (Philippi et al 1999) (Tabela 4 e Figura 11).

Assim como no presente estudo, Cavadine et al (1999), verificaram que o grupo alimentar com maior freqüência de consumo foram os alimentos ricos em carboidratos, apenas diferindo nos tipos, sendo o arroz no primeiro caso e o pão no segundo (Figura 12). Essa diferença pode ter ocorrido, pois o consumo do arroz faz parte do hábito da população, da merenda escolar e é um alimento economicamente mais acessível. Essas características também auxiliam no entendimento da manutenção da quantidade de consumo deste alimento durante os todos os dias analisados (Tabela 4).

O pão não possuiu alterações em seu consumo, mas vale ressaltar que sua freqüência de consumo atingiu mais de $50 \%$ dos adolescentes em todos os dias de análise, indicando ser um alimento importante na dieta habitual dos adolescentes (Figura 13). 
Um aspecto interessante em relação ao macarrão é que houve uma diminuição no consumo na segunda-feira em relação ao feriado, parecendo indicar que nos finais de semana e feriados há uma tendência em se ingerir mais massa (Tabela 8).

Apesar do alto consumo de alimentos fonte de carboidrato, o percentual de contribuição energética desse nutriente não atinge os $50 \%$ do total de energia (Tabela 2). O valor estimado deve estar entre 55 a $60 \%$, e seu baixo consumo provavelmente é compensado pelo excesso de consumo de proteínas e gorduras (Giovannini et al 2000). Os valores sugeridos pelas DRIs (2002) de distribuição de carboidrato, para adolescentes entre 14 e 18 anos, variam de 45 a 65\%. Necessita-se de análises mais específicas e aprofundadas para verificação de distribuição deste nutriente e assim chegar a uma conclusão quanto sua adequação. 


\section{Gordura total e insaturada}

O excesso de consumo de gordura está vinculado às doenças crônicas não transmissíveis. O The National Cholesterol Education Program assim como The Dietary Guidelines for Americans recomendam que a dieta americana deve conter não mais que $30 \%$ de energia proveniente da gordura total. A Academia Americana de Pediatria (AAP) recomenda que a dieta do adolescente deva conter entre $20 \mathrm{e}$ $30 \%$ de energia proveniente da gordura. Para as DRIs (2002) os valores sugeridos para adolescentes entre 14 e 18 anos de ambos os gêneros é de 25 a 35\% (US Department of Health and Human Services 1991, AAP 1998; Nicklas et al. 2000; US Department of Agriculture and Health and Human Services 2000; Prochaska et al. 2001; DRI 2002).

No cenário geral, esse consumo recomendado de gordura total está longe de ocorrer. Estudo com 319 adolescentes, com média de idade de 14,8 anos, avaliou o consumo alimentar por meio do recordatório 24 horas, resultando em cerca de $19 \%$ dos indivíduos ingeriram mais de $40 \%$ de energia proveniente de gorduras (Nicklas et al. 2000). Feunekers et al (1998) em estudo realizado nos Estados Unidos, verificaram que o consumo de gordura total é maior em adolescentes do que em adultos e as médias de consumo foram de $41,0 \%$ para gênero feminino e $42,4 \%$ no masculino. Somando-se a isso, Samuelson (2000) mostrou que adolescentes dinamarqueses consumiam $34 \%$ de gorduras; os finlandeses $39 \%$ para o gênero masculino e $37 \%$ para o feminino e suíços de $32 \%$.

O excesso de consumo de gordura total não foi diferente nos adolescentes no presente estudo, os percentuais de energia proveniente de gordura total foram de: 
$34 \%, 37 \%, 36 \%$ e $36 \%$ no feriado, na segunda, na quarta e quinta-feira respectivamente (Tabela 2). Como não houve diferenças no consumo entre os dias analisados, o consumo excessivo de gordura total, segundo a APP, é constante na dieta do adolescente, independendo se é feriado ou dia de semana (Tabela 3).

Para gordura insaturada, constatou-se que houve um consumo maior na segunda e quarta-feira em relação ao feriado, parecendo haver uma tendência de aumento de consumo desse nutriente durante a semana. $O$ incremento da desta gordura deve ser considerado um fator positivo no consumo alimentar dos adolescentes, levando a crer que durante os dias úteis seus hábitos alimentares são mais saudáveis (Tabela 3). 


\section{Fibras}

Com relação às fỉbras, houve aumento na quantidade consumida durante a semana, devido a um provável estímulo dos pais ao consumo (Tabela 3 ). Os feriados, finais de semanas e férias são costumeiramente considerados dias para "relaxar", "descansar" e "se divertir", e devido a isso as frutas e verduras, itens alimentares pouco apreciados pelos adolescentes, são excluídos conseqüentemente diminuindo a ingestão de fibras.

Apesar dessa melhora no consumo de fibras durante os dias da semana, ele ainda é baixo variando de 9,3 a 11,8g diárias (Tabela 3). A recomendação segundo a American Health Fundation (AFF) é de $5 \mathrm{~g}$ de fibra somado a $1 \mathrm{~g}$ multiplicada pela idade do indivíduo, ou seja, para um adolescente com 15 anos, a recomendação é 20 gramas (Nicklas et al. 2000). Para as DRIs (2001), a ingestão adequada de fibras é de $38 \mathrm{~g}$ por dia para o gênero masculino e $26 \mathrm{~g}$ para o feminino em indivíduos entre $14 \mathrm{e}$ 18 anos.

O consumo baixo de fibras é um fator preocupante não só aqui, mas em todo o mundo, Rockett et al (2001) em estudo com mais de 16 mil adolescentes encontraram um consumo médio de fibras de $16 \mathrm{~g}$ para o gênero feminino e $17 \mathrm{~g}$ para o gênero masculino. Ainda nos EUA entre 1989 e 1991 estudo mostrou que a média de consumo de fibras entre individuos de 2 a 19 anos de idade foi de $11,7 \mathrm{~g}$, valor muito semelhante ao encontrado no presente estudo (Muñoz et al 1997).

Nicklas et al (2000) verificaram entre dois grupos, o consumo de fibras diárias. O primeiro possuía um consumo considerado baixo e o segundo alto, sendo o critério de $<15 \mathrm{~g}$ de fibras por dia, para o baixo consumo $\mathrm{e}>20 \mathrm{~g}$ para o alto, 
segundo as recomendações da AHF para um adolescente de 15 anos. Assim, o consumo entre as adolescentes do gênero feminino para os dois grupos foi respectivamente de $9,0 \mathrm{~g}$ e $24,9 \mathrm{~g}$ por dia e para o gênero masculino $10,2 \mathrm{~g}$ e $29,8 \mathrm{~g}$.

O baixo consumo de fibras está relacionado à ausência das frutas e verduras no dia alimentar. Apesar do consumo de frutas ter se mantido e o de vegetais ter aumentado, nos últimos 30 anos nos Estados Unidos, suas ingestões ainda foram considerados baixos. Elas corresponderam a 1,4 porções de frutas e 3 porções de verduras, segundo a Pirâmide Americana que recomenda a ingestão de 2 a 4 porções diárias de frutas e de 3 a 5 porções diárias de verduras (USDA 1992; Muñoz et al 1997; Cavadini et al $2000^{\mathrm{a}}$ ).

Tanto as frutas como as verduras obtiveram um consumo constante entre a semana e o feriado, mas não freqüente variando por volta de $30 \%$ (Tabela 9) e (Figura 14). A baixa freqüência somou-se a pouca quantidade consumida, sendo que para as frutas variou de 228,8 a $323,5 \mathrm{~g}$ e para as verduras de 67,3 a $94,4 \mathrm{~g}$ (Tabela 5). Esses valores equivalem a 2 porções de frutas (exemplo: uma maçã e meio mamão papaia) e 1 porção de verduras (exemplo: 1 colher e meia de sopa de cenoura cozida) não atingindo o recomendado de 3 a 5 porções de frutas e 4 a 5 porções de verduras, segundo a PAA (Philippi et al 1999).

No presente estudo, a alface foi avaliada separadamente e a média de quantidade consumida foi maior na segunda-feira em relação aos outros dias (feriado, quarta e quinta-feira) (Tabela 4 e 9). Esse aumento de consumo em um dia específico talvez possa ser explicado pelo mesmo motivo que o refrigerante tenha 
decaído, ou seja, o início da semana parece levar os adolescentes a uma tentativa de melhoria no padrão alimentar.

De modo geral a quantidade consumida do grupo da alface pode variar de $1 / 3$ de porção a uma, segundo a PAA e conforme a folha selecionada. Mesmo somando o número de porções obtidas pelo consumo do grupo de verduras, o total seria 2 porções, metade da porção mínima estipulada (Philippi et al 1999).

Lien et al. (2002) verificaram em estudo de coorte que os adolescentes ao mudarem de faixa etária diminuem o consumo diário de frutas e vegetais. Cerca $53 \%$ dos adolescentes do gênero masculino com 14 anos consumiam frutas diariamente e $43 \%$ consumiam vegetais, aos 21 anos esse número caiu para $20 \%$ para o primeiro grupo e $22 \%$ para o segundo, o mesmo ocorreu com o gênero feminino variando de 59 para $29 \%$ em relação às frutas e de 39 para $22 \%$ das verduras. Esses dados indicam que conforme os adolescentes vão se tornando adultos, o consumo desses alimentos diminuem, colocando sua saúde em risco, pois o que já era consumido em baixa quantidade tende a piorar. Ainda a relação de consumo entre os gêneros indica que as meninas tendem a consumir mais frutas e verduras do que os meninos, ou seja, a ingestão de fibras é maior entre o gênero feminino (Cavadini et al 1999, Lien 2002). 


\section{Vitamina $C$}

Com relação ao consumo de vitamina $C$, observou-se uma melhoria no consumo durante os dias da semana em relação ao feriado. Isso pode ter ocorrido pelos mesmos motivos do aumento do consumo de fibras, pois os alimentos ricos em vitamina $C$ também são ricos em fibras (Tabela 3). Confirmando esse dado, Nicklas et al. (2000) em estudo com adolescentes, observaram que aqueles que consumiram mais fibras e menos gorduras obtiveram maior consumo de vitamina $\mathrm{C}$.

$\mathrm{O}$ incremento da ingestão de vitamina $\mathrm{C}$ durante a semana aproxima-se muito dos valores de referencias, segundo as DRIs (2001), que são de 75mg (14-18 anos) por dia para o gênero masculino e $65 \mathrm{mg}$ para o feminino, pois de $56,0 \mathrm{mg}$ consumidas no feriado, passou a $64,9 \mathrm{mg}$ na segunda-feira, $76,7 \mathrm{mg}$ na quarta-feira e 69,4 mg na quinta-feira (Tabela 3).

Nos Estados Unidos, o consumo de vitamina C não gera preocupações, pois estudos mostram que o consumo deste nutriente se martém constante ao longo dos arios e que atingem as recomendações (Muñoz et al. 1997; Cavadini et al. 2000a; Rockett et al. 2001). Ao analisar diversos estudos realizados na Espanha, Portugal e Grécia, Cruz (2000), verificou essa mesma constância nos dados.

Apesar dos valores ingeridos serem melhores durante a semana, deve-se incentivar o aumento da ingestão dessa vitamina também nos feriados e finais de semanas para que haja uma manutenção do consumo. 


\section{Cálcio}

O consumo de cálcio foi significativamente maior apenas em um dia da semana em relação ao feriado, podendo-se assim considerar seu consumo semelhantes entre os dias de semana e do feriado. Apesar desta constante, a média de cálcio consumida por dia, $580 \mathrm{mg}$ no feriado, $629,9 \mathrm{mg}$ segunda-feira, $635,5 \mathrm{mg}$ na quarta-feira e 496,1 mg na quinta-feira (Tabela 3), provavelmente não atingiu as recomendações, que segundo as DRIs devem ser de $1300 \mathrm{mg}$ entre 14 e 18 anos para ambos os gêneros (DRI 2001).

No estudo de Cavadine et al (2000a), a tendência de consumo de cálcio ao longo de 30 anos, foi uma diminuição significativa, passando de $1100 \mathrm{mg}$ por diâ em 1965 a $960 \mathrm{mg}$ em 1996. Mesmo com a diminuição do consumo os adolescentes estudados obtiveram um consumo muito superior aos do presente estudo, mostrando que provavelmente a situação em relação a esse nutriente seja crítica (Tabela 3).

O baixo consumo de cálcio na adolescência é um fator preocupante, pois está relacionado, principalmente entre as meninas, a osteoporose na idade adulta. Estudo ao analisar mais de 16 mil adolescentes entre 9 e 14 anos, verificou que apenas as meninas não atingiram a recomendação de cálcio (Cavadine et al. 2000a; Rockett et al. 2001).

A aquisição de massa óssea é gradual durante a infância e acelerada durante a adolescência, até que o indivíduo atinja a maturidade sexual. Quase $50 \%$ da massa óssea é adquirida, pois o acúmulo de cálcio é triplicado nessa fase da vida. Maximizar pico de formação óssea é uma forma de prevenção da osteoporose e a osteopenia (Burke 1994; Wiggins \& Wiggins 1997; Nattiv \& Armsey 1997). 
A ostcoporose é a doença em que ocorre importante perda de densidade óssea, aumentando assim sua fragilidade e a tendência às fraturas. Nos Estados Unidos essa doença atinge cerca de 25 milhões de pessoas, ocasionado 1,5 milhões de fraturas por ano, representando cerca de 6 bilhões de dólares gastos por ano, tornando-a sério problema de saúde pública (Wiggins \& Wiggins 1997; West 1998).

O baixo consumo de cálcio normalmente ocorre devido à diminuição no consumo de leites e demais produtos lácteos. Em contraste a esse aspecto mais de $60 \%$ dos adolescentes consumiram leite, sendo que em todos dias da semana em relação ao feriado não houve alteração no consumo, além disso, por volta de $20 \%$ de adolescentes consumiram queijos em todos os dias analisados (Figuras 11 e 15).

Apesar da freqüência de consumo do grupo de leite atingir mais de 50\% dos adolescentes, está longe de ser considerada satisfatória. Na Suíça, estudo com questionário de frequêencia alimentar verificou que o consumo diário de produtos lácteos não chegava a $50 \%$ dos adolescentes, colocando-os em risco de baixo consumo de cálcio (Cavadini et al 1999).

A ingestão insuficiente encontrada para esse mineral, provavelmente ocorreu pela constância de baixas quantidades, pois se consumiu por volta de um copo de leite e uma fatia de queijo por dia, o equivalente a 2 porções segundo PAA.

Na Pirâmide Americana, assim como na PAA, o número de porções de leite e produtos lácteos a serem consumidas é de 3 , indicando que à quantidade de porções consumidas pelos adolescentes estudados, não atingiram o recomendado (Muñoz et al. 1997; Philippi et al 1999; Rockett et al. 2001). 
Ao contrário deste resultado, alguns estudos nos Estados Unidos verificaram que a média de consumo para esse grupo alimentar atingiu o recomendado. Contudo, sabe-se que o consumo de produtos lácteos vêem diminuindo nos últimos anos entre os adolescentes no mesmo país (Muñoz et al. 1997; Cavadini et al 2000a; Rockett et al. 2001).

O cálcio é um nutriente que deve ser analisado mais profundamente, especialmente em adolescentes para que haja a prevenção contra doenças relacionadas à falta deste mineral. 


\section{Ferro}

No presente estudo os adolescentes mantiveram uma ingestão de ferro semelhante em todos os dias da semana, variando de 11,3 a 12,0mg (Tabela 3). Segundo as DRIs os indivíduos do gênero masculino entre 14 a 18 anos devem consumir $11 \mathrm{mg}$ de ferro por dia e do gênero feminino $15 \mathrm{mg}$ (DRI 2001).

A manutenção no consumo de ferro provavelmente ocorreu devido à ingestão de carne bovina, principal grupo fornecedor desse mineral (Tabela 4). Nos EUA a tendência de consumo desse nutriente foi de aumento ao longo de 30 anos, apesar disso muitos adolescentes não atingem a recomendações para o mineral (Muñoz 1997; Cavadini et al $2000^{\mathrm{a}}$ ).

O ferro é essencial para o crescimento e desenvolvimento do adolescente que é particularmente vulnerável à sua deficiência, devido ao aumento das necessidades desse mineral, imposto pela rápida expansão da massa celular vermelha e pelo crescimento de tecidos (INACG 1979). O baixo consumo de ferro acarreta em anemia ferropriva que atinge cerca de 1,5 a 2 bilhões de pessoas em todo o mundo (Herschbruch et al 1999, Silva 2000). 


\section{Refeições}

Com relação à distribuição de refeições dos adolescentes durante a semana, observou-se que as refeições consideradas principais como o café da manhã, almoço e jantar foram aquelas que possuíram as maiores freqüências variando entre $80 \%$ a $97 \%$ de consumo (Figuras $17,19,21$ ). Os adolescentes americanos também possuem uma frequêencia de consumo das principais refeições semelhante ao presente estudo, porém variando de $67 \%$ a $79 \%$ (Lien 2001$)$.

No feriado, constatou-se uma queda de $40 \%$ na freqüência de consumo do café da manhã, havendo significativa mudança entre os adolescentes que consumiam e os que deixaram de consumir (Tabela 12). Essa redução pode ser justificada pela possibilidade do individuo dormir até mais tarde no feriado, acordando diretamente para o almoço. A não variação do consumo de energia entre o feriado e os outros dias parece indicar que houve a compensação energética em outras refeições (RollandChacherra et al 2000).

Com exceção do feriado, devido à queda no consumo, de maneira geral, diferente de outros países onde a freqüência do café da manhã é considerada baixa, no presente estudo ela atinge cerca de $80 \%$ dos adolescentes, indicando que esta situação não é tão alarmante como os descritos na literatura (Cavadini 1999; Slater 2001; Samuelson 2000, Cruz 2000; Spear 2002). Gambardella et al (1999) também encontraram que $82 \%$ dos adolescentes consumiam algum tipo de alimento no café da manhã. Apesar disso, apenas $45 \%$ consumiram o que os autores consideraram ideal para a refeição (Figura 17). 
Com relação aos lanches intermediários, no feriado e na segunda-feira, um maior número de adolescentes consumiram o lanche da manhã e da tarde. Na quarta e quinta-feira, o lanche da tarde foi o mais consumido entre os adolescentes (Figura 23). De uma forma geral, o lanche menos consumido é o da noite, provavelmente pela proximidade do jantar com o horário de dormir que conseqüentemente distancia o almoço do jantar, aumentando o consumo do lanche da tarde.

Apesar da constância do consumo dos lanches intermediários nos 4 dias de análise, discute-se que para uma melhor distribuição energética e qualitativa durante o dia alimentar, deve-se aumentar a freqüência dos mesmos. Especialmente o lanche da noite que atinge apenas $20 \%$ de consumo.

É importante salientar que os lanches intermediários são fundamentais para diminuir a tempo de jejum dos adolescentes, mas sua qualidade nutricional deve ser alta para que haja uma diferenciação dos "snacks". 


\section{CONCLUSÕES}


De uma forma geral a variável dia da semana não influenciou no consumo de energia, carboidratos, proteínas, gordura total, cálcio e ferro. Com relação à gordura insaturada, fibras e vitamina $\mathrm{C}$ houve uma significativa melhora no consumo durante os dias úteis da semana analisados.

Os únicos alimentos que obtiveram uma quantidade de consumo alterada o foram alface e carne bovina na segunda-feira. Com relação aos outros grupos de alimentos, a quantidade média consumida foi igual entre o feriado e os três dias da semana, segunda, quarta e quinta-feira. Quanto à freqüência de consumo, os grupos que obtiveram alteração em relação ao feriado foram: alface (aumentou na segundafeira); arroz (aumentou na segunda e quarta-feira); salgados (aumentou em todos os dias úteis); feijão (aumentou na segunda e quarta-feira); macarrão e refrigerante (diminuíram na segunda-feira).

Quanto à realização das refeições, o café da manhã sofreu grande influência da variável dia da semana, tendo um decréscimo em sua freqüência de consumo. $O$ almoço e jantar obtiveram freqüências altas e semelhantes durante todos os dias analisados. O lanche da noite é o menos consumido e o fato do lanche da tarde ter sido o mais consumido na quarta e quinta-feira pode ser considerado um evento aleatório, excluindo assim a influência da variável dia da semana tanto no lanche da manhã como no da tarde. 


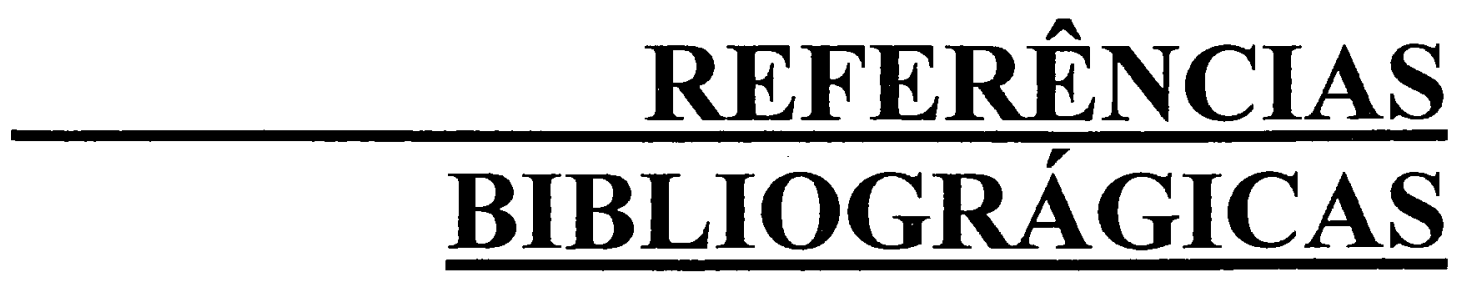


1. Adamson AJ, Rugg Gunn AJ, Butler TJ, Appleton DR. The contribution of foods from outside the home to the nutrient intake of young adolescents. $\mathbf{J}$. Hum. Nutr. Diet. 1996; (9): 55-68.

2. Albano RD, Souza SB. Estado Nutricional de adolescentes: "risco de sobrepeso" e "sobrepeso" em uma escola pública do município de São Paulo. Cad. Saúde Pública. 2001; 17(4):941-47.

3. [AAP] American Academy of Pediatrics, Committee on Nutrition. Cholesterol in children. Pediatrics. 1998; 101:141-47.

4. Arija V, Salvadó JS, Fernández-Ballart J, Cucó G, Mart-Henneberg C. Consumo, hábitos alimentarios y estado nutricional de la población de Reus. Evolución de la ingestión de energia y nutrientes entre 1983 y 1993. Med Clin; 1996; (106) 45-50

5. Barker M, Robinson S, Wilman C, Barker DJP. Behaviour, body composition and diet in adolescent girls. Appetite. 2000; (35):161-170.

6. Belton NR, Macvean ADL, Richards ND, Elton RA, Moffat WMU, Beattie TF. Nutrient intake in Scottish adolescents. Proc. Nutr. Soc. 1997; (56) $303 \mathrm{~A}$.

7. Bianculli $\mathrm{CH}$, Crecimiento físico y endocrinología en la pubertad In: Maddaleno M; Munist MM; Serrano CV; Silber TJ; Ojeda ENS, Yunes J. La salud del adolescente y del joven. Oganización Panamericana de La Salud, Washington, EUA, 1995 publicación científica n552 p.87-94. 
8. Burke L. Sports amenorrhea, osteopenia, stress fratures and calcium. In: Bruke L, Deakin V. Clinical Sports Nutrition. Australia:McGraw-Hill Book Company; 1994. p. 200-26.

9. Campos, ALR de. Aspectos psicológicos da obesidade. In: Fisberg M. Obesidade na infância e adolescência. São Paulo: Fundação BYK; 1995. p. $71-79$.

10. Cavadini C, Decarli B, Dirren H, Cauderay M, Narring F, Michaud PA. Assessment of adolescent food habits in Switzerland. Appetite. 1999; (32): $97-106$.

11. Cavadini C, Decarli B, Grin J, Narring F, Michaud PA, Food habits and sport activity during adolescence: differences between athletic and non-athletic teenagers in Switzerland. European Journal of Clinical Nutrition. 2000; 54 (Suppl 1):S16-S20b.

12. Cavadini C, Siega-Riz AM, Popkin BM. US adolescents food intake trendas from 1965 to 1996. West J Med. 2000; (173): 378-83a.

13. Choquet $M$ \& ledoux S. Adolescents. Enquête Nacionale. Paris. Ed. INSERM, 1994.

14. Clavien H, Theintz G, Rizzoli R, Bonjour JP. Does Puberty alter dietary habits in adolescents living in a western society? Journal of Adolescent Health. 1996; (19):68-75. 
15. Colli, A.S. Conceito da Adolescencia. In: Marcondes E. Pediatria Básica. $8^{\text {a }}$ ed. São Paulo:Sarvier; 1999. p. 539a.

16. Colli, A.S. Crescimento e desenvolvimento. In: Marcondes E. Pediatria Básica. $8^{a}$ ed. São Paulo: Sarvier; 1999. p. 544-50b.

17. Crawley H. Dietary and lifestyle differences between Scottish teenagers and those living in England and Wales. Eur. J. Clin. Nutr. 1997; (51)87-91

18. Cruz JAA. Dietary habits and nutritional status in adolescents over Europe Southern Europe. European Journal of Clinical Nutrition. 2000; 54(Suppl 1):S29-S35.

19. Domel SB, Baranowski T, Leonard SB, Davis H, Riley P, Baranowski J. Accuracy of fourth- and fifth-grade stuuents food records compared with school-lunch observations. Am J Clin Nutr 1994; 59 Suppl:21 8S-20.

20. Dunker KLL. Avaliação Nutricional e comportamento alimentar de adolescentes com sintomas de anorexia nervosa. São Paulo; 1999. [Dissertação de Mestrado - Universidade de São Paulo - Curso de PósGraduação Interunidades em Nutrição Humana Aplicada -PRONUT ].

21. Dunker KLL, Philippi ST. Evaluation of the food intake of adolescents: 24 hour dietary recall "modified". In: The Fifth International Conference on Dietary Assessment Methods. Expanding the horizon: dietary assessment in a mutl-cultural world. 26 a 29/01/2003; Chiang Rai, Thailand, 2003. 
22. Dwyer J. Avaliação do consumo alimentar. In Shills ME, Olson JA, Shike M, Ross AC. Tratado de nutrição moderna na saúde e na doença. $9^{a}$ ed. Manole; 2003. p.1001-26.

23. Dwyer J. Dietary Assessment. In Shills ME, Olson JA, Shike M. Modern Nutrition in health and disease. $8^{a}$ ed. Lea \& Febiger; 1994. p.842-60.

24. Eisenstein, E Nutrición y salud em la adolescência In: Maddaleno M; Munist MM; Serrano CV; Silber TJ; Ojeda ENS, Yunes J. La salud del adolescente y del joven. Oganización Panamericana de La Salud, Washington, EUA, 1995 publicación científica n552 p.144-54

25. FAO/OMS. Alimentación y nutrición: creación de un mundo bien alimentado. Roma: Organización de las naciones Unidas para la Agricultura y la Alimentación; 1992.

26. Feunekes G I, Graaf Cees, Meyboom S, Staveren WA. Food choice and fat intake of adolescents and adults: associations of intakes within Social Networks. Preventive Medicine. 1998; (27): 645-56.

27. Frank GC. Environmental influences on methods used to collest dietary data from children. Am J Clin Nutr 1994; 59 Suppl:20 7S-11.

28. Gama, CM. Consumo alimentar e estado nutricional de adolescentes matriculados em escolas da rede particular e estadual do bairro de Vila Madalena, São Paulo. São Paulo, 1999 [Tese de Doutorado - Universidade Federal de São Paulo - Escola Paulista de Medicina]. 
29. Gambardella, AMD Adolescente, estudantes de período noturno: como se alimentam e gastam suas energias. São Paulo, 1995. [Tese de Doutorado Faculdade de Saúde Pública da USP].

30. Gambardella AMD, Frutoso MFP, Franchi, C. Prática alimentar de adolescentes. Rev. Nutr. Campinas. 1999; 12(1):55-63.

31. Gibson RS. Principles of Nutritional Assessment New York: Oxford University Press; 1990. Food Consumption of individual; p. $37-51$.

32. Giovannini M, Agostini C, Gianní M, Bernardo L, Riva E. Adolescence: macronutrient needs. European Journal of Clinical Nutrition. 2000; 54 (Suppl 1):S7-S10.

33. Harel Z, Riggs S, Vaz R, White L, Menzies G. Adolescents and calcium: what they do and do not know and how much they consume. Journal of Adolescent Health. 1998. 22: 225-28.

34. Herschbrch MD, CASTRO MS. Anemia Ferropriva e o efeito de alguns alimentos na biodisponibilidade de ferro na dieta. ["on line"] São Paulo, 1999. < URL: http://207.159.134.59/nutri/aplpesq.htm > [1999 maio 17].

35. [IBGE] Fundação Instituto Brasileiro Geografia e Estatística - Censo demográfico Brasil 2000: Resultados Universo - Tabela da População residente, por situação de domicílio e sexo segundo grupos de idade - Brasil. Disponível em <URL: www.ibge.net/home/estatistica/populacao/censo2000/tabelabrasil11.shtm> [2002 Maio 25]. 
36. [INACG] International Nutritional Anemia Consultative Group - Iron deficiency in infancy and childhood. Washington, DC, 1979.

37. Liu K. Statistical issues related to semiquantitative food-frequency questionnaires. Am J Clin Nutr 1994; 59: 262S-265S.

38. Lian N, Lytle L, Klepp KI. Stability in consumption of fruit, vegetables, and sugary foods in a Chort from 14 to age 21. Prev Med. 2001; 33: 217-26.

39. Lytle LA. Nutricional issues for adolescents. Journal of the American Dietetic association. 2002; 3(suppl 102):S8-S12

40. Majem LIS. Evaluación del consumo de alimentos en poblaciones. Encuestas alimentarias. In: Serra Majem L. Nutrición y Salud Pública: métodos, bases científicas y aplicaciones. España: Masson; 1995. p. 90-96.

41. Majem LIS., Bartrina J.A. Introducción a la epidemiología nutricional. In: Serra Majem L. Nutrición y Salud Pública: métodos, bases científicas y aplicaciones. España: Masson; 1995. p. 59-65.

42. Majem LIS, Barba Recordatorio de 24 horas In: Serra Majem L. Nutrición y Salud Pública: métodos, bases científicas y aplicaciones. España: Masson; 1995. p. 113-9.

43. McPherson RS., Hoelscher D.M., Alexander M., Scanlon K.S., Serdula M.K. Dietary Assessment Methods Among School-Aged Children: Validity and Reliability. Preventive Medicine 2000; 31:S11- S33. 
44. Monteiro CA, Mondini L, Souza M, Popkin BM. The nutrition transition in Brazil. European Journal of Clinical Nutrition. 1995; 49: 105-113.

45. Monteiro CA. Velhos e novos males da saúde no Brasil de São Paulo. São Paulo: Ed HUCITC, 1995.

46. Monteito CA, Epidemiologia da Obesidade In: Halpern A. Obesidade São Paulo:Editora Lemos Editorial 1998. p. 15-30.

47. Muñoz KA, Krebs-Smith S, Ballard-Barbash R, Cleveland L. Food intakes of US children and adolescents compared with recommendations. Pediatrics. $1997 ; 100(3): 323-329$.

48. [NAS/NRC] National Academy of Sciences, National Research Council. Methodological Considerations in Evaluating the Evidence. In: Diet and Health: Implication for reducing chronic disease risk. Washington: National Academic Press; 1992. p.23- 40.

49. Nattiv A, Armsey JR TD. Stress injury to bone in the female athlete. Clinics Sports Medicine. 1997; 16(2):197-224.

50. [NCHS] National Center for Health Statistics - Prevalence of overweigh among children and adolescents: United States 1999-2003 Disponível em <URL:http://www.cdc.gov/nchs/products/pubs/pubd/hestats/overwght99.htm \#Table 1.> [2003 Abril 23]. 
51. Nicklas TA, Myers L, O’Neil C, Gustafson N. Impact of Dietary fat and fiber intake on nutritional intake of adolescents. Pediatrics. 2000 105(2):1-7.

52. Nielsen SJ, Siega-Riz AM, Popkin, BM. Trends in Energy intake in U.S. between 1977 and 1996: similar shifts seen across age groups. Obesity Researh. 2002. 10(5):370-378.

53. [NRC] National Research Council. Dietary Reference Intakes. Applications in Dietary Assessment. Washington DC: National Academy Press, 2001.

54. [NRC] National Research Council. Dietary Reference Intakes for Energy, Carbohydrate, Fiber, Fat, Fatty Acids, Cholesterol, Protein, and Amino Acids (Macronutrients). Washington DC: National Academy Press, 2002.

55. Nuzzo, L Avaliação do estado nutricional de adolescentes de uma instituição particular de ensino São Paulo; 1998. [Dissertação de Mestrado Universidade de São Paulo - Faculdade de Saúde Pública - FSP].

56. Olmedilla B \& Granado F. Growth and micronutrient needs of adolescents. European Journal of Clinical Nutrition. 2000; 54 (Suppl 1):S11-S15.

57. [OMS] Organizacion Mundial de la Salud. La salud de los Jóvenes: Un reto y una Esperanza. Geneva: OMS 1995.

58. Parry-Jones, W. Ll. Psychological and psychiatric aspects of adolescence. Int. Child_Health. 1994; (5):23-31. 
59. Philippi ST, Latterza AR , Cruz ATR, Ribeiro LC Pirâmide alimentar adaptada: Guia para escolha dos alimentos. Rev Nutr. 1999; 12(1):65-80.

60. Philippi ST, Szarfarc SC, Latterza AR. Virtual Nutri (software) versão 1.0 , for windows. Departamento de Nutrição da Faculdade de Saúde Pública / USP. São Paulo; 1996.

61. Philippi, S T. Hábitos alimentares. Bol. Técnico. 1992; (1):1-6.

62. Popkin BM, Keyou G, Fengying Z, Guo X, Ma Haijiang, Zohoori N. The nutrition transition in China: a cross-section analysis. Eur J Clin Nutr. 1993; 47: $333-46$.

63. Popkin BM. Nutritional patterns and transitions. Population and Development Review. 1993; 19:810-13.

64. Prochaska J, Sallis JF, Rupp J. Screening measure for assessing dietary fat intake among adolescents. Prev. Med. 2001; 33: 699-706.

65. Rockett HRH, Berkey CS, Field AE, Colditz GA. Cross-sectional measurement of nutrient intake among adolescents in 1996. Prev med. 2001; $33: 27-37$

66. Rolland-Cacherra MF, Bellisle F, Deheeger M. Nutritional status and food intake in adolescents living in Western Europe. European Journal of Clinical Nutritrion. 2000; 54 (Suppl 1):S41-S46.

67. Rosenbaum M, Leibel RL. Obesity. N Engl. J. Med. 1997; 337: 396-407. 
68. Saito, MA. Crescimento e desenvolvimento. In: Marcondes E. Pediatria Básica. $8^{\mathrm{a}}$ ed. São Paulo: Sarvier; 1999. p. 555-60.

69. Samuelson G. Dietary habits and nutritional status in adolescents over Europe. An overview of current studies in the Nordic Countries. European Journal of Clinical Nutrition. 2000; 54 (Suppl 1):S21-S28.

70. Schmidt, E. Obesity in Adolescence. Int. Child Health; 1994 5(1):15-22.

71. Silva KL. Revisão da literatura In: Internatina Life Sciences Institute Brasil Enriquecimento e restauração de alimentos com micronutrientes: uma proposta para o Brasil. São Paulo, 2000. p.15 -41.

72. Slater, ES. Desenvolvimento e avaliação de um questionário semiquantitativo de freqüência alimentar para adolescentes. São Paulo; 2001. [Tese de Doutorado - Apresentada à Universidade de São Paulo - Faculdade de Saúde Pública].

73. Spear BA. Adolescent growth and development. Journal of The American Dietetic Association. 2002; 3(suppl 102): S23-S31.

74. Story M, Neumark-Sztainer D, French S. Individual and environmental inflences on adolescent eating behaviors. Journal of the American Dietetic association. 2002; 3(suppl 102):S40-S51

75. Thompson FE, Byers T. Dietary Assessment Resource Manual. J Nutr 1994; $124: 2245 S-2317 S$. 
76. Treiber FA, Leonard SB, Frank G, Musante L, Davis H, Strong WB, Levy M. Dietary assessment instruments for preschool children: reability of parental responses to the 24 hour recall and food frequency questionnaire. J Am Diet Assoc 1990; $90(6): 814-20$.

77. [USDA] United States Department of Agriculture. The food Guide Pyramid. Washington DC; 1992.

78. US Department of Agriculture and Health and Human Services. Nutrition and your health: dietary guidelines for Americans. $5^{a}$ ed: Washington. US Department of Agriculture and Health and Human Services; 2000. Home and Garden Bulletin 232.

79. US Department of Health and Human Services. National Cholesterol Education Program: report of the expert panel and blood cholesterol levels in Children and adolescents. Washington DC: US Department of Health and Human Services; 1991. NIH publication 91-2732.

80. Verdú JM, Gonzaléz Л. Evaluación del estado nutricional. In: Serra Majem L. Nutrición y Salud Pública: métodos, bases científicas y aplicaciones. España: Masson; 1995. p. 73-89.

81. West RV. The female athlete. The triad of disordered eating, amenohrrea and osteporosis. Sports Medicine. 1998;26(2): 63-71.

82. Willett WC. Nutrition and epidemiology. Nature of Variation in Diet. New York: Oxford University Press; 1998. P. 33-49. 
83. Willett WC. Future direction in the development of food-frequency. Am J Clin Nutr 1994; 59 (suppl):171S - 4S.

84. Wiggins DL, Wiggins ME. The female athlete. Clinics Sports Medicine. $1997 ; 16(4):$ 593-612.

85. Zizza C, Siega-Riz AM, Popkin BM. Significant Increase in Young Adults Snacking between 1977-1978 and 1994-1996 represents a cause for concern! Preventive Medicine. 2001; (32): 303-10. 
ANEXOS 
Komogorov-Smirnov - aderência à curva normal para energia e nutrientes

Figura 24: Distribuição da curva normal para as médias de energia consumidas no feriado, segunda-feira, quarta-feira e quinta-feira, de uma Escola Estadual do Município de São Paulo em 1999.

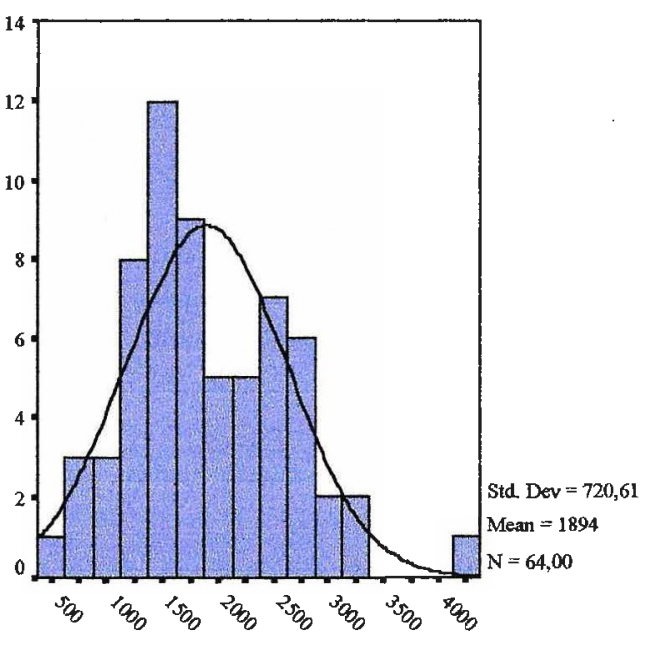

energia feriado

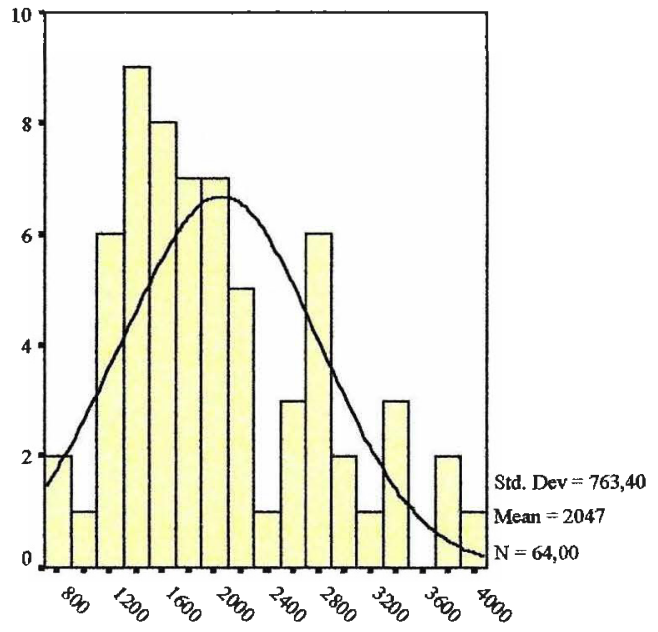

energia $4 \mathrm{a}$

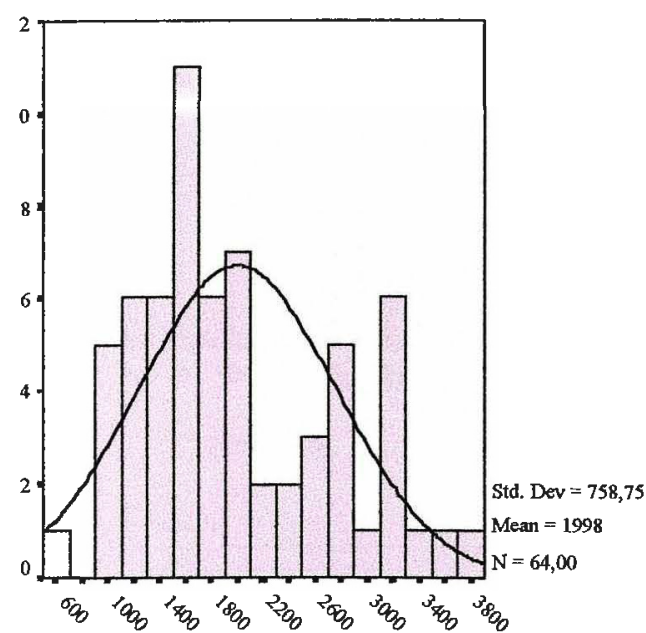

energia $2 a$

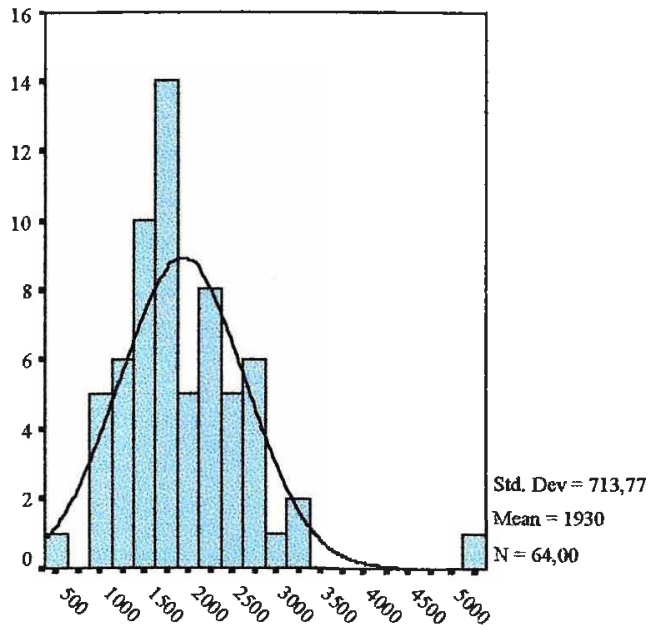

energia 5 a 
Figura 25: Distribuição da curva normal para as médias de proteína consumidas no feriado, segunda-feira, quarta-feira e quinta-feira, de uma Escola Estadual do Município de São Paulo em 1999.

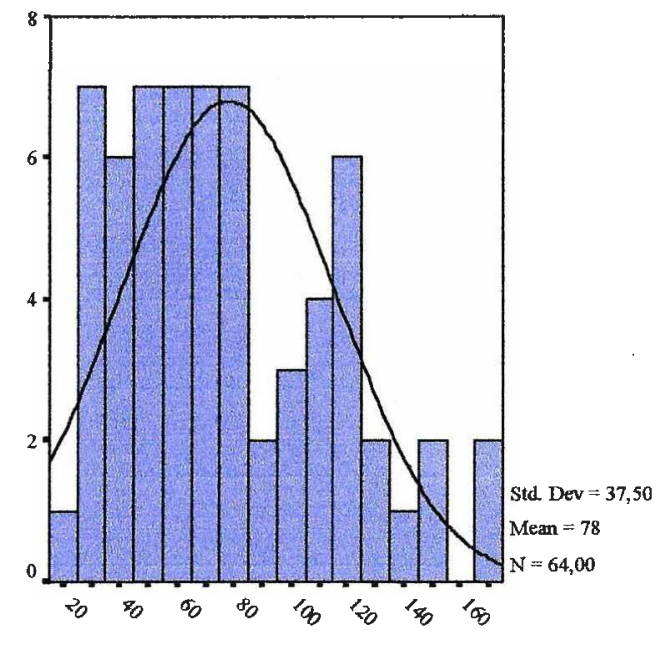

proteína feriado

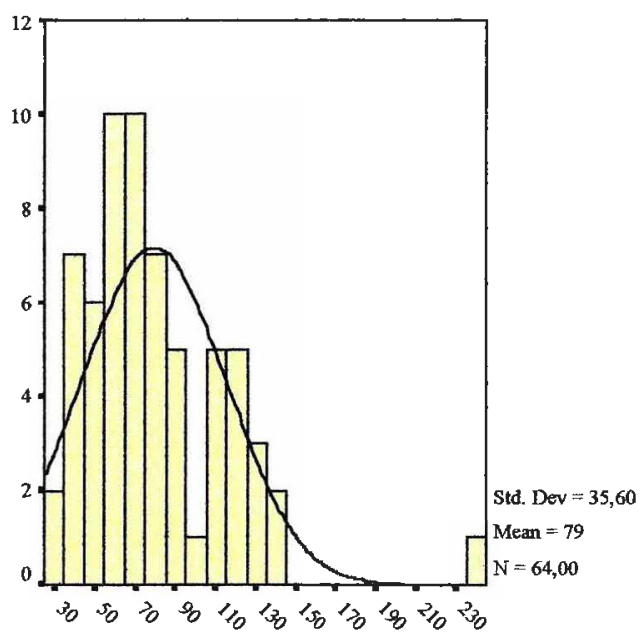

proteína $4 a$
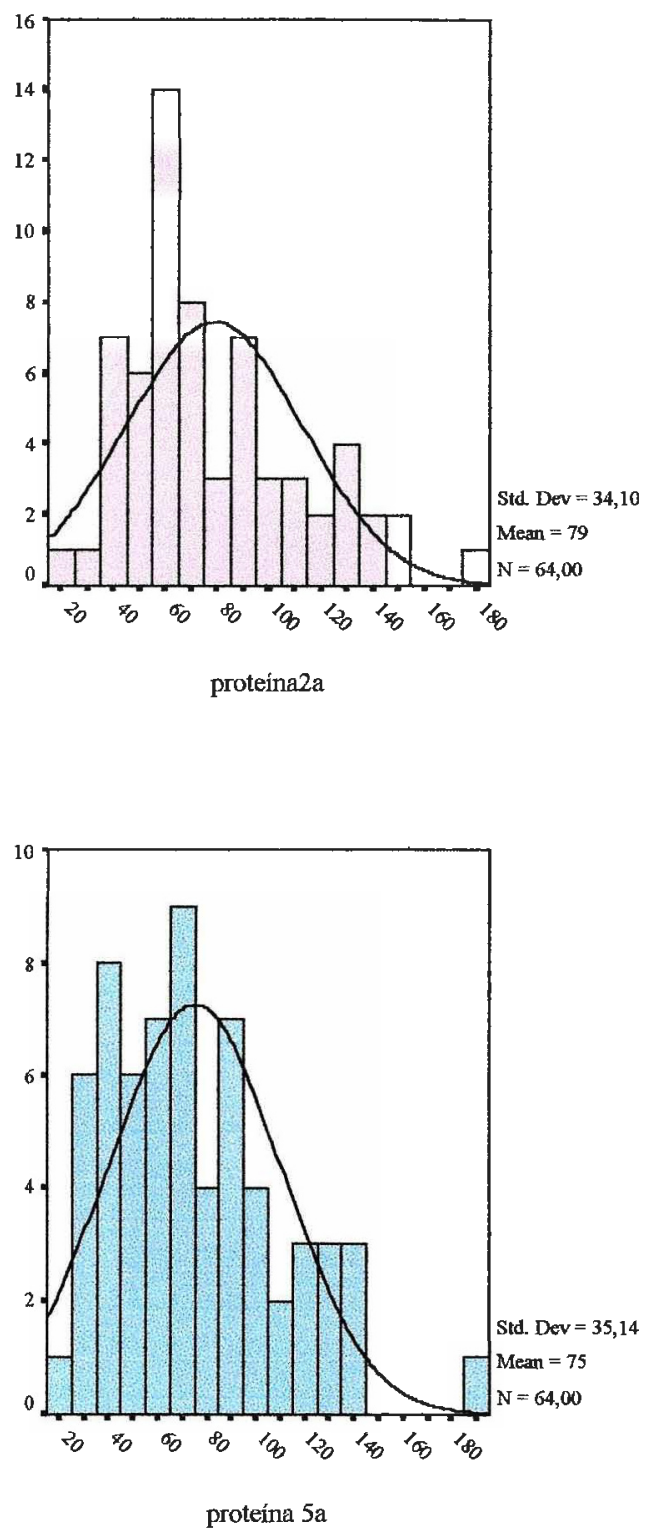
Figura 26: Distribuição da curva normal para as médias de carboidrato consumidas no feriado, segunda-feira, quarta-feira e quinta-feira, de uma Escola Estadual do Município de São Paulo em 1999.
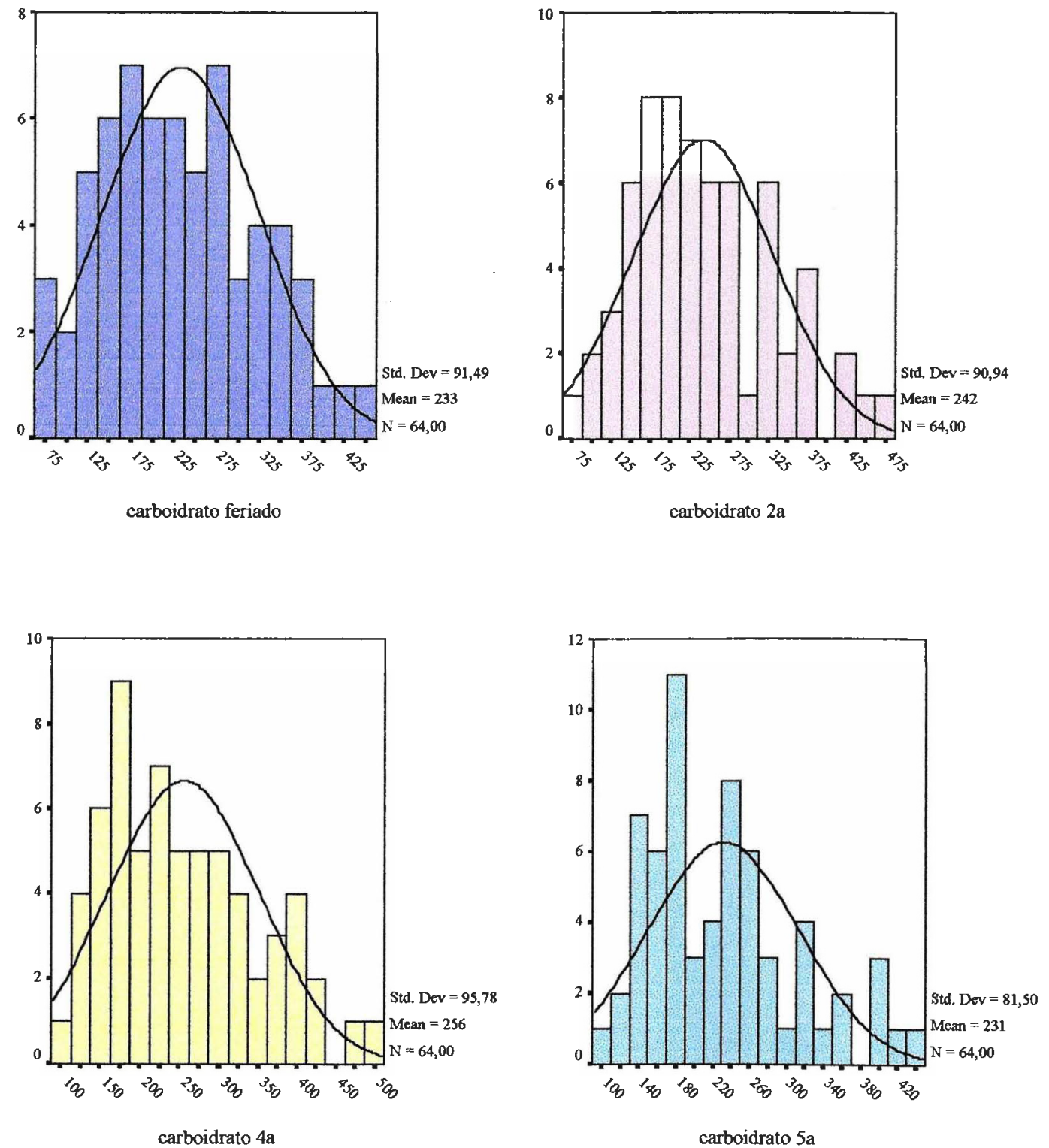
Figura 27: Distribuição da curva normal para as médias de gordura total consumida no feriado, segunda-feira, quarta-feira e quinta-feira, de uma Escola Estadual do Município de São Paulo em 1999.
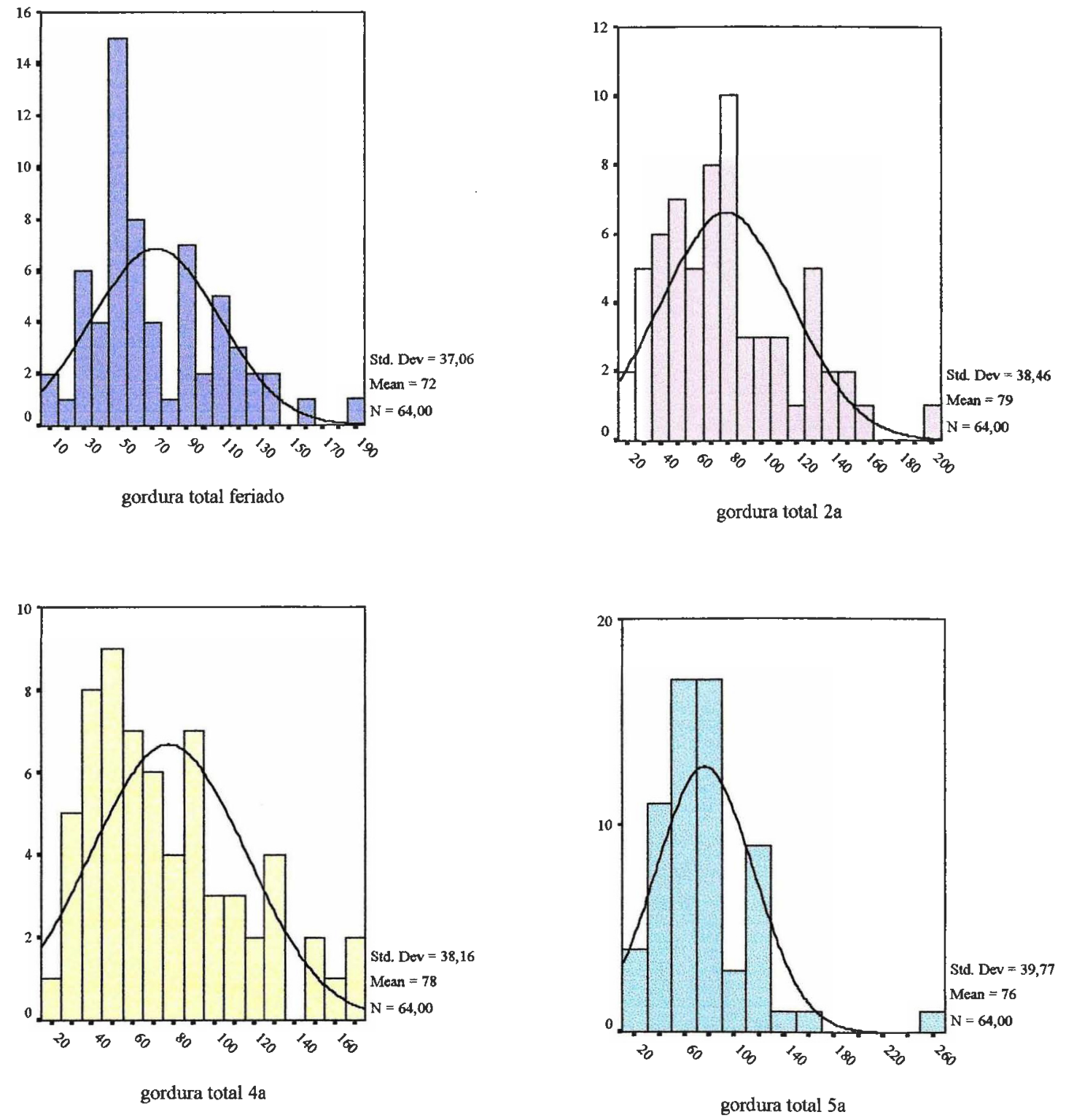
Figura 28: Distribuição da curva normal para as médias de gordura insaturada consumidas no feriado, segunda-feira, quarta-feira e quinta-feira, de uma Escola Estadual do Município de São Paulo em 1999.
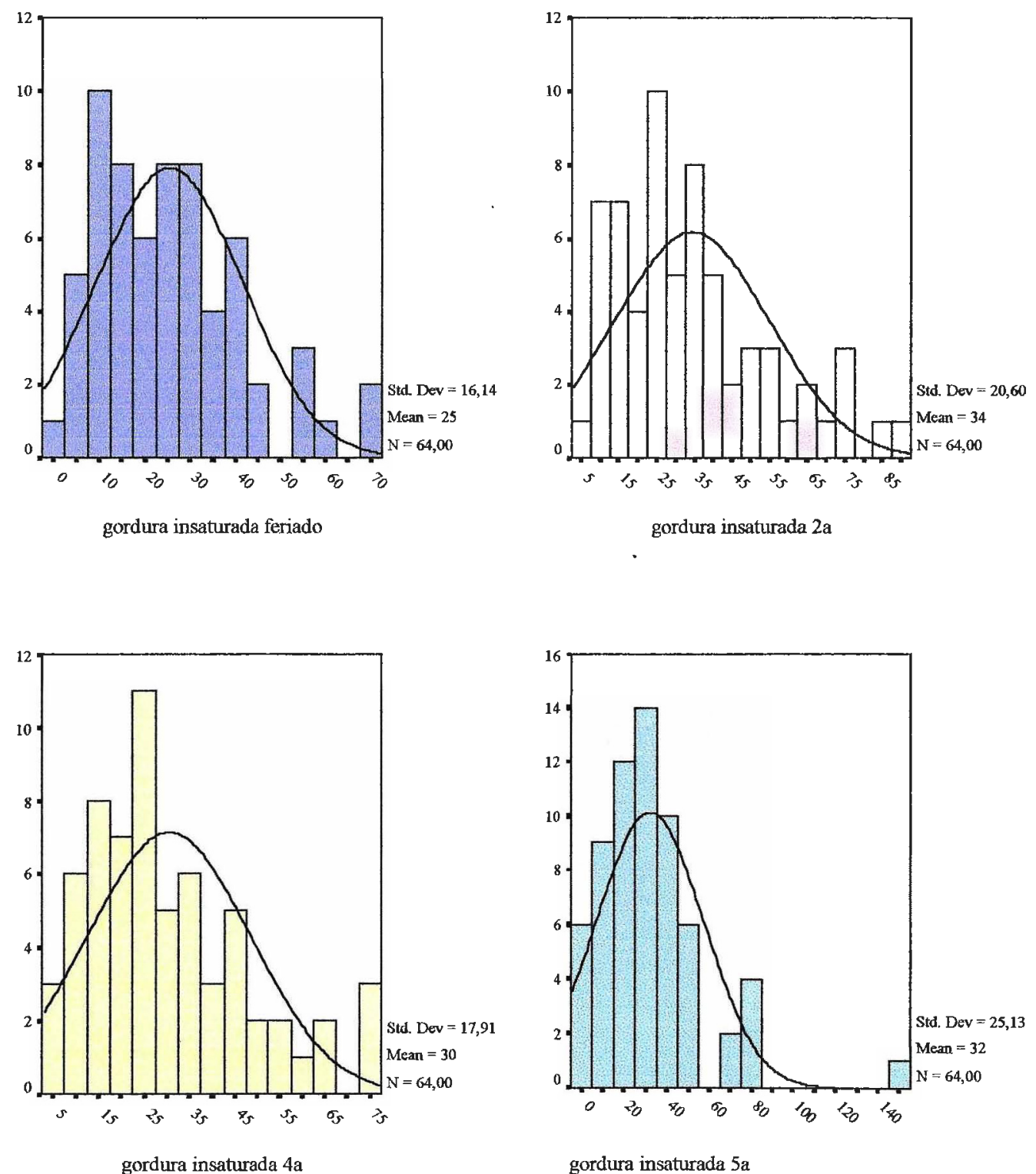

gordura insaturada $5 a$ 
Figura 29: Distribuição da curva normal para as médias de fibra consumidas no feriado, segunda-feira, quarta-feira e quinta-feira, de uma Escola Estadual do Município de São Paulo em 1999.

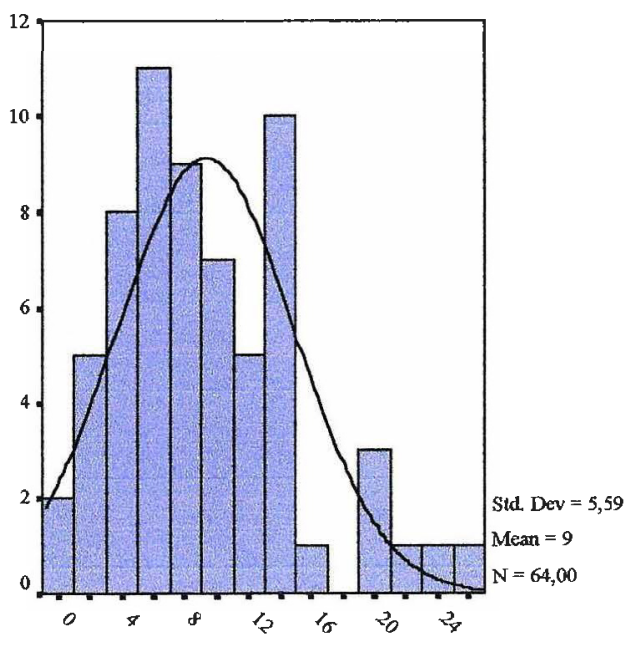

fibra feriado

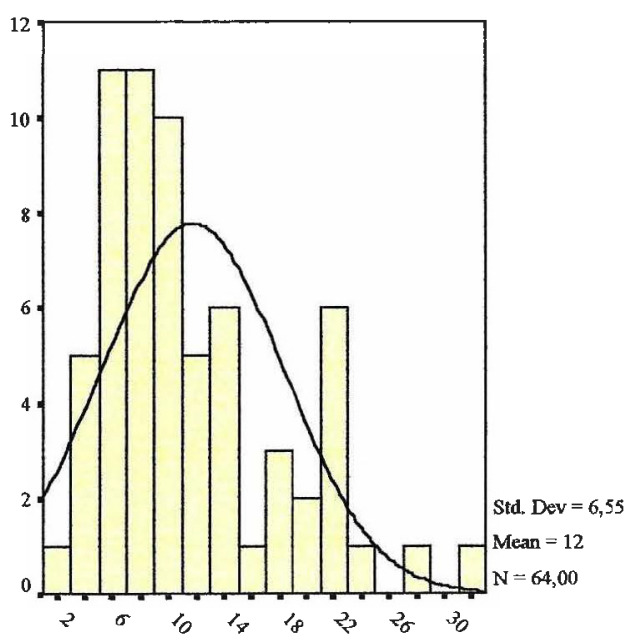

fibra $4 a$
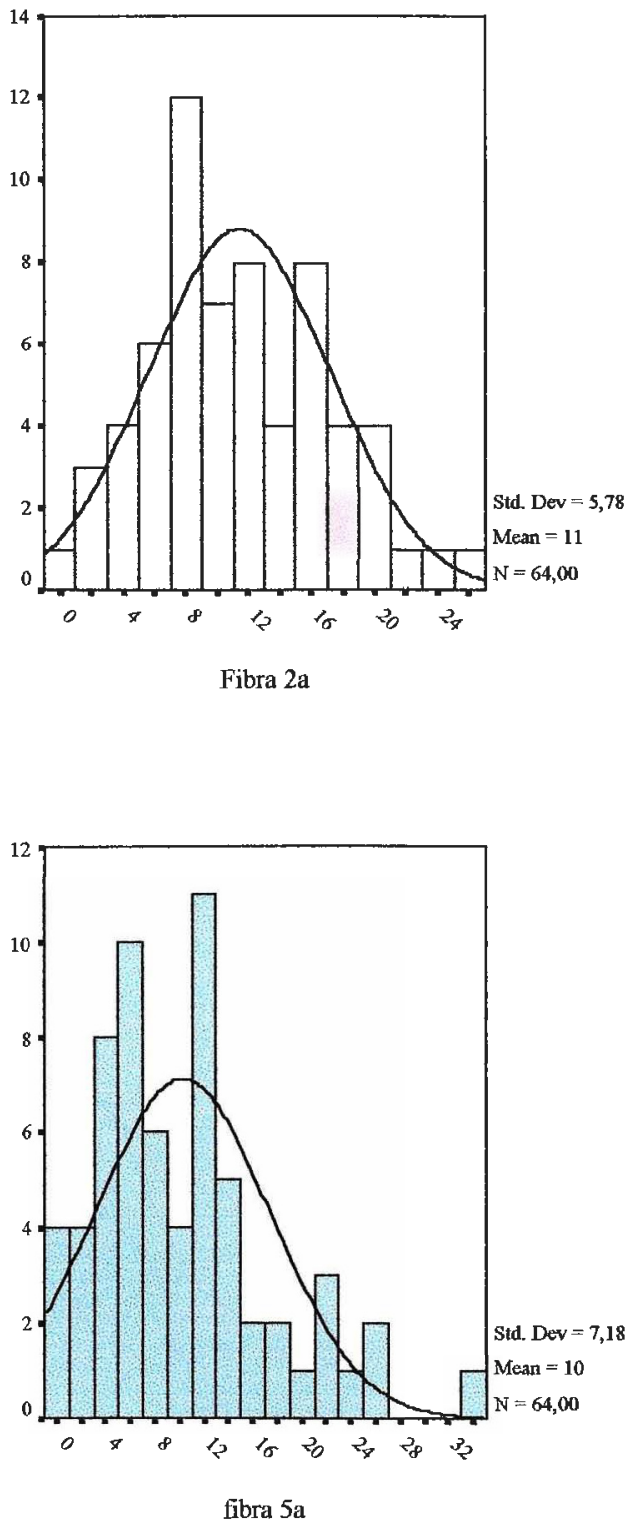
Figura 30: Distribuição da curva normal para as médias de vitamina $\mathrm{C}$ consumidas no feriado, segunda-feira, quarta-feira e quinta-feira, de uma Escola Estadual do Município de São Paulo em 1999.

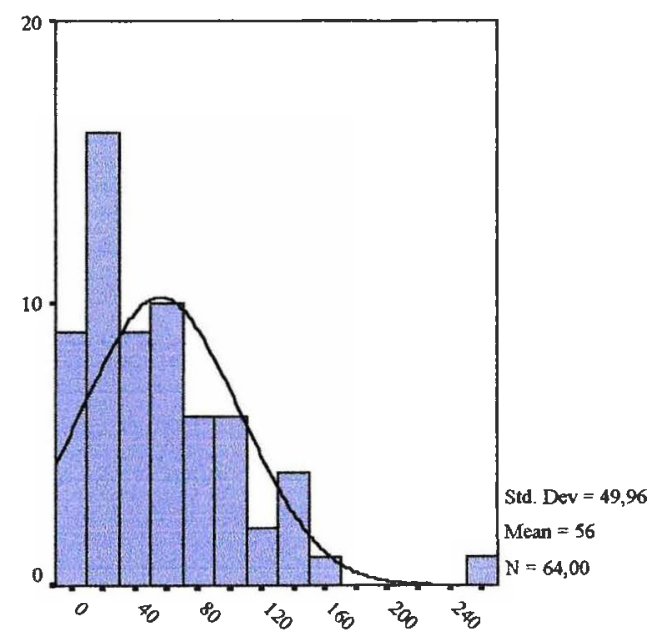

vitamina $\mathrm{C}$ feriado

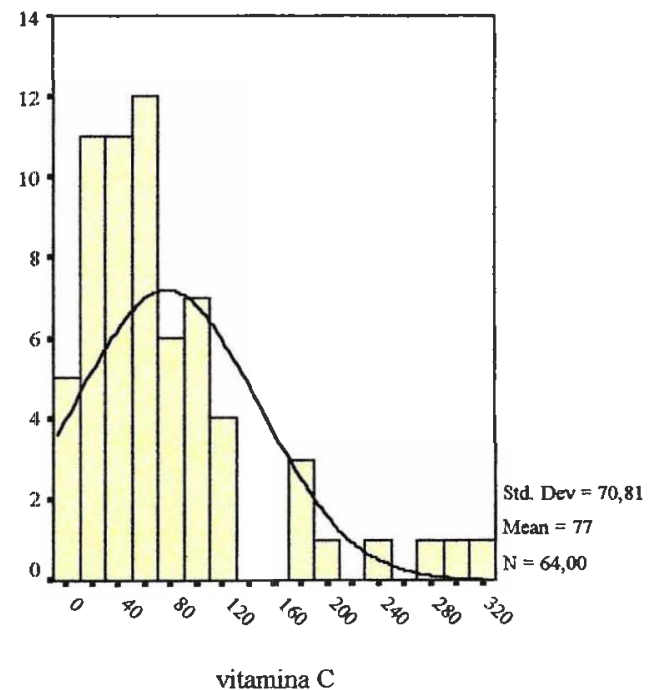

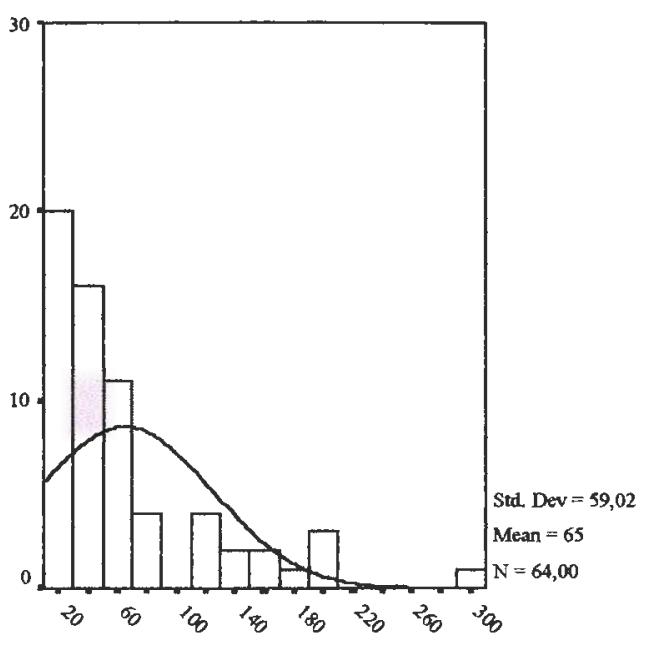

Vitamina C 2a

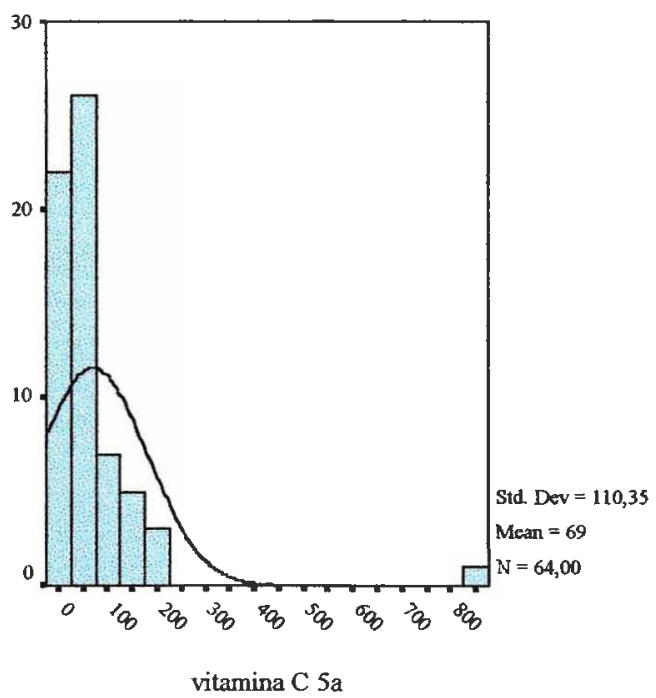


Figura 31: Distribuição da curva normal para as médias de cálcio consumidas no feriado, segunda-feira, quarta-feira e quinta-feira, de uma Escola Estadual do Município de São Paulo em 1999.
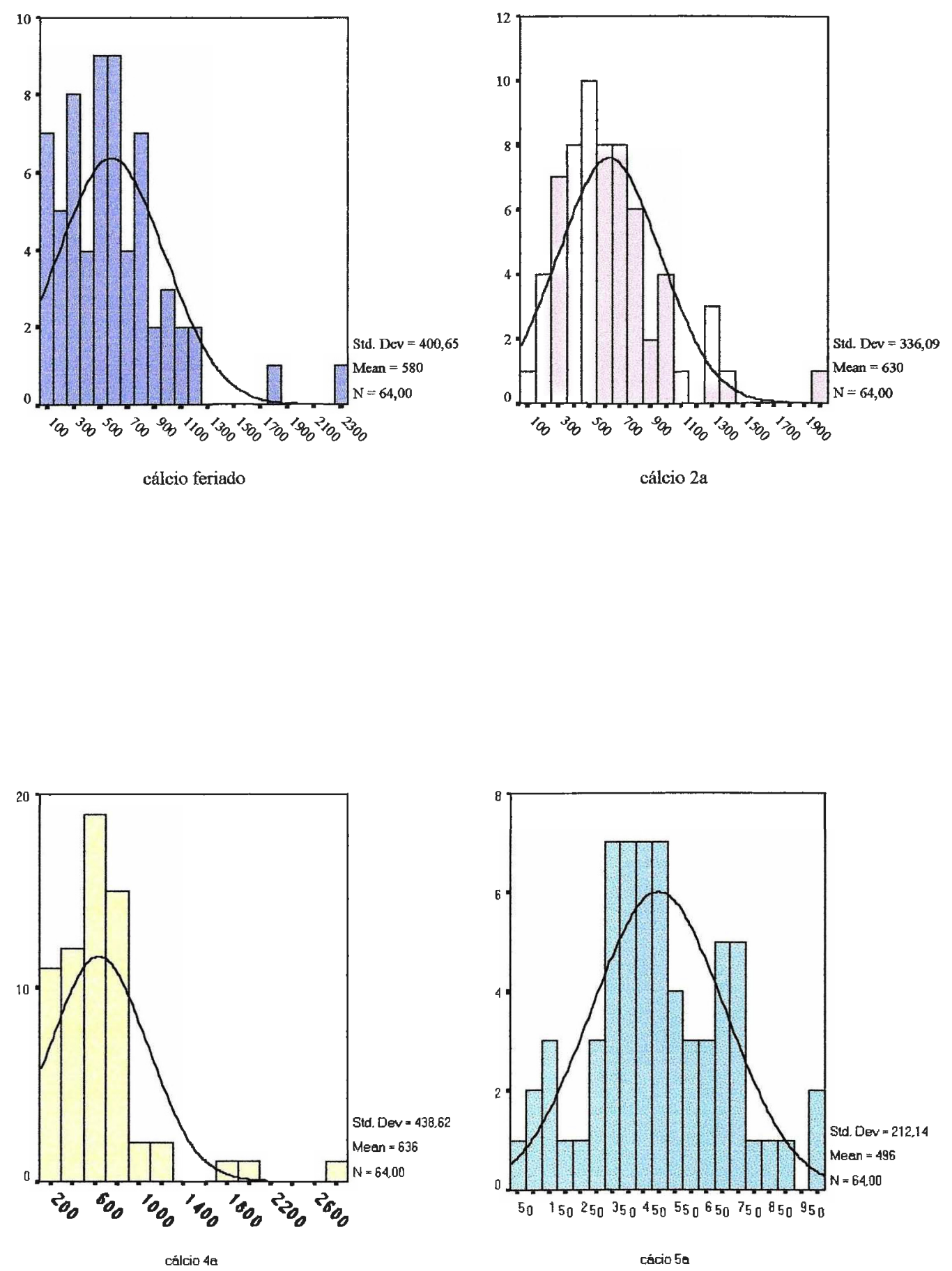
Figura 32: Distribuição da curva normal para as médias de ferro consumidas no feriado, segunda-feira, quarta-feira e quinta-feira, de uma Escola Estadual do Município de São Paulo em 1999.

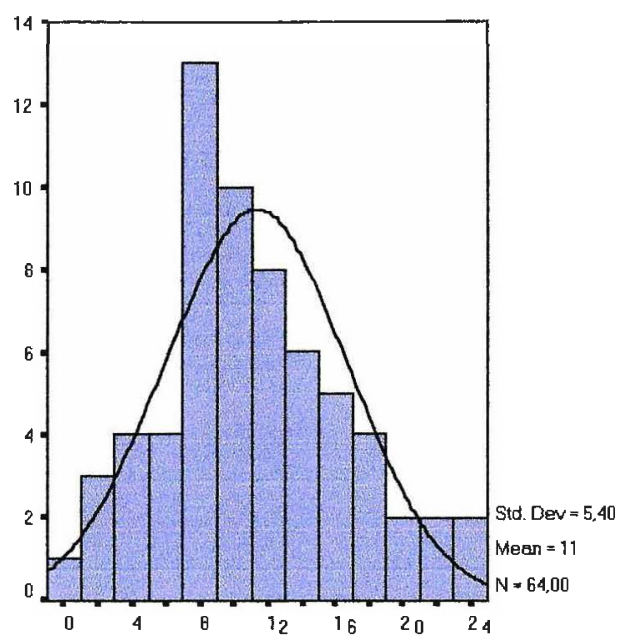

ferro feriado

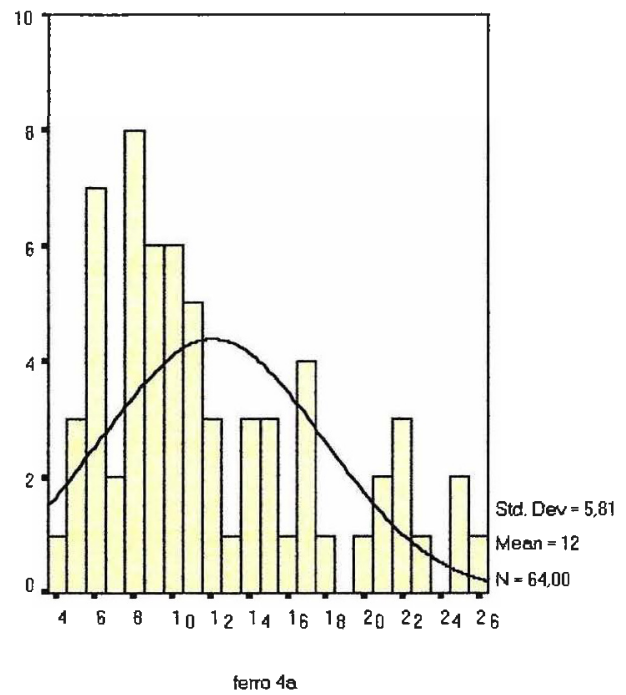

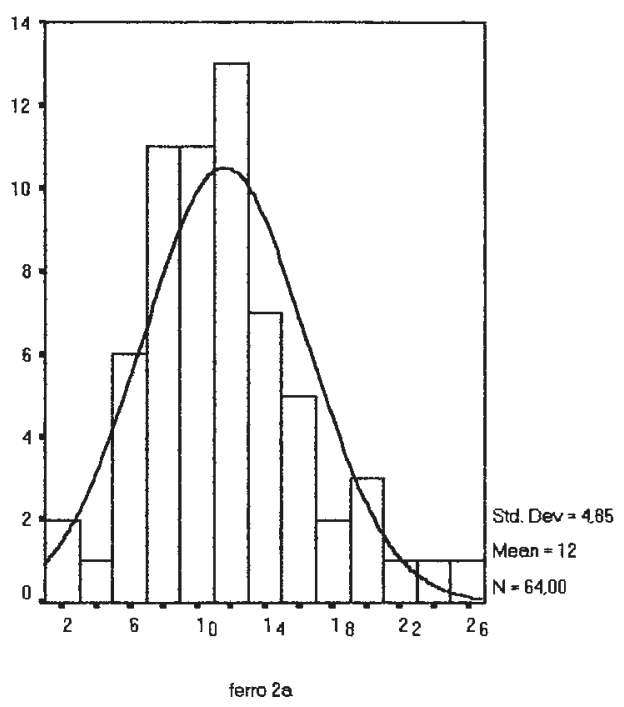

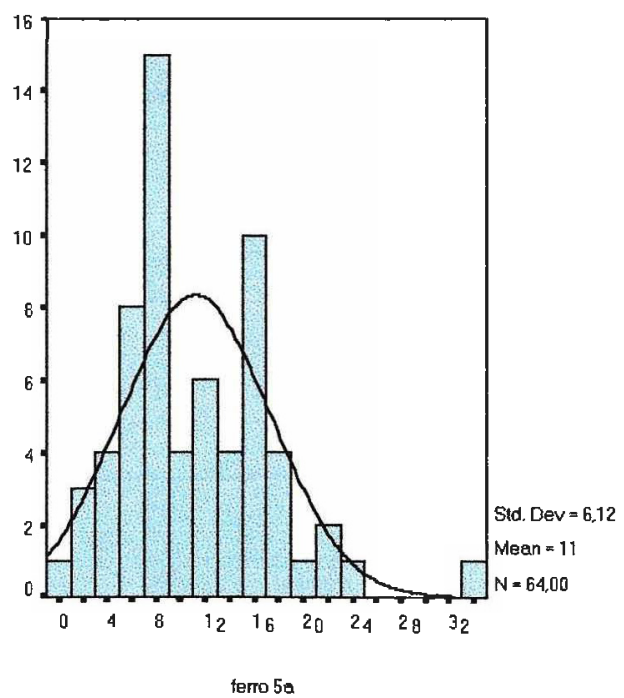




\section{ANEXO 2}

Komogorov-Smirnov - aderência à curva normal para LOG10 da energia e nutriente

Tabela 13: Média, desvios padrão, kolmogorov-smirnov e nível de significância dos valores consumidos de energia e nutrientes em logaritmo na base 10, dos adolescentes no feriado, segunda, quarta e quintas-feiras, de uma escola estadual do Município de são Paulo, 1999.

\begin{tabular}{c|c|c|c|c|c|c|c|c|c}
\hline & $\begin{array}{c}\log 10 \\
\text { energia } \\
\text { F }\end{array}$ & $\begin{array}{c}\log 10 \\
\text { proteína } \\
\text { F }\end{array}$ & $\begin{array}{c}\log 10 \\
\text { carbo } \\
\text { F }\end{array}$ & $\begin{array}{c}\text { log 10 } \\
\text { gord F }\end{array}$ & $\begin{array}{c}\log 10 \\
\text { insat F }\end{array}$ & $\begin{array}{l}\text { log 10 } \\
\text { fibra F }\end{array}$ & $\begin{array}{c}\log 10 \\
\text { vitC F }\end{array}$ & $\begin{array}{c}\log 10 \\
\text { cálcio } \\
\text { F }\end{array}$ & $\begin{array}{c}\log 10 \\
\text { ferro F }\end{array}$ \\
\hline Média & 3,2447 & 1,8400 & 2,3301 & 1,7970 & 1,3034 &, 8691 & 1,5185 & 2,6540 &, 9903 \\
\hline $\begin{array}{c}\text { Desvio } \\
\text { Padrão }\end{array}$ &, 17464 &, 21678 &, 18692 &, 24204 &, 32794 &, 33406 &, 54663 &, 33814 &, 26590 \\
\hline $\begin{array}{c}\text { Kolmogorov- } \\
\text { Smirnov Z }\end{array}$ &, 561 &, 674 &, 649 &, 712 &, 818 & 1,032 &, 989 & 1,122 & 1,033 \\
\hline $\begin{array}{c}\text { Asymp. Sig. } \\
\text { (bicaudal) }\end{array}$ &, $\mathbf{9 1 2}$ &, $\mathbf{7 5 3}$ & $\mathbf{, 7 9 4}$ & $\mathbf{, 6 9 1}$ & $\mathbf{, 5 1 6}$ & $\mathbf{, 2 3 7}$ & $\mathbf{, 2 8 2}$ & $\mathbf{, 1 6 1}$ & $\mathbf{, 2 3 7}$ \\
\hline
\end{tabular}

\begin{tabular}{c|c|c|c|c|c|c|c|c|c}
\hline & $\begin{array}{c}\text { log 10 } \\
\text { energia } \\
\text { 2a }\end{array}$ & $\begin{array}{c}\text { log 10 } \\
\text { proteína } \\
\text { 2a }\end{array}$ & $\begin{array}{c}\log 10 \\
\text { carbo } \\
\text { 2a }\end{array}$ & $\begin{array}{c}\text { log 10 } \\
\text { gord } \\
\text { 2a }\end{array}$ & $\begin{array}{c}\log 10 \\
\text { insat } \\
\text { 2a }\end{array}$ & $\begin{array}{c}\text { log 10 } \\
\text { fibra } \\
\text { 2a }\end{array}$ & $\begin{array}{c}\log 10 \\
\text { vitC 2a }\end{array}$ & $\begin{array}{c}\log 10 \\
\text { cálcio } \\
\text { 2a }\end{array}$ & $\begin{array}{c}\log 10 \\
\text { ferro } \\
\text { 2a }\end{array}$ \\
\hline Média & 3,2689 & 1,8798 & 2,3649 & 1,8671 & 1,4841 & 1,0167 & 1,6839 & 2,7531 & 1,0618 \\
\hline $\begin{array}{c}\text { Desvio } \\
\text { Padrão }\end{array}$ &, 16981 &, 28123 &, 22017 &, 30279 &, 38252 &, 45001 &, 42524 &, 25002 &, 36625 \\
\hline $\begin{array}{c}\text { Kolmogorov- } \\
\text { Smirnov Z }\end{array}$ &, 631 &, 930 &, 809 &, 944 &, 790 & 1,536 &, 891 &, 725 & 1,534 \\
\hline $\begin{array}{c}\text { Asymp. Sig. } \\
\text { (bicaudal) }\end{array}$ &, $\mathbf{8 2 1}$ &, $\mathbf{3 5 3}$ &, $\mathbf{5 2 9}$ & $\mathbf{, 3 3 5}$ & $\mathbf{, 5 6 0}$ & $\mathbf{, 0 1 8}$ & $\mathbf{, 4 0 5}$ & $\mathbf{, 6 6 9}$ & $\mathbf{, 0 1 8}$ \\
\hline
\end{tabular}

\begin{tabular}{|c|c|c|c|c|c|c|c|c|c|}
\hline & $\begin{array}{c}\log 10 \\
\text { energia } \\
4 a\end{array}$ & \begin{tabular}{|c|}
$\log 10$ \\
proteína \\
$4 \mathrm{a}$ \\
\end{tabular} & $\begin{array}{c}\log 10 \\
\text { carbo } \\
4 a \\
\end{array}$ & $\begin{array}{c}\log 10 \\
\text { gord } \\
4 a\end{array}$ & $\begin{array}{c}\log 10 \\
\text { insat } \\
4 a \\
\end{array}$ & $\begin{array}{c}\log 10 \\
\text { fibra } \\
4 a \\
\end{array}$ & $\begin{array}{c}\log 10 \\
\text { vitC 4a }\end{array}$ & $\begin{array}{c}\log 10 \\
\text { cálcio } \\
4 a \\
\end{array}$ & $\begin{array}{c}\log 10 \\
\text { ferro } \\
4 a \\
\end{array}$ \\
\hline Média & 3,2824 & 1,8606 & 2,3775 & 1,8379 & 1,4037 & 1,0029 & 1,6982 & 2,7228 & 1,0334 \\
\hline $\begin{array}{l}\text { Desvio } \\
\text { Padrão }\end{array}$ &, 15976 &, 18005 &, 16499 & 21661 &, 28274 & 25279 &, 45170 & ,26895 & ,20532 \\
\hline $\begin{array}{l}\text { Kolmogorov- } \\
\text { Smirnov Z }\end{array}$ &, 585 &, 549 &, 595 &, 384 & ,499 &, 603 & ,928 & ,935 & ,502 \\
\hline \multirow[t]{2}{*}{$\begin{array}{c}\text { Asymp. Sig. } \\
\text { (bicaudal) }\end{array}$} & $\begin{array}{l}, 884 \\
\end{array}$ & ,924 & ,870 & ,998 & ,965 & ,860 & ,356 & ,346 &, 963 \\
\hline & $\begin{array}{c}\log 10 \\
\text { energia } \\
5 a \\
\end{array}$ & \begin{tabular}{|c|}
$\log 10$ \\
proteína \\
$5 a$ \\
\end{tabular} & \begin{tabular}{|c|}
$\log 10$ \\
carbo \\
$5 a$ \\
\end{tabular} & $\begin{array}{c}\log 10 \\
\text { gord } \\
5 \mathrm{a} \\
\end{array}$ & $\begin{array}{c}\log 10 \\
\text { insat } \\
5 a \\
\end{array}$ & $\begin{array}{c}\log 10 \\
\text { fibra } \\
5 a \\
\end{array}$ & $\begin{array}{c}\log 10 \\
\text { vitC } 5 a\end{array}$ & $\begin{array}{c}\log 10 \\
\text { cálcio } \\
5 \mathrm{a} \\
\end{array}$ & $\begin{array}{c}\log 10 \\
\text { ferro } \\
5 a \\
\end{array}$ \\
\hline Média & 3,2586 & 1,8274 & 2,3389 & 1,8318 & 1,3623 & 1,3623 & 1,5621 & 2,6442 & ,9718 \\
\hline $\begin{array}{l}\text { Desvio } \\
\text { Padrão }\end{array}$ &, 15512 & ,20817 &, 15030 & ,21446 & ,39740 & ,39740 &, 55503 & 23668 & 28176 \\
\hline $\begin{array}{l}\text { Kolmogorov- } \\
\text { Smirnov Z }\end{array}$ & ,598 &, 484 & ,635 &, 543 & 1,038 & 1,038 & 1,021 & 1,292 &, 723 \\
\hline $\begin{array}{l}\text { Asymp. Sig. } \\
\text { (bicaudal) }\end{array}$ &, 867 & ,973 &, 815 & ,929 & ,231 & ,231 & ,248 & ,071 & ,672 \\
\hline
\end{tabular}


ANEXO 3

Quadro 1: Agrupamento inicial dos alimentos consumidos pelos adolescentes no feriado, segunda-feira, quarta-feira e quinta-feira, em uma Escola Estadual do Município de São Paulo em 1999.

\begin{tabular}{|c|c|}
\hline Grupo & Alimentos \\
\hline 1. & Batatinhas chips/Salgadinhos cheetos \\
\hline 2. & Chocolate/brigadeiro \\
\hline 3. & Bolo comum/ pullmam \\
\hline 4. & Sorvete massa/palito \\
\hline 5. & Achocolatado em pó, sustagem \\
\hline 6. & Pipoca estourada \\
\hline 7. & Açúcar \\
\hline 8. & Balas \\
\hline 9. & Doce de frutas (goiabada, marmelada, geléia) \\
\hline 10. & Sobremesas doces (doce de leite, leite condensado), suspiro \\
\hline 11. & Cheeseburguer de carne/frango \\
\hline 12. & Sanduíche (misto, queijo, quente ou frio) \\
\hline 13. & Sanduíche natural \\
\hline 14. & Coxinha/esfiha/rissolis/pastel/bolinho de chuva/bolinha de queijo \\
\hline 15. & Salada de batata c/maionese \\
\hline 16. & Sopa (canja, feijão, legume) \\
\hline 17. & Farofa (farinha de mandioca) \\
\hline 18. & Pão de queijo/ pão de batata \\
\hline 19. & Pizza \\
\hline 20. & Cachorro quente \\
\hline 21. & Croissant \\
\hline 22. & Leite fluído integral, toddynho, A, B, C, molho branco \\
\hline 23. & Leite fluído desnatado \\
\hline 24. & Iogurte natural/frutas yakult \\
\hline 25. & Iogurte diet \\
\hline 26. & Queijo minas frescal/ricota, cottage \\
\hline 27. & Requeijão \\
\hline 28. & Manteiga, chantilly, creme de leite \\
\hline 29. & Margarina \\
\hline 30. & Azeite de oliva, óleo \\
\hline 31. & Maionese tradicional \\
\hline 32. & Arroz cozido \\
\hline 33. & Macarrão/ instantâneo/sugo/manteiga \\
\hline 34. & Massas (lasanha, ravióli, capaleti, nhoque) \\
\hline 35. & Biscoito doce sem recheio, cream cracker, água e sal \\
\hline 36. & Biscoito recheado \\
\hline 37. & Pão francês/ forma/ integral \\
\hline 38. & Cereal matinal sucrilhos, neston, mingau de aveia \\
\hline 39. & Batata frita de palito, polenta frita \\
\hline 40. & Batata cozida (purê, sautée), batata doce, mandioca cozida \\
\hline 41. & Alface \\
\hline 42. & Acelga/ repolho \\
\hline 43. & Agrião \\
\hline 44. & Couve-flor, brócolis \\
\hline 45. & Beterraba \\
\hline
\end{tabular}




\begin{tabular}{|c|c|}
\hline 46. & Cenoura, pimentão \\
\hline 47. & Espinafre, couve \\
\hline 48. & Ervilha, vagem \\
\hline 49. & Milho verde, seleta de legumes \\
\hline 50. & Pepino, rabanete \\
\hline 51. & Tomate, molho \\
\hline 52. & Abacate \\
\hline 53. & Abacaxi, suco \\
\hline 54. & Banana \\
\hline 55. & Laranja, mexerica \\
\hline 56. & Maçã, pêra \\
\hline 57. & Mamão \\
\hline 58. & Melão, melancia \\
\hline 59. & Manga, pêssego, goiaba \\
\hline 60. & Morango \\
\hline 61. & Uva \\
\hline 62. & Carne cozida (bife role/moída/panela/bife frito/almôndega/bolonhesa) \\
\hline 63. & Frango, peru (cozido/assado/grelhado/frito) \\
\hline 64. & Peixe frito/cozido \\
\hline 65. & Carne suína (bisteca/lombo/bacon/lingüiça) \\
\hline 66. & Ovo frito/mexido/omelete \\
\hline 67. & Embutidos (presunto, salame, mortadela) \\
\hline 68. & Salsicha \\
\hline 69. & Feijão, grão de bico, PTS \\
\hline 70. & Refrigerante normal \\
\hline 71. & Refrigerante diet \\
\hline 72. & Chá mate com sabor \\
\hline 73. & Sucos naturais com leite \\
\hline 74. & Café puro \\
\hline 75. & Água \\
\hline 76. & Bebida alcoólica \\
\hline 77. & Queijos amarelos (mussarela, prato) \\
\hline 78. & Tortas doces \\
\hline 79. & Tortas salgadas \\
\hline 80. & Chuchu, abobrinha \\
\hline 81. & Suco artificial (tang) \\
\hline 82. & Suco de laranja \\
\hline 83. & Café com açúcar \\
\hline 84. & Amendoim \\
\hline 85. & Molhos para tempero \\
\hline 86. & Cuscuz, polenta cozida \\
\hline 87. & Feijoada \\
\hline 88. & Alho, cebola \\
\hline 89. & azeitona \\
\hline 90. & Bife \\
\hline 91. & Salada de frutas \\
\hline 92. & Café com leite \\
\hline
\end{tabular}


Quadro 2: Grupos alimentares consumidos mais freqüentemente pelos adolescentes no feriado, segunda-feira, quarta-feira e quinta-feira, em uma Escola Estadual do Município de São Paulo em 1999.

\begin{tabular}{|ll|l|}
\hline \multicolumn{2}{|c|}{ Grupos } & \\
\hline 1. & Achocolatado em pó & Achocolatado em pó, sustagem \\
\hline 2. & Aḉcar & Açúcar \\
\hline 3. & Alface & Alface, agrião, acelga, repolho \\
\hline 4. & Arroz & Arroz branco integral \\
\hline 5. & Batata & $\begin{array}{l}\text { Batata frita de palito, polenta frita, batata cozida (purê, sautée), } \\
\text { batata doce, mandioca cozida }\end{array}$ \\
\hline 6. & Biscoitos & Biscoitos doces, recheados e salgados \\
\hline 7. & Café & Café puro \\
\hline 8. & Carne bovina & Bife role, moída, panela, almôndega, bolonhesa, bife frito de boi \\
\hline 9. & Doces & $\begin{array}{l}\text { Chocolate, brigadeiro, sobremesas doces (doce de leite, leite } \\
\text { condensado), suspiro, sorvete massa, palito, torta doce, doce de } \\
\text { frutas }\end{array}$ \\
\hline 10. & Salgados & $\begin{array}{l}\text { Coxinha, esfiha, rissolis, pastel,bolinho de chuva, bolinha de queijo, } \\
\text { pão de queijo, pão de batata, croissant }\end{array}$ \\
\hline 11. & Feijão & Feijão, grão de bico, Proteína texturizada de soja. \\
\hline 12. & Carne de frango & Frango, cozido,assado,grelhado, frito e peru \\
\hline 13. & Frutas & Frutas e sucos naturais \\
\hline 14. & Leite & $\begin{array}{l}\text { Leite fluído integral e desnatado, toddynho, leite A, B, C, molho } \\
\text { branco, iogurte }\end{array}$ \\
\hline 15. & Macarrão & Macarrão, instantâneo, sugo, manteiga e massa \\
\hline 16. & Óleos & $\begin{array}{l}\text { Manteiga, chantilly, creme de leite, margarina, azeite de oliva, óleo, } \\
\text { maionese }\end{array}$ \\
\hline 17. & Pães & Pão francês, forma, integral \\
\hline 18. & Queijos & Queijo minas frescal, ricota, cottage, requeijão queijos amarelos \\
\hline 19. & Refrigerante & Refrigerante normal \\
\hline 20. & Verduras & Verduras cruas e cozidas (cenoura, tomate, couve flor, etc) \\
\hline 21. & Salgadinhos extrusados & Batatinhas chips, Salgadinhos cheetos \\
\hline 22. & Sanduíches & Sanduíche natural, cheeseburgers, hamburgers \\
\hline 23. & Bolo & Bolo comum, pullmam \\
\hline & & \\
\hline
\end{tabular}


ANEXO 5

UNIVERSIDADE DE SÃO PAULO

FACULDADE DE SAÚDE PÚBLICA

COMITÈ DE ÉTICA EM PESQUISA DA FSP/USP - COEP

Av, Dr. Amaldo, 715 - CEP $01246-904$ - São Paulo - Brasil

Telefones: (55-11) 30667742 - $\operatorname{fax}$ (55-11) 30647314

Of.COEP/60/98

11 de agosto de 1998.

Pelo presente, informo que o Comitê de Ética em Pesquisa, aprovou, em sua $6 .{ }^{2} / 98$ Sessão Ordinária, realizada em 10.08.98, de acordo com os requisitos da Resolução CNS/196/96, o Projeto de Pesquisa "QUESTIONÁRIO DE FREQUĖNCIA ALIMENTAR. VALIDADE RELATIVA E REPRODUTIBLLIDADE DA ESTIMATIVA DO CONSUMO DE ALIMENTOS, ENERGIA E NUTRIENTES DE CRIANÇAS PRÉ-ESCOLARES", apresentado pela pesquisadora Betzabeth Slater Villar.

Atenciosamente,

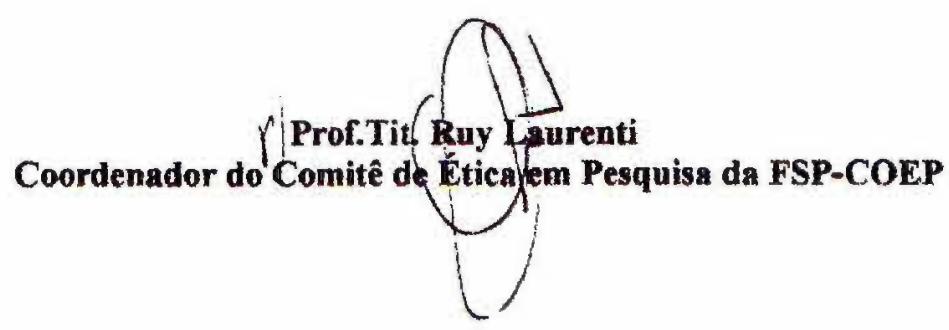

